Including: Social Work, Humanitary Health Intervention, Nursing, Missionary Work

\title{
CLINICAL SOCIAL WORK AND HEALTH INTERVENTION
}

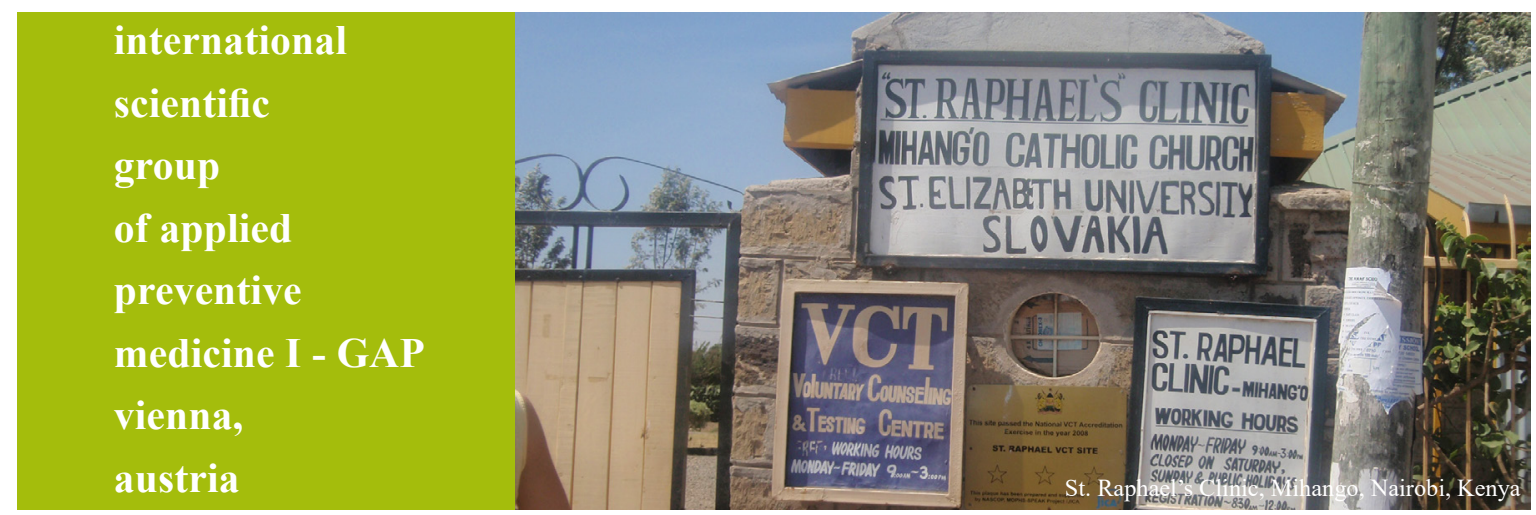

Issue: Health intervention

Original Articles

EFFECT OF SPA TREATMENT AND SPELEOTHERAPY IN THE TREATMENT OF CHRONIC OBSTRUCTIVE PULMONARY DISEASE - A PILOT STUDY

PATIENT SAFETY ASSESSMENT: USA AND SLOVAK HOSPITALS ORGAN TRANSPLANTATION RATES IN CENTRAL EUROPE: CULTURAL AND BIOETHICAL CONSIDERATIONS

EFFECT OF SPA TREATMENT AND THE EPIDEMIOLOGY OF TUBERCULOSIS IN THE SLOVAK REPUBLIC IN THE YEAR 2014 BURNOUT SYNDROME IN NEUROLOGICAL NURSING AN OBJECTIVE VIEW OF HOMEOPATHY IN SLOVAKIA MOBBING EXPERIENCED BY NURSES IN HEALTH CARE FACILITIES ANALYSIS OF PSYCHOMETRIC FEATURES OF THE MMSE AND MOCA METHODS MANAGEMENT OF DIABETIC INDIVIDUALS WITH EMPHASIS ON PREVENTION OF FOOT AMPUTATION

DETERMINANTS CHARACTERIZING THE USE OF HORMONAL CONTRACEPTION REGARD TO AWARENESS ASSESSMENT OF THROMBOEMBOLIC DISEASE IN THE CONTEXT OF EVIDENCE-BASED NURSING SATISFACTION LEVEL OF PARTICIPANTS IN WORKERS SOCIAL SECURITY AGENCY (BPJS) EMPLOYMENT SERVICES IN HEALTH CARE IN INDONESIA 


\section{Editors}

\section{Editor-in-Chief:}

Prof. Peter G. Fedor-Freybergh, MD, D.Phil, PhD, DSc

Dr.h.c. mult. (Vienna)

editoranel.edu

Prof. Dr. Michael Olah, Ph.D. (Prague)

selfmirror@protonmail.com

\section{Deputy Chief Editors:}

Prof. Dr. Dr. med. Clauss Muss, PhD. (I-GAPVienna) office@i-gap.org

\section{Editorial board and reviewers:}

Doc. Dr. Andrea Shahum, MD (University of North Carolina at Chapel Hill School of Medicine, USA)

Andrea.Shahum@unchealth.unc.edu

Prof. Dr. Vlastimil Kozoň, PhD. (Allgemeines Krankenhaus

- Medizinischer Universitätscampus, Vienna)

vlastimil.kozon@univie.ac.at

Prof. Daniel J. West, Jr. Ph.D, FACHE (University of

Scranton, Department of Health Administration and

Human Resources, USA)

daniel.west@scranton.edu

Dr. Steve Szydlowski, MBA, MHA, DHA (University of

Scranton school of education, USA)

steven.szydlowski@scranton.edu

Prof. zw. dr hab. Pawel S. Czarnecki, Ph.D. (Rector of the

Warsaw Management University, PL)

pawel@czarnecki.co

Dr. Michael Costello, MA, MBA, J.D. (University of

scranton school of education, USA)

michael.costello@scranton.edu

Doc. Dr. Gabriela Lezcano, Ph.D. (University of California,

San Francisco, USA)

gabikak@gmail.com

Prof. Dr. Roberto Cauda, Ph.D. (Institute of Infectious

Diseases, Catholic University of the Sacred Heart,

Rome, IT)

rcauda@rm.unicatt.it

\begin{tabular}{|c|}
\hline Contact \\
International Gesellschaft \\
für angewandte Präventionsmedizin i-gap e.V. \\
(International Society of Applied \\
Preventive Midicine i-gap) \\
Währinger Str. 63 \\
A-1090 Vienna, Austria \\
Tel. : +49 - 176- 24215020 \\
Fax : +43 / 1408313129 \\
Mail : office@i-gap.org \\
Web : www.i-gap.org
\end{tabular}

Dr. Daria Kimuli, Ph.D. (Catholic university of Eastern

Africa, Nairobi, Kenya) pechacova.daria@gmail.com

Dr. Monica Wictor Namulanda Wanjala, Ph.D. (Catholic

university of Eastern Africa, Nairobi, Kenya)

Non-public

Dr. Vitalis Okoth, Ph.D. (Catholic university of Eastern

Africa, Nairobi, Kenya)

Non-public

Dr. Johnson Mawole, Ph.D. (Catholic university of Eastern

Africa, Nairobi, Kenya)

Non-public

Dr. Jirina Kafkova, Ph.D. (Nairobi, St. Bakitha Clinic, Kenya)

jirinka.lala@gmail.com

Prof. Dr. Selvaraj Subramanian, Ph.D. (president of

SAAaRMM, Kuala Lumpur, Malaysia)

doc.selvarajagmail.com

Dr. Harald Stefan, PhD. (Krankenanstalt Rudolfstiftung,

Vienna, AT )

harald.stefan@wienkav.at

Dr. Günter Dorfmeister, PhD., MBA (Wilhelminenspital,

Vienna, AT) guenter.dorfmeister@wienkav.at

Dr. hab. Zofia Szarota, Ph.D. (Pedagogical University of (racow, PL) dziekwp@up.krakow.pl

\section{Commissioning and language editor:}

Prof. Dr. John Turner (Amsterdam) Non-public

Dr. Lubica Vareckova (Trnava) lubica.vareckova@yahoo.com

\section{Proofreader:}

Dr.h.c mult. prof. MUDr. Vladimír Krcmery, DrSc. FRSP,

FACP (Tropical international team of St. Elizabeth) tropicteamagmail.com

Issue Guarantor:
Vlastimil Kozon Prof. PhD. RN
Vienna General Hospital - Medical University Campus,
Vienna, Austria
Impact Factor (GIF)
2,875
Affiliated Institutions:
Panuska College of Professional Studies, Scranton, USA
Pedagogical University of Cracow, PL
Catholic university of Eastern Africa, Nairobi, Kenya
St. Elizabeth University of Health and Social Work, SK
Subscription rates 2016, Vol. 7, No. 2
Hybrid Open Access Journal
Additional information on Internet:
www.clinicalsocialwork.eu

The journal works on the non-profit basis. The Original Articles are published free of charge / the scope up up to 3,500 words, over the scope should be paid 50 EUR / USD for every 500 words/. All the published Articles are charged 100 EUR / USD with standard range which cannot be exceed. 


\section{Table of Contents}

\section{Original Articles}

Lucia Kendrová, Peter Takáč, Anna Kubincová, Wioletta Mikuláková, Pavol Nechvátal

Effect of spa treatment and speleotherapy in the treatment

of chronic obstructive pulmonary disease - a pilot study

Helen Allen Kwofie

Patient safety assessment: USA and Slovak hospitals

Christopher Nebzydoski, Daniel J. West, J.

Organ transplantation rates in Central Europe:

cultural and bioethical considerations

Martin Samohyl, Ivan Solovic, Roman Rams, Katarina Hirosova, Diana Vondrova,

Daniela Krajcova, Anna Nadazdyova, Alexandra Filova, Jana Jurkovicova

Effect of spa treatment and the epidemiology of tuberculosis in the Slovak republic

in the year 2014

\section{Zuzana Slezáková, Gabriela Vörösová, Gabriela Mičinová}

Burnout syndrome in neurological nursing

Joseph A. Spinelli III

An objective view of homeopathy in Slovakia

Eva Zacharová, Ivan Bartošovič

Mobbing experienced by nurses in health care facilities

Ol'ga Kabátová, Silvia Puteková, Jana Martinková, Marcela Súkenníková

Analysis of psychometric features of the MMSE and MoCA methods

Mária Korintušová, Vlastimil Kozoň, Eva Zacharová

Management of diabetic individuals with emphasis on prevention of foot amputation

Katarína Kotradyová, Lenka Rosková, Miriam Andrejiová

Determinants characterizing the use of hormonal

contraception regard to awareness

L'ubomíra Tkáčová, Beáta Grešš Halász

Assessment of thromboembolic disease in the context of evidence-based nursing .....

Matias Siagian

Satisfaction level of participants in workers social security agency (BPJS)

employment services in health care in Indonesia...

Vlastimil Kozon, Eva Zacharová

Stress factors in the work of nurses 



\section{Guest Editorial and Introduction}

Cince 2010, 20 issues of the journal "Clinical Social Work and Health Intervention CCSWHI" with more than one hundred and fifty professional articles were printed. After some time, it is appropriate to subject every activity to evaluation. Because of that, we decided to perform a specific analysis of the journal and its articles. We would like to mention at least the quantitative content targeting of already published articles.

Of course most, 40\%, were devoted to topics of Clinic Social Work. Followed by medical topics Humanitary Intervention Health and Tropical Medicine in roughly a third of the contribution. Approximately $10 \%$ of articles are devoted to the topic of Nursing. Similarly, $10 \%$ of contributions are devoted to topics of Education and Tuition. The rest of posts are devoted to topics such as Missionary Work, Ethic, Justice, Policy and other areas that are in the focus of the magazine. Of course, it is sometimes difficult to clearly break down the content of the articles into one of these areas. Especially since Clinical Social Work and Health Intervention are subjects that requires approaches and solutions from several fields of the human, social and physical sciences and their application to social practice.

This edition of "Clinical Social Work and Health Intervention" No. 2, Vol. 7, 2016 is specifically dedicated to health related areas of Medicine and Nursing. 13 scientific articles were chosen.

In the field of medicine two articles are devoted to spa treatment and how it is related to the treatment of chronic obstructive pulmonary disease and the epidemiology of tuberculosis. In the area of health and medicine there is an article on patient safety assessment in the US and Slovak hospitals. It is a very interesting article created by a comparative method. It points out the most important parameters and characteristics of patient safety evaluation in hospital care in the US and SK. In the conclusion the causes of adverse events and medical errors are defined as well as there are outlined preventive strategies to ensure patient safety in hospitals.

Interesting are also other medical articles, like for example the article Cultural and bioethical considerations organ transplantation in Central Europe. Although the article about homeopathy is quite short, it touches the most relevant topics that are also currently debated in complementary and alternative medicine. It states that homeopathy looks at preventing and curing illnesses by focusing on multiple aspects of the patient, that is, how mental, physical or emotional aspects of an individual are interconnected to maintain health. The article concludes by stating the limitations of this method of treatment and risks involved with homeopathic remedies. It is recommended to continue clinical research until the effectiveness of many of its remedies can be proved.

Approximately half of the articles in this issue of CSWHI are dedicated to Nursing. Especially with always actual themes such as: Mobbing by Nurses, Management of diabetic individuals, Assessment of thromboembolic disease in the context of evidence-based nursing and Stress in the Work of Nurses. Analysis of psychometric features is also an important area for practical gerontological nursing, as well as for nursing research.

The health special edition issue properly shows the extent of interconnectivity of health, clinical social work and health intervention.

Prof. Dr. Vlastimil Kozoň, PhD.

Allgemeines Krankenhaus -

Medizinischer Universitätscampus, Vienna 



\title{
Few words from the Edition in Chief
}

$\mathrm{T}$ his journal brings authentic experiences of our social workers, doctors and teachers working for the International Scientific Group of Applied Preventive Medicine I-GAP Vienna in Austria, where we have been preparing students for the social practise over a number of years. Our goal is to create an appropriate studying programme for social workers, a programme which would help them to fully develop their knowledge, skills and qualification. The quality level in social work studying programme is increasing along with the growing demand for social workers.

Students want to grasp both: theoretical knowledge and also the practical models used in social work. And it is our obligation to present and help students understand the theory of social work as well as showing them how to use these theoretical findings in evaluating the current social situation, setting the right goals and planning their projects.

This is a multidimensional process including integration on many levels. Students must respect client's individuality, value the social work and ethics. They must be attentive to their client's problems and do their best in applying their theoretical knowledge into practice.

It is a challenge to deliver all this to our students. That is also why we have decided to start publishing our journal. We prefer to use the term 'clinical social work' rather than social work even though the second term mentioned is more common. There is some tension in the profession of a social worker coming from the incongruity about the aim of the actual social work practice. The question is whether its mission is a global change of society or an individual change within families. What we can agree on, is that our commitment is to help people reducing and solving the problems which result from their unfortunate social conditions. We believe that it is not only our professional but also ethical responsibility to provide therapeutic help to individual and families whose lives have been marked with serious social difficulties.

Finding answers and solutions to these problems should be a part of a free and independent discussion forum within this journal. We would like to encourage you - social workers, students, teachers and all who are interested, to express your opinions and ideas by publishing in our journal. Also, there is an individual category for students' projects.

In the past few years there have been a lot of talks about the language suitable for use in the field of the social work. According to Freud, a client may be understood as a patient and a therapist is to be seen as a doctor. Terminology used to describe the relationship between the two also depends on theoretical approach. Different theories use different vocabulary as you can see also on the pages of our journal.

Specialization of clinical social work programmes provides a wide range of education. We are determined to pass our knowledge to the students and train their skills so they can one day become professionals in the field of social work. Lately, we have been witnessing some crisis in the development of theories and methods used in clinical social work. All the contributions in this journal are expressing efforts to improve the current state. This issue of CWS Journal brings articles about social work, psychology and other social sciences.

\author{
Michael Olah \\ Peter G. Fedor-Freybergh \\ Edition of the journal
}





\title{
Effect of spa treatment and speleotherapy in the treatment of chronic obstructive pulmonary disease - a pilot study
}

\author{
L. Kendrovái, P. Takáč², A. Kubincová², W. Mikul'áková³, \\ P. Nechvátal ${ }^{3}$
}

Original Articles

${ }^{1}$ University of Prešov in Prešov, Faculty of Health Care, Department of Physiotherapy, Slovak Republic and UPJŠ, Faculty of Medicine, Department of Public Health, Slovak Republic

2 Pavol Jozef Šafárik University, Faculty of Medicine, Louis Pasteur University Hospital in the Košice, Department of Physiotherapy, Balneology and Medical Rehabilitation, Slovak Republic

${ }^{3}$ University of Prešov in Prešov, Faculty of Health Care, Department of Physiotherapy, Slovak Republic

\section{Correspondence to:}

University of Prešov, Faculty of health care disciplines, Department of Physiotherapy,

Partizánska 1,080 01 Prešov, Slovak Republic; e-mail: Lucia.Kendrova@unipo.sk

Submitted: 6.5.2016 Revised: 11.6.2016 Accepted: 5.8.2016

\section{Reviewers:}

S. Subramanian, president of SAAaRMM, Kuala Lumpur, Malaysia

I. Bartosovic, Tropical international team of St. Elizabeth, Slovak Republic

\section{Key words:}

Chronic obstructive pulmonary disease, Speleotherapy, spa treatment, quality of life, anxiety, depression.

CSWHI 2016; 7(2): 7-15 @ 2016 Clinical Social Work and Health Intervention

\section{Abstract:}

Objective: The aim of our research was to determine the effect of Speleotherapy on the quality of life, anxiety and depression in patients with COPD. Design: Pilot study. Participants: The 128 patients with CPOD participated in the study (average age 64.05), examined during a spa treatment in a sanatoriums in the High Tatras. The experimental group (29 patients) completed spa treatment and Speleotherapy in the Belianska Cave. The control group (99 patients) completed a spa treatment without Speleotherapy. All patients were examined on admission and discharge, for an average 20-day treatment stay. Methods: They 
were evaluated on the basis of the quality of life (SGRQ), Beck and Zung, the Spirometric Test (FEV1 and FEV1/FVC) and the 6-minute Walk Test. Results: After the treatment, concerning the patients of the experimental group we recorded that within the evaluation of quality of life there was significant improvement in symptoms $(\mathrm{p}<0.05)$. There was also statistically significant improvement in anxiety and the six-minute Walk Test $(\mathrm{p}<0.05)$. Conclusion: The pilot study shows that spa treatment along with Speleotherapy improves the quality of life and anxiety in patients with COPD. However, there is a need for prolonged study with more patients in order to demonstrate the effectiveness of this therapy.

\section{Introduction}

Lung diseases are currently a serious problem worldwide for their high prevalence, morbidity and mortality, as well as the negative impact on the patient's quality of life. GOLD (Global Initiative for Chronic Obstructive Lung Disease) ${ }^{1}$ defines chronic obstructive pulmonary disease (COPD) as a treatable disease that can be prevented, although it has some serious extra-pulmonary consequences. Pulmonary disease manifestations are characterized by airflow limitation that is not fully reversible. It is usually progressive and often associated with an abnormal inflammatory response of the lungs to inhaled noxious particles and gases. COPD is a respiratory disorder, which is currently one of the leading causes of chronic morbidity and mortality ${ }^{2}$. It is characterized as a very progressive and irreversible pulmonary obstruction with dyspnea ${ }^{3}$.

Each patient who becomes breathless when Walking or at an easy pace on level ground, should be provided with rehabilitation, which should particularly include resistance training and daily activities, further respiratory gymnastics, respiratory physiotherapy, positional drainage and physical therapy, as well as nutritional support.
Rehabilitation improves the quality of life, participation in daily activities, load tolerance and relieves shortness of breath and fatigue ${ }^{1,3,4,5}$. According to the ATS/ERS pulmonary rehabilitation is a multidisciplinary and comprehensive intervention for patients with chronic lung disease in which symptoms predominate and often limit daily activities. It is part of an individual patient's treatment and is designed to optimize functional status, enhanced participation in physical and social activities, improve the quality of life and reduce healthcare costs by stabilizing or reversing the systemic manifestations of the disease ${ }^{6}$.

Speleotherapy is a treatment method, using the specific and unique features of the environment, especially particulate matter contained in the air of underground spaces, mostly karst caves, in the treatment of chronic and allergic respiratory diseases. Speleotherapy in the treatment of COPD is recommended by the broader community ${ }^{7}$ and is often described as a verifiably reviewed treatment method for people with the disease. In Eastern Europe, natural salt caves were used for the relief of respiratory symptoms ${ }^{8}$. This therapy is known as Speleotherapy, in which a natural salt cave 
is used as climate therapy for poor health ${ }^{9}$. The unique properties of the micro-climate in caves are the constant air temperature of moderate to high humidity, the presence of fine aerosol elements, as well as the lack of pollutants and pollen in the air ${ }^{10}$. Nowadays, salt caves are used for treatment at health centers in Austria, Poland, Slovakia, Romania, Azerbaijan, Kyrgyzstan, Russia and Ukraine $^{11}$.

Spa Therapy. Spa Medicine includes all medical activities derived from the tradition of spas based on the scientific knowledge of prevention, health promotion, treatment and rehabilitation ${ }^{12}$. The benefits of spas are therefore still under discussion, although natural healing is used for therapeutic purposes ${ }^{13}$. Related to this point is also the particular climatic effects and psychosomatic effects associated with temporary changes in the family and working environment. Due to complexity various forms of physical therapy are also used.

The climactic conditions and solar radiation also potentiate the effects of these procedures. Regarding the effect of spa treatments, there are also other important social and psychological factors, such as social networking, leisure and cultural activities, as well as implementation of various recreational and sports activities, a pleasant atmosphere and natural environment conducive to health ${ }^{14}$.

\section{Groups and methods}

Our pilot study, which ran from $\mathrm{Au}-$ gust to December 2014, was attended by 128 patients ( 87 men and 41 women) with a mean age of 64.05 years $(\mathrm{SD} \pm 11.29)$. The actual research was conducted in three spa facilities located in the Slovak part of the High Tatras, in Sanatoriu Tatranská Kotlina, n.o., Sanatoriu Dr. Guhra n.o. Tatranská Polianka and in the Nová Polianka
Highly-Specialized Institute for Lung Diseases. Patients were informed of the examination and signed a consent form. The spa treatment lasted 19 days $(\mathrm{SD} \pm 1.5)$ and contained 5-6 treatments, 5 times a week. Patients underwent climatic therapy, respiratory physiotherapy, physical therapy and hydrotherapy. The experimental group consisted of 29 patients who underwent spa treatment and Speleotherapy 4 times a week for 50 minutes, that is 10 to 12 times during the stay. The Speleotherapy was performed in the Belianska Cave and combined with breathing gymnastics. The control group consisted of 99 patients who completed just a spa treatment without Speleotherapy. The patients were examined at the beginning and end of the spa stay. The examination consisted in assessing the Saint George's Respiratory Questionnaire (SGRQ). We further evaluated the Anxiety and Depression Questionnaires by Beck and Zung. Through the Spirometry Test we evaluated FEV 1 and $\mathrm{FEV}_{1} / \mathrm{FVC}$. Part of the examination was also a 6-minute Walk Test (6MWT).

The obtained results were statistically evaluated through the SPSS Program, Version 18 . We used a paired t-test.

\section{Saint George's Respiratory Question-} naire (SGRQ) was designed to measure the quality of life in patients with COPD. The questionnaire, in addition to an overall score assesses the health of the patient through three aspects: symptoms, activity and impact of the disease. The resulting scores are real numbers in the range of $0-100$, the higher score indicating a worse condition for this aspect. The first component symptom score displays the frequency and strength of respiratory complaints such as coughing, wheezing, and the strength of the number of seizures (Questions 1-8). The score activity relates to activities that are limited by dyspnea (Questions 11 and 15). The score impact (activity) shows the 
aspects related to social function and psychological problems caused by respiratory disease (Questions 10, 12, 13, 14, 16 and 17). In the final step, the total is calculated, which serves to summarize the impact of the disease on general health. The worst possible score for symptoms is 662.5, for activity 1,209.1, and for impact of disease $2,117.8$, for a total score of $3,989.4^{15}$.

BAI - Beck Anxiety Inventory According to the Likert Scale of 1-4, where 1 means not at all and 4 strongly (I'm barely holding on). The total score ranges from 0 to 63 . The results are interpreted as: $0-7$ : free of signs of anxiety, 8-15: moderate anxiety: 16-25: moderate anxiety 26-63: severe anxiety. It contains 13 items and is suitable for the general population ${ }^{16}$.

\section{SDS - Zung's Self-Rating Depression}

Scale is intended for the general public regarding the presence of depression. According to the Likert Scale of 1-4, where 1 means sometimes or rarely and 4 very often or always. The results (SDS Index Score) are interpreted as follows: less than 50: normal, no sign of depression, 50-59: signs of minimal or mild depression, 60- 69: moderate to very clearly expressed depression, 70 and over: severe or extremely severe depression $^{17}$.

6-minute Walk Test (6-MWT). The American Thoracic Society says that the 6-MWT does not allow the quantification of the factors limiting physical activity and does not provide an indication of maximum oxygen consumption during exercise. 6-MWD correlates well with the quality of life, better reflects the change in dyspnea after therapeutic interventions, and in patients with COPD after the completion of pulmonary rehabilitation is correlated with life expectancy. Evaluation test - the normal value on the basis of studies is considered distance $>500 \mathrm{~m}$ for women and $>600$ for men. Accounting for the age of the patient can be expressed by the following formula: $6 \mathrm{MWD}=800-(5.4 \mathrm{x}$ age $)$. For COPD patients there is given the value of 50 to 55 $\mathrm{m}^{18,19,20}$.

In the Spirometry Test we focused on the presence of a post bronchodilator, where according to GOLD $\mathrm{FEV}_{1}<80 \%$, the predicted value in combination with $\mathrm{FEV}_{1} / \mathrm{FVC}<70 \%$ confirms the presence of bronchial restrictions. $\mathrm{FEV}_{1}$ is the volume of air exhaled in one second and FVC is the forced vital capacity, i.e. the volume of air forcibly blown out after full inspiration $^{1,21}$.

\section{Results}

To evaluate the quality of life, the Saint George's Respiratory Questionnaire (SGRQ) was used. The results of the comparison of the experimental and control groups regarding quality of life confirm one component, namely the symptoms that display the frequency and strength of respiratory complaints such as coughing, shortness of breath, number of seizures and strength on the level of statistical significance $\mathrm{p}=0.014$ (Table 1).

Despite improvements in spirometry in the $\mathrm{FEV}_{1}$ and $\mathrm{FEV}_{1} / \mathrm{FVC}$, we did not record a statistically significant difference in spirometry $(p<0.05)$. Spirometry was improved in respondents who underwent spa treatment together with Speleotherapy in the $\mathrm{FEV}_{1}$ parameter at the end of treatment by $4.07 \%$ and $\mathrm{FEV}_{1} / \mathrm{FVC}$ by $4.26 \%$. In respondents who completed only spa treatment there was spirometry improvement in $\mathrm{FEV}_{1}$ at the end of treatment by $2.54 \%$ and $\mathrm{FEV}_{1} / \mathrm{FVC}$ $3.21 \%$. A statistically significant difference $(p=0.031)$ was recorded through the Beck Anxiety Inventory at the end of treatment. Respondents who completed spa treatment along with Speleotherapy suffered only mild anxiety. A statistically significant difference 
Tab. 1 SGRQ comparison of quality of life SGRQ

\begin{tabular}{|l|c|c|c|c|c|c|}
\hline & Group & $\mathbf{N}$ & Mean & SD & t & p \\
\hline \multirow{2}{*}{ Symptoms score } & experimental & 29 & 31.50 & 16.72 & 2.513 & $\mathbf{0 . 0 1 4}$ \\
\cline { 2 - 7 } & control & 63 & 41.53 & 18.25 & & \\
\hline \multirow{2}{*}{ Activity score } & experimental & 29 & 46.47 & 17.39 & 1.560 & 0.122 \\
\cline { 2 - 7 } & control & 63 & 51.94 & 14.74 & & \\
\hline \multirow{2}{*}{ Impacts score } & experimental & 29 & 29.20 & 21.30 & 0.533 & 0.595 \\
\cline { 2 - 7 } & control & 63 & 31.49 & 18,20 & & \\
\hline \multirow{2}{*}{ Total score } & experimental & 29 & 34.89 & 17.64 & 1.277 & 0.205 \\
\cline { 2 - 7 } & control & 63 & 39.37 & 14.61 & & \\
\hline
\end{tabular}

${ }^{*} \mathrm{p}<0.05$, wherein a significant difference in the experimental group for symptoms

was observed in the evaluation of the 6MWT $(\mathrm{p}=0.004)$. Respondents who completed spa treatment along with Speleotherapy passed at the end of treatment by 26.56 meters more than before, while respondents who completed only spa treatment passed by 24.13 meters more (Table 2). at night. In some cases, the significant decrease of flow of air can develop without the presence of a cough. Shortness of breath is the reason most patients seek medical attention and is a major cause of disability and anxiety associated with the disease $\mathrm{e}^{1,22}$.

According to the ATS/ERS ${ }^{6}$ pulmonary

Tab. 2 Comparison of Spirometry, Depression, Anxiety \& 6-minute Walking test

\begin{tabular}{|l|c|c|c|}
\hline \multicolumn{1}{|c|}{ Analysis } & $\begin{array}{c}\text { Admission } \\
\text { Examination }\end{array}$ & Experimental group & Control group \\
\hline FEV $_{\mathbf{1}}$ & $65.06 \pm 22.17$ & $69.13 \pm 22.28$ & $73.44 \pm 23.40$ \\
\hline FEV $_{\mathbf{1}} / \mathbf{F V C}$ & $76.36 \pm 18.64$ & $80.62 \pm 17.28$ & $83.04 \pm 19.18$ \\
\hline Beck & $14.03 \pm 9.18$ & $8.00 \pm 5.02^{*}$ & $11.13 \pm 6.88$ \\
\hline Zung & $56.22 \pm 11.07$ & $49.41 \pm 8.08$ & $46.52 \pm 8.14$ \\
\hline 6-minute Walking test & $221.72 \pm 80.05$ & $248.28 \pm 84.81^{* *}$ & $320.00 \pm 118.24$ \\
\hline
\end{tabular}

Legend: FEV 1 - The volume of air exhaled in the first second of forced expiratory flow, FVC - Total forced lung capacity

$* \mathrm{p}<0.05$, wherein a significant difference in the experimental group regarding anxiety

** $p<0.005$, where there is a significant difference in the experimental group in the 6-minute Walk Test

\section{Discussion}

According to GOLD and WHO, a cough is usually the first sign of CPOD. Initially it may be intermittent, but later it is present every day, often throughout the day, rarely rehabilitation is multidisciplinary and comprehensive intervention for patients with chronic lung disease in which symptoms predominate, often limiting daily activities. It is part of an individual patient's treatment, and is designed to optimize functional status, 
enhance participation in physical and social activities, improve the quality of life and reduce healthcare costs by stabilizing or reversing the systemic manifestations of the disease $^{6,23}$. Puhan and Gimeno-Santos indicate that pulmonary rehabilitation has become an essential element in the care of patients with $\mathrm{COPD}^{24}$. Systematic evaluation has shown the large and important clinical effects of pulmonary rehabilitation in patients with COPD. Pulmonary rehabilitation leads to an improvement in several resulting areas, and plays a significant role for the patient, including dyspnea, exercise ability, health status and health care utilization ${ }^{25,26}$. The minimum length of time for an effective rehabilitation program is two months and should include the self-management of patients ${ }^{1}$.

To evaluate quality of life, we used the standard Saint George's Respiratory Questionnaire (SGRQ). Using the t-test, we compared whether respondents who completed a spa treatment along with Speleotherapy have a better quality of life. It confirmed one component, the symptoms displaying the frequency and strength of respiratory complaints - coughing, shortness of breath, number of seizures and the strength at the significance level of $\mathrm{p}=0.014$. Horvath ${ }^{9}$, Chervinskaya \& $\mathrm{Ziber}^{10}$ reported an improved quality of life in COPD patients after the completion of Speleotherapy and Halotherapy. Horváth confirmed that $90.4 \%$ of patients treated by Speleotherapy showed an improved clinical condition, compared to $72.8 \%$ in the control group. The authors found that clinical improvement enhances the quality of life of patients with COPD, thereby reducing exacerbations and hospitalization?.

It improves physical tolerance and reduces fatigue. Withers et al and Emery et al report that pulmonary rehabilitation improves depression and anxiety in patients with $\mathrm{COPD}^{27,28}$.

Despite improvements in spirometry in the $\mathrm{FEV}_{1}$ and $\mathrm{FEV}_{1} / \mathrm{FVC}_{\text {parameters, we re- }}$ corded a statistically significant difference in spirometry ( $p>0.05)$. At the end of treatment the spirometry showed improvement in respondents who underwent a spa treatment together with Speleotherapy in the $\mathrm{FEV}_{1}$ parameter by $4.07 \%$ and $\mathrm{FEV}_{1} / \mathrm{FVC}$ by $4.26 \%$. At the end of treatment, for respondents who completed only the spa treatment, the spirometry showed an improvement in the $\mathrm{FEV}_{1}$ parameter of $2.54 \%$ and $\mathrm{FEV}_{1} / \mathrm{FVC}$ of $3.21 \%$. Horvath, in his studies, described improved airway function by measuring $\mathrm{FEV}_{1}$ before and after treatment. The mean $\mathrm{FEV}_{1}$ in the treated group $(\mathrm{n}=230)$ was improved from $1.47 \pm 0.631$ liters to $1.68 \pm 0.71$ liters. The respondents completed respiratory physical therapy, which included Speleotherapy. In the control group $(n=151)$ there was an improvement of $1.64 \pm 0.61$ liters to $1.67 \pm 0.68$ liters $^{9,10}$. Nurov, in his studies, reported improved immune function after completing Speleotherapy, but did not report specific tests on lung function in patients with COPD. He concluded that Speleotherapy improves the immunological status of patients with COPD, and consequently reduces the inflammatory process, particularly during exacerbations ${ }^{29}$.

A statistically significant difference $(\mathrm{p}=$ 0.031) was recorded in the Beck Anxiety Inventory at the end of treatment. Respondents who completed spa treatment along with Speleotherapy had moderate anxiety. Kunik et al in their study describes the improvement of quality of life, anxiety and depression $(p<0.005)$ after 8 weeks of Cognitive-Behavioral Therapy ${ }^{30}$.

A statistically significant difference was observed in the evaluation of the 6-minute Walk Test $(p=0.004)$. Respondents who completed spa treatment along with Speleotherapy passed at the end of treatment 26.56 meters more than before, while respondents who completed only spa treatment passed by 24.13 meters more. Leupold, in his study, 
examined 210 patients with COPD and investigated the effects of intensive 3 -week outpatient pulmonary rehabilitation, focused on exercising lung capacity, dyspnea and improving quality of life. He made investigations before and after pulmonary rehabilitation and assessed physical activity with the 6MWT. The test results showed an improvement in the 6MWT of $(+39 \mathrm{~m}$, $\mathrm{p}<0001)$ following treatment and simultaneously reduced dyspnea in the 6MWT of $(-0.5, \mathrm{p}<0.001)$. The improvement in all dimensions of the SF-36 reflects the improved quality of life after treatment $(\mathrm{p}<0.001)^{31}$. Takata et al found that spa treatment improved ventilation dysfunction and in the 6MWT the distance traveled by COPD patients increased ${ }^{32}$.

Dramsdahl, Harari \& Avriel et al described the term "Dead Sea Climatotherapy" including several therapeutic methodologies under the supervision of a physician: Heliotherapy, Balneotherapy, Hydrotherapy, Physiotherapy, Sports and Physical Education with the optimal use of unique climatic factors ${ }^{33,34,35}$. The Dramsdahl Study in Norway showed significant improvement in patients with COPD in health and the quality of life after completing Climatotherapy by the Dead Sea, describing their stay as a turning point in their history of the disease in their lifetime. Most patients were able to continue working, training or studying ${ }^{33}$.

\section{Conclusion}

As a partial department Speleomedicine can be found on the border of natural and medical sciences. It includes the creation and application of appropriate therapies. In Slovakia, it is carried out in various forms in natural caves. According to medical approaches and self-treatment in caves, besides Speleotherapy, climatic and reconditioning stays are also carried out. The condition and success guarantee of the cave treatment is so-called salt water aerosol, which is air with finely-dispersed components of the solid and liquid phases. In comparison with other studies, we found that regarding Speleotherapy, there are few studies that confirm the success or failure of therapy. This will reduce the potential evidence in support of this therapy. In our research, we found improvement in anxiety and an increase of the distance covered in the 6MWT after completing Speleotherapy with spa treatment.

\section{Declaration of interest}

The authors report no conflicts of interest. The authors alone are responsible for the content and writing of the paper.

\section{References}

1. RAHERISON C, GIRODET PO (2013) Global Initiative for Chronic Obstructive Lung Disease. Global strategy for the diagnosis, management and prevention of chronic obstructive pulmonary disease; [cited 2015 Jan 3]. Available from: //www. goldcopd.org/guidelines-global-strategyfor-diagnosism management. html Epidemiology of COPD In European Respiratory Review; 18(114), 213-21.

2. CELLI BR (2008) Update on the management of COPD. (2008) [cited 2014 Dec 19]. Available from: http://www.ncbi.nlm.nih. gov/pubmed/18574288.

3. NICI L et al (2006) American Thoracic Society/European Respiratory Society Statement on Pulmonary Rehabilitation. In: American Journal of Respiratory and Critical Care Medicine, 173, 2006, s. 13901413.

4. NICI L, DONNER C, WOUTERS E, ZUWALLACK R, AMBROSINO N, BOURBEAU J et al (2006) Pulmonary Rehabilitation Writing Committee American Thoracic Society/European Respiratory Society 
Statement on Pulmonary Rehabilitation. In: American Journal of Respiratory and Critical Care Medicine, 2006, 173: 1390-1413.

5. RICE, KL, DEWAN, N, BLOOMFIELD, HE et al (2010) Disease management program for chronic obstructive pulmonary disease: a randomized controlled trial. $\mathrm{In}$ : Am J Respir Crit Care Med. 2010 [cited 2015 Jan 1]. Available from: http://www.ncbi.nlm. nih.gov/pubmed/20075385.

6. SPRUIT M A, SINGH S J, GARVEY CH, ZUWALLACK R, NICI L et al (2013) An Official American Thoracic Society/European Respiratory Society Statement: Key Concepts and Advances in Pulmonary Rehabilitation.. [cited 2015 February 9]. Available from: http://www.thoracic.org/statements/ resources/copd/PRExecutive_Summary 2013.pdf.

7. RASHLEIGH R, SMITH S MS, ROBERTS NJ (2014) A review of Halotherapy for chronic obstructive pulmonary disease.. [cited 2014 Dec 1]. Available from: http:// www.google.sk $/ 1$ ? sa $=$ t\&rct $=j \& q=e d=0 C$ CEQFjAA\&url=http $\% 3 \mathrm{~A} \% 2 \mathrm{~F} \% 2 \mathrm{~F}-$ Ww w.s.m\%2F getfile.p\%3FfileID\%3D19102\&ei=NKvhVPqOD9PZatecgPAD\&usg=AFQjCNFCHdpIETtZ9RnZG80km_8g\&sigVv8U81GFleQA\&b$\mathrm{vm}=\mathrm{bv} .85970519, \mathrm{~d} . \mathrm{d} 2 \mathrm{~s}$.

8. GRIMSHAW, T (2012) Salt Therapy (2012 [cited 2014 Dec 1]. Available from: http://aca. ninemsn.com.au/article/8472866/salt-therapy.

9. HORVATH T (1968) Speleotherapy: a special kind of Climatotherapy, its role in respiratory rehabilitation. Int Rehabil Med. 1986;8:90-92.

10. CHERVINSKAYA AV, ZIBER NA (1995) Halotherapy for treatment of respiratory diseases. J Aerosol Med. 8:221-232.

11. CHERVINSKAYA, AV (2003) Halotherapy of respiratory diseases. Physiotherapy, Balneology and Rehabilitation; 6:8-15.

12. GUTENBRUNNER C, BENDER T, CANTISTA P, KARAGÜLLE Z (2010) A proposal for a worldwide definition of health resort medicine, balneology, medical hydrology and climatology. In: Int J Biometeorol; 54(5): 495-507.

13. ROVENSKÝ J, PAYER J, CLAGUE RB et al (2009) Dictionary of Rheumatic Disease. Wien, Springer Verlag, 23.

14. CIMBIZ A, BAYAZIT V, HALLACELI H, CAVLAK U (2005) The effect of combined therapy (spa and physical therapy) on pain in various chronic diseases. In Complementary Therapies in Medicine: Elsevier,. ISSN 0965-2299, č.13. Str. 244-250.

15. JONES P (2008) St. George's respiratory questionnaire for COPD patients (SGRQ-C) manual London: Division of Cardiac and Vascular Science St George's, University of London [cited 2014 Dec 11]. Available from: http://www.healthstatus.sgul.ac.uk/SGRQ download/SGRQC\%20Manual\%202008. pdf.

16. BECK AT et al (1988) An Inventory for measuring clinical anxiety: Psychometric properties. Journal of Consulting and Clinical Psychology. Vol. 56, no.6, p. 893-897.

17. ZUNG WK (1965) A Self-rating Depression Scale. Archives of General Psychiatry. 1965, Vol. 12, no. 1, p. 63-70.

18. American Thoracic Society (2002) ATS Statement: Guidelines for the Six-Minute Walk Test. [cited $2014 \mathrm{dec}$ 14]. Available from: http://www.thoracic.org/statements/resources/pfet/sixminute.pdf.

19. WEISS RA et al (2000) Six minute Walk Test in severe COPD: reliability and effect of Walking course layout and length. Paper presented at ACCP Conference; Sept 2000; San Francisco.

20. CHLUMSKÝ J (2003) Standard pro šestiminutový test chưzí. 2003. [cited 2014 Sec 28]. Available from: http://www.pneumologie.cz/odborne/doporucene-postupy.php

21. GOLD (2003) Global Initiative for Chronic Obstructive Lung Disease, updated. 2007. [cited 2014 dec 28]. Available from: http:// www.goldcopd.com/Guidelineitem.as$\mathrm{p} ? 11=2 \& 12=1 \&$ int $\mathrm{Id}=2003$. 
22. World Health Organization (2009) Global surveillance, prevention and control of CHRONIC RESPIRATORY DISEASES. A comprehensive approach. Switzerland. 2007. [cited 201412 28]. Available from: http://www.who.int/gard/publications/ GARD Manual/en/.

23. HODGKIN JE, BARTHOLOME RG, CONNORS GL (2009) Pulmonary rehabilitation. St. Luis. Mosby.

24. PUHAN MA, GIMENO-SANTOS E (2011) Pulmonary rehabilitation following exacerbations of chronic obstructive pulmonary disease (Review). The Cochrane Collaboration and published in The Cochrane Library. [cited 2014 Dec 28]. Available from: http://summaries.cochrane.org/CD005305 /pulmonary-rehabilitation-for-people-who-have-been-in-hospital-with-an-exacerbation-of-chronic-obstructive-pulmonary-disease.

25. CELLI BR et al Standards for the diagnosis and treatment of patients with COPD: a summary of the ATS/ERS position paper 2004. [cited 2014 Dec 8]. Available from: http://erj. ersjournals. com/content/23/6/932.full.

26. LACASSE Y, Wong E et al (1996) Meta-analysis of respiratory rehabilitation in chronic obstructive pulmonary disease. [cited 2014 Dec 8]. Available from: http:// www.luzimarteixeira.com.br/wp-content/ uploads/2009/06/art_lacasse-e-col-1996meta-analysis-of-respiratory-rehabilitation-copd.pdf.

27. KOHÚTIK NJ, RUDKIN ST, WHITE RJ (1999) Anxiety and depression in severe chronic obstructive pulmonary disease: the effects of pulmonary rehabilitation. J Cardiopulm Rehabil.19:362-5.

28. EMERY CF, SCHEIN RL, HAUCK ER, MACINTYRE NR (1998) Psychologické a kognitívne výsledky randomizovanej štúdii s cvičením u pacientov s chronickou obštrukčnou chorobou pl'úc zdravie Psychol 17: 232-40.

29. NUROV I (2010) Immunologic features of
Speleotherapy in patients with chronic obstructive pulmonary disease. Medical and Health Science Journal. 2:44-47.

30. KUNIK ME, Veazey C, Cully JA, Souchek J, Graham DP, Hopko D et al (2008) COPD education and cognitive behavioral therapy group treatment for clinically significant symptoms of depression and anxiety in COPD patients: a randomized controlled trial. [cited 2014 Dec 19]. Available from: http://www. pulib.sk: 2088/w/204500266/13CFD01DF4C20534B6E/1?Accountid=14716\#

31. LEUPOLDT A.,Hahn E et al (2008). Effects of 3-week Outpatient Pulmonary Rehabilitation on Exercise Capacity, Dyspnea, and Quality of Life in COPD. [cited 2014 Dec 19]. Available from: http://www.pulib. sk:2088/docview/231707084/13C9F2EB 52068EF0AE2/2?accountid=14716].

32. TAKATA S, ASHID, K, HOSAKI Y et al (2008) Effects of spa therapy on the six-minute Walk Test in patients with chronic obstructive pulmonary disease. [online]. 2008. [cited 2014 Dec 19]. Available from: http://scholar.google.sk/r?hl=en\&q=TAKATA $\% 2 \mathrm{C}+\mathrm{S} . \% 2 \mathrm{C}+\mathrm{ASHIDA} \% 2 \mathrm{C}+\mathrm{K}$. $\% 2 \mathrm{C}+\mathrm{HOSAKI} \% 2 \mathrm{C}+$ Y. +et.+al.+Effects + of + spa + therapy + on + the + sixminute +Walk+test + in + patients + with + chron$\mathrm{ic}+$ obstive + pulmonary + disease. $+\& b t-$ $\mathrm{nG}=$ \&as_sdt $=1 \% 2 \mathrm{C} 5$ \&as_sdtp $=$

33. DRAMSDAHL E (2012) Multidisciplinary Rehabilitation and Climatotherapy for Chronic Diseases at the Dead Sea. Anales de Hidrología Médica Vol. 5, Núm. 1, 53-63. ISSN 1887-0813.

34. HARARI M, DRAMSDAHL E (2011) Multidisciplinary rehabilitation at the Dead Sea. Norway Medical Association. Indremedisineren. Jun; 39-41.

35. AVRIELL A, FUCHS L, PLAKHT Y et al (2011) Quality of life at the dead sea region: the lower the better? an observational study. [online].[cited $2014 \mathrm{dec}$ 19]. Available from: http:/www.ncbi.nlm.nih.gov/pmc/articles/ PMC3123541/. 


\title{
Patient safety assessment: USA and Slovak hospitals
}

\author{
H. A. Kwofie
}

Original Articles

Panuska School of Professional Studies, University of Scranton, Pennsylvania, USA

\section{Correspondence to:}

University of Scranton, 800 Linden St, Scranton, PA 18510, USA

Submitted: 16.11.2015

Revised: 2.5 .2016

Accepted: 7.8 .2016

\section{Reviewers:}

D. J. West, Jr.

University of Scranton, Department of Health Administration and Human Resources, USA

P. G. Fedor-Freybergh

International Society of Applied Preventive Medicine I-Gap, Vienna, Austria

\section{Keywords:}

Patient Safety, Adverse Events, Medical Errors, Incident Reporting, Harm, HAIs

CSWHI 2016; 7(2): 16-19 @ 2016 Clinical Social Work and Health Intervention

\section{Abstract:}

It is the priority of all health care organizations to promote patient safety. All over the world, numerous people suffer from hospital acquired infections and other adverse events day in and day out. The goal of this study was to verify whether there were any disparities in the way patient safety issues are handled in the United State and the Slovak Republic. This article also explores the types of adverse event and errors and their causes, some universal strategies to minimize safety issues, and some basic steps involved in incident reporting. It was concluded that there was a wide difference in the number of adverse events that are reported in both countries.

\section{Introduction}

Patients are likely to be exposed to some degree of risk during the delivery of care. Patient safety was defined by the Institute of Medicine (IOM) "as the prevention of harm to patients" with emphasis being placed on the system of care delivery that (1) prevents errors, (2) learns from the errors that do occur, (3) and is built on a culture of safety that involves healthcare professionals, organizations, and patients. 
According to the Institute of Medicine, at least 48,000 people and as many as 98,000 people die from medical errors each year and these errors are known to be preventable. Total cost of preventable errors per year in hospitals nationwide was estimated to be between $\$ 17$ billion and \$29 billion (Institute of Medicine; To Err Is Human, 1999). The healthcare system in the United States has not achieved its desired level of safety likewise that of the Slovak Republic and any other country in the world. But major efforts are being made to improve patient safety and the quality of care delivered.

\section{What Constitute an Adverse Event and Medical Errors}

An adverse event is defined as the injury caused by medical management rather than the underlying condition of a patient whilst medical error is the failure of a planned action to be completed as intended (Institute of Medicine). Common types of adverse events and medical errors are: foreign objects found in a patient after surgery; surgery done on the wrong part of the body; medication errors; patient falls; injuries from electric shock; surgery on the wrong patient; pressure ulcers; wrong surgical procedure; nosocomial infections/HAIs; mistakes in communication; missing standards or guidelines and many more. Some of these errors are mandatory reportable and some are voluntarily reportable.

In a study done by the Office of the Inspector General, which reports adverse events in hospitals among Medicare beneficiaries, reveals that an estimated $13.5 \%$ of Medicare beneficiaries experienced adverse event during their hospital stay that resulted in temporary harm. Physician's reviewers also determined that $44 \%$ of these adverse events were known to be preventable. Care associated with adverse events and temporary harm events cost Medicare an estimated \$324 million in October, 2008. Based on their findings, they recommended that AHRQ and CMS broaden their patient safety efforts to include all kinds of adverse events and should enhance their efforts to identify adverse events (OIG, 2010).

In a recent study, researchers surveyed three different hospitals with a sample size of 1,787 hospital staff in the Trnava Region of the Slovak Republic. Their aim was to identify the perception of healthcare workers with regards to the safety of patients in the workplace. The study revealed that team work across hospital units and hospital management support for patient safety issues were very weak with a $35 \%$ and $39 \%$ survey results respectively. Hospital staff also admitted to the fear of reporting adverse events. Physicians and nurses also had different perceptions on communication; adverse event reporting and staffing in the hospitals surveyed for this study (Veronika et.al, 2012).

In a similar study on the distribution of the number of adverse events reported both in the United States and the Slovak Republic, the result shows that $80 \%$ of healthcare workers in the Slovak Republic never reported any adverse event that occurred as opposed to $52 \%$ in the United States. Those who reported one or two events when they occurred were $11 \%$ and $28 \%$ for the Slovak Republic and the United States respective1y. Again, $8 \%$ of healthcare workers in Slovak Republic reported three to five events, whilst $13 \%$ of healthcare workers in the United States reported three to five events when they occurred. This shows there was under-reporting of adverse events and medical errors in the Slovak Republic and the reason for this was the fear of adverse event reporting; the fear of losing one's job; being punished (Viera Rusnáková et.al, 2010). 


\section{Causes of Adverse Events and Medical Errors}

Fragmented nature of healthcare delivery system; negligence; task complexity and the availability and use of protocols; inadequately trained personnel and staffing levels; excessive workload; administrative and managerial support problems; problems associated with skill mix; equipment failure or malfunction; poor verbal and written communication; and poor leadership and supervision.

\section{Preventive Strategies}

- Encourage information sharing and promote good team work.

- All healthcare facilities must make sure they have sufficient personnel's to provide patient care.

- They must always take into consideration the ratio of patients to healthcare staff.

- There must be policies and procedures in place to check that.

- Care and consideration should be given when hiring and assigning jobs to healthcare personnel.

- Patients should be involved in their care. They should be allowed to ask questions.

- Suitable working environment which is free from harm should be provided at all times.

- There should be transparency in the delivery of care.

- Patient safety lies in our hands; therefore, promoting a culture of safety is a must.

\section{Conclusion}

All healthcare workers should be involved in safeguarding the health and safety of the patient. Research reveals that there is a wide disparity in the number of adverse events that are reported in both the United States and the Slovak Republic. Therefore, healthcare workers should be encouraged to report adverse events and errors as soon as they occur because it is the only way the healthcare facility can address the issue and come up with a solution. Errors are very costly; a lot of people are losing their lives due to preventable errors. There is also the lack of trust in the system and a decreased satisfaction by both patients and healthcare professionals. Patient safety can be enhanced by allowing patients to ask questions and involving them in their care; putting in a lot of consideration in hiring and assigning task to employees; and by promoting transparency in the delivery of care and allowing open communication.

\section{References}

1. Agency for Healthcare Research and Quality (2009) Advancing Patient Safety: A decade of Evidence Design and Implementation. Retrieved from www.ahrq.gov

2. Agency for Healthcare Research and Quality. (2013) Error Reporting and Disclosure. Retrieved from: www.ahrq.gov

3. Center for Medicare and Medicaid Services (2013). Partnership for Patient. Retrieved from: http://partnershipforpatients.cms.gov/ about-the-partnership/what-is-the-partnership-about/lpwhat-the-partnership-is-about. html.

4. Department of Health and Human Services (OIG). (2010) Adverse Events in Hospitals: National Incidence among Medicare Beneficiaries. Retrieved from: http://oig.hhs.gov/ oei/reports/oei-06-09-00090.pdf

5. McCAUGHAN D, KAUFMAN G (2013) Patient Safety: threats and solutions. Nursing Standard, 27(44), 48-55.

6. MIKUŠOVÁ V et al (2012). Patient Safety Assessment in Slovak Hospitals. International Journal of Collaborative Research 
on Internal Medicine and Public Health (IJCRIMPH), 4(6), 1236-1244.

7. RUSNÁKOVÁ V et al (2010). Patient Safety Culture-Pilot Hospital Survey in Slovakia. Slovak Medical University

8. WAKEFIELD M, DeLEON PH (2000) To Err Is Human: An Institute of Medicine Report. Professional Psychology: Research \& Practice, 31(3), 243.
9. Washington State Department of Health. (2012) Adverse Event List: National Quality Forum (NQF) Serious Reportable Events. Retrieved from: http://www.doh.wa.gov/ Portals/1/Documents/Pubs/689003.pdf

10. World Alliance for Patient Safety: WHO Draft Guidelines for Adverse Event Reporting and Learning Systems. WHO Press, Geneva 2005. Retrieved from: www. Who.Int. 


\title{
Organ transplantation rates in Central Europe: cultural and bioethical considerations
}

\author{
Ch. Nebzydoski, D. J. West, jr.
}

Original Articles

University of Scranton, Department of Health Administration and Human Resources, USA St. Elizabeth University College of Health and Social Work in Bratislava, Slovak Republic

\section{Correspondence to:}

University of Scranton, Department of Health Administration and Human Resources, 800 Linden St, Scranton, PA 18510, US

Submitted: 29.12.2014

Revised: 1.8 .2015

Accepted: 4.3.2016

\section{Reviewers:}

J. Breza

Head of Department of Urology, Medical Faculty of Comenius University Hospital

Bratislava, Slovak Republic

J. Kafkova

Nairobi, St. Bakitha Clinic, Kenya

\section{Key words:}

Organ Transplantation, Central Europe, Cultural and Bioethical

CSWHI 2016; 7(2): 20-23 @ 2016 Clinical Social Work and Health Intervention

\section{Abstract:}

Organ transplantation rates vary amongst every nation in the world, including countries in Central Europe and the European Union. Healthcare systems are faced with many discrepancies regarding the number of deceased versus living donors in all countries. This article focuses on examining the current cultural and bioethical considerations in the organ transplantation system of Central Europe, specifically Slovakia, Czech Republic, Austria, Hungary, and Poland. Current discussion and research data show the need to consider these implications as a healthcare system in order to increase promotion within the area of organ transplantation. The European Commission supports the need for these specific countries, along with the whole European Union, to increase their organ transplantation rates and promote public awareness of this issue. EurActiv (European Union Information Website) continues to promote European Parliament's legislation that sets common EU quality and safety standards for transplants. However, the push to promote efficiency and accessibility of transplantation systems will not come without problems due to cultural and bioethical dilemmas. The issues 
presented in this article seek to address these concerns, as well as to explore donation rates, transplantation practices, and the varying acceptability of donation across Central Europe.

\section{Why organ transplantation?}

Organ transplantation rates vary widely across the globe, with several regions of the world exhibiting greater variability than others. This does not come as a surprise, however, because this same variations hold true for other healthcare related identifiers as well. Research into this phenomenon still holds value because there remains an almost universal shortage of deceased donors throughout the global healthcare system (Rudge et al. 2012).

Although many cultural and bioethical considerations remain at the forefront of organ transplantation discussion, the demand for more donors continues to be significant. Use of this healthcare practice is essential for the treatment of certain diseases. It can also be rendered as the best and sometimes the only form of treatment for many patients with end-stage organ failure that seeks to prolong the life of patients who suffer from this medical condition. There are several medical conditions that necessitate organ transplant as the only viable treatment (World Health Organization, 2013).

Organ transplantation should continue to be a key ingredient for approaching the promotion of improved and successful public health outcomes. The need for this medical treatment to exist is real. Since the gap between the number of organ transplants and number of people on the current waiting list continues to widen, it is essential that healthcare leaders advocate for implementation of new strategies and health policies to solve this problem. It is imperative that leaders in this field keep in mind that the search for new practices, policies and the need to generate public debate in the areas of legal and ethical acceptability. Professional bodies, such as the World Health Organization, have been seen in recent years focusing on the development of legal and ethical frameworks designed to encourage all countries to eradicate unacceptable practices of organ transplantation and promote donation to its maximum potential using established criteria and ethical practices (Rudge et al. 2012).

\section{Central Europe}

To study this phenomenon in an area where the European Union (EU) has recently adopted new rules on organ transplantation will remain at the forefront of this study. Analysis and interpretation of organ transplantation rates in five Central European countries will be addressed. These include Slovakia, Czech Republic, Austria, Hungary, and Poland. It is important to note that organ transplantation in this area of the world comes almost strictly from the deceased population, which differs from many other countries like the Netherlands, Britain, Sweden, Canada, and the United States where organ donation includes live donors (Oliver et al. 2010).

Currently, the demand for organs exceeds their availability in all EU Member States and demand increases faster than organ donation rates in most Member States. The same conclusion, as stated before, holds true for Europe: organ transplantation rates 
and organ availability vary widely across all countries, per million of population (pmp). Few Member States have succeeded in increasing significantly the number of donors. These changes can be linked to the introduction of better organizational practices. Although there are Member States that lie above the EU average for transplantation rates, the five Member States evaluated in this study do not lie near this average. To adjust this study for the context in which it lies, the five EU Member States will be compared to five Western EU Member States (Council of Europe, 2011).

\section{Central Europe vs. Western europe}

To further define the Western EU Member States, the study analyzed Ireland, the United Kingdom, France, Spain, and Portugal. Analysis and interpretation of the organ transplantation data available shows that Western EU Member States hold higher deceased and living donor rates (pmp). The averages for the Central EU Member States associated with deceased and living donor rates are $16.4 \mathrm{pmp}$ and $3.68 \mathrm{pmp}$, respectively. The averages for the Western EU Member States associated with deceased and living donor rates are $25.2 \mathrm{pmp}$ and 7.62 pmp, respectively. This interpretation serves as evidence that organ transplantation rates vary widely across the EU Member States (Global Observatory on Donation \& Transplantation, 2012).

It is also important to take this analysis and observe other data that support this conclusion. In the United States, the rates associated with deceased and living donor rates are $26.0 \mathrm{pmp}$ and $18.4 \mathrm{pmp}$, respectively. This helps to confirm that organ transplantation rates continue to vary widely on a global health scale as well (Global Observatory on Donation \& Transplantation, 2012).

\section{Cultural and bioethical considerations}

After confirmation of the variation in organ transplantation rate, it is imperative that we seek to discuss some concluding factors about why this exists. Analysis of religion, surveys, and socio-economic status will prove to be important for this discussion because there is evidence that proves these measures have an impact on organ transplantation as well.

The EU Member States hold a religious value surrounding the Christian faith. Research data shows that the EU has a predominant Christian population of nearly $75 \%$, but only $12 \%$ of that population holds an organ donor card. This is a discrepancy in the data because although the Christian faith appears to generally accept and endorse organ transplantation, there are clearly different nuances in opinion (Oliver et al., 2010).

Further analysis of these measures leads us to the conversation about surveys in the EU constructed around willingness and discussion of organ transplantation. Two surveys were constructed to analyze both the willingness to donate to a family member and family discussion about organ transplantation (Eurobarometer, 2007). Answers to both questions correlate to the lack of willingness and knowledge about the topic. For the five Central European Member States, the rates for willingness to donate to a family member and discussion of organ transplantation between family members were below $60 \%$ and below $30 \%$, respectively. This leads us to the conclusion that there continues to be an issue with the trust of the healthcare transplantations system, as well as other cultural and bioethical problems (Eurobarometer, 2007).

Concluding the discussion on this topic, we need to also realize that socio-economic status and years of education may lead to 
variation in the system as well. Studies in the EU have concluded that political status, sex, and education all lead to changes in willingness to donate (Mocan \& Tekin, 2007). If individuals are Liberal in political affiliation and have one year of additional educational background, the willingness to donate increases. Furthermore, being a male is attributed to a 5-percentage point reduction in the willingness to donate organs. It is also important to note that individuals who are aware of the rules and regulations about organ transplantation tend to donate by $16-18$ percentage points higher than the unknowledgeable individuals (Mocan \& Tekin, 2007).

\section{Conclusion}

"Organ transplantation is unique a patient can only become the recipient of a transplant because another human has donated the organ, either in life or after death (Rudge, et al., 2012)." The quote associated with organ transplantation explains the uniqueness of this type of healthcare topic. In order to increase the number of organs available worldwide, governmental policies, laws, and procedures must be adopted so that the quality, safety, and knowledge of the organ transplantation system increases. Organ transplantation must continue to be a key ingredient when approaching the promotion of improved and successful public health outcomes. Successful treatment outcomes for specific medical problems require a donation system where the supply of organs begins to address the need.

\section{References}

1. RUDGE, C, MATESANZ, R, DELMONICO, L, CHAPMAN, J (2012). International practices of organ donation.British Journal of Anaesthesia, 1(8), 48-55.

2. Human organ transplantation (2013). Retrieved from http://www.who.int/transplantation/organ/en/.

3. OLIVER, M, WOYWODT, A, AHMED, A, SAIF, I (2010). Organ donation, transplantation, and religion. Nephrology Dialysis Transplantation.

4. Key facts and figures on EU organ donation and transplantation. (2011, 2007). Retrieved http://ec.europa.eu/health/ph threats/human_substance/oc_organs/docs/ fact_figures.pdf .

5. International donation and transplantation activity. (2012). Retrieved from web www. europeantransplantcoordinators.org/uploads/pdfs/02_Preliminary figures 2011.pdf.

6. MOCAN, N, TEKIN, E (2007). The determinants of the willingness to donate an organ among young adults: Evidence from the United States and the European Union. Social Science \& Medicine, 65, 2527-2538. 


\title{
Effect of spa treatment and the epidemiology of tuberculosis in the Slovak republic in the year 2014
}

\author{
M. Samohyl1, I. Solovic 2,3, R. Rams 3,4, K. Hirosova?', \\ D. Vondrova', D. Krajcova', A. Nadazdyova5, A. Filova', \\ J. Jurkovicova'
}

Original Articles

${ }^{1}$ Institute of Hygiene, Faculty of Medicine, Comenius University, Bratislava, Slovak Republic

${ }^{2}$ Institute of Tuberculosis, Lung Diseases and Thoracic Surgery, Vysne Hagy, Slovak Republic

${ }^{3}$ Faculty of Health, Catholic University, Ruzomberok, Slovak Republic

${ }^{4}$ Institute of Public Health, Jessenius Medical Faculty Comenius University, Martin, Slovak Republic

${ }^{5}$ Department of Stomatology and Maxillofacial Surgery, Faculty of Medicine, Comenius University, Bratislava, Slovak Republic

\section{Correspondence to:}

Institute of Hygiene, Faculty of Medicine, Comenius University in Bratislava, Spitalska 24, 81372 Bratislava, Slovak Republic; e-mail: martin.samohyl@fmed.uniba.sk

Submitted: 26.8 .2016

Revised: 20.7.2016

Accepted: 12.8 .2016

\section{Reviewers:}

V. Krcmery

Institute of Microbiology, Faculty of Medicine of Comenius University and University Hospital Bratislava, Slovak Republic

J. Suvada

St. Charles Foucauld Health Centre, St. Elisabeth University, Beirut, Lebanon

\section{Key words:}

Tuberculosis, epidemiology, TB prevalence, treatment success.

CSWHI 2016; 7(2): 24-35 @ 2016 Clinical Social Work and Health Intervention

\section{Abstract:}

Tuberculosis (TB) is an infectious disease characterized by specific granular inflammation and granuloma (tuberculoma) formation. In the Slovak Republic, there were 336 cases of TB in the year 2014, which signifies a prevalence of $6.20 / 100,000$ in the total population. The TB prevalence decreased by about $1.21 / 100,000$ population compared to the year 2013. The proportion of extra-pulmonary TB was 59 cases to 277 cases of pulmonary TB. The highest incidence of TB in women was in the age group $0-4$ years (19 cases), and in men in the age of 50 
- 54 years (27 cases). The highest prevalence of TB was in the Presov Region (13.07/100,000) and in Kosice Region (8.05/100,000), the lowest TB prevalence was in Trnava Region (3.23/100,000). The TB prevalence in childhood was 45 cases, of which 39 cases were in Roma children. The highest prevalence of TB in childhood was in the Presov Region (22.24/100,000) and Banska Bystrica Region (4.35/100,000). The Slovak Republic reached the highest percentage of successful TB treatment $(85 \%)$ in newly diagnosed microscopically positive cases among European countries. The incidence of TB in Slovakia decreased over recent years, but nevertheless, more attention should be paid to looking for patients, particularly in high-risk population groups.

\section{Introduction}

Tuberculosis is an infectious disease characterized by specific granular inflammation and granuloma formation - tubercles. Tuberculosis usually affects the lungs (75\%), but TB can also affect other parts of the body (bones, joints, heart, muscles, skin, pancreas, digestive tract, thyroid, kidneys, brain, etc.) - this is the so-called extra-pulmonary TB (25\% of cases) (RPHA, 2014; Solovic, 2014). Extra-pulmonary TB more often occurs in immunocom-promised patients and in very young children. Tuberculosis is an air-borne infection spread by coughing and/or sneezing patient with the active TB. Most infected people (90\%) have asymptomatic, latent forms of TB. Miliary TB is the most dangerous form, which attacks several organs simultaneously. Extra-pulmonary and pulmonary tuberculosis can run simultaneously (RPHA, 2014).

Tuberculosis is mainly caused by the bacteria Mycobacterium tuberculosis, less frequently by Mycobacterium Bovis and Mycobacterium Africanum. Around one third of the world population has been infected by the Mycobacterium tuberculosis (Dye et al., 1999; Frieden et al., 2003). The bacteria $M$. tuberculosis are expectorated by patients with active pulmonary TB typically by coughing. The active transmission in the countries with high TB incidence most often happens in households and crowded spaces with large numbers of people. The risk of infection depends on several factors: degree of the reservoir infectivity; contact closeness; quantity of inhaled bacteria; and the condition of the host immune system (Solovic, 2008).

The worldwide annual incidence of active TB forms is more than 8 million, with more than $90 \%$ of deaths in developing countries, so tuberculosis remains one of the most important global threats in public health (Ahlburg 2000; Maher, Raviglione, 2005;

Gupa et al., 2004). Tuberculosis is the most common cause of death of all treatable infectious diseases (Dye, 2006).

Since 2006, TB prevalence in the European Union (EU) has dropped annually on average by $4.4 \%$ (ECDC, 2012). The TB prevalence decrease can be attributed to the better national and international TB monitoring (Glaziou et al., 2013). In the developed countries, the TB prevalence has dramatically fallen, but in these countries it is still relatively high. (Mathema et al., 2006).

Currently, despite the new quantiferon TB tests (Zanova et al., 2012), and accessible and efficient anti-tuberculotic drugs, TB 
remains after more than 50 years a significant global health problem (Mathema et al., 2006).

\section{TB Epidemiology in Slovakia in 2014}

The prediction of the TB incidence decrease in Slovakia, relevant in the 1980s of the 20th Century, is now being fulfilled. The highest TB prevalence in Slovakia was in 1960 when there were 7,817 registered TB cases, and since then it has a declining trajectory. According to the National TB Registry (NRT) statistics, the absolute number of reported cases decreased up to 1970. In the second half of the 1980s the decline was even more significant. In 2002, there were 1,053 reported cases of newly diagnosed TB and in 2003 the number of newly diagnosed cases was less than one thousand for the first time.

Nowadays, the incidence situation is stabilized in Slovakia. In 2013, 401 TB cases were reported to the NRT (prevalence of 7.41/100,000 population). In 2014, 336 TB cases were reported (prevalence of $6.2 / 100,000$ population), of which 42 were relapses (Fig. 1). In 2014, compared to 2013 , there was a decrease of TB prevalence by $1.21 / 100,000$ population. The pulmonary forms of tuberculosis accounted for 277 cases and 59 cases involved extra-pulmonary TB. Comparison by sex and age showed more diagnosed cases in men (nearly of 200), while in women TB occurrence is predominantly in the older age groups. In 2014, no cases of co-infection of TB and HIV were reported. In total, $222 \mathrm{~TB}$ cases were verified $(66.1 \%)$ - by bacteriological, histological and other methods.

Since 1988, the highest number of cases/ incidence of pulmonary and extra-pulmonary TB forms was in 1993 and the lowest in 2014 (277 of pulmonary and 59 of extra-pulmonary cases). Since 1993, the incidence of pulmonary and extra-pulmonary TB has a descending tendency (Fig. 2).

In 2014, a higher TB incidence was in men in age groups 25 - 79 years than in women, with the highest incidence in the 50 - 54 age group (27 cases). In women there was a higher TB incidence in the 0 - 19 age group, with the highest TB incidence in the 0 - 4 age group (19 cases) (Fig. 3).

Fig. 1 The TB prevalence in Slovakia, 1960 to 2014 (adapted according to National TB Registry, 2014)

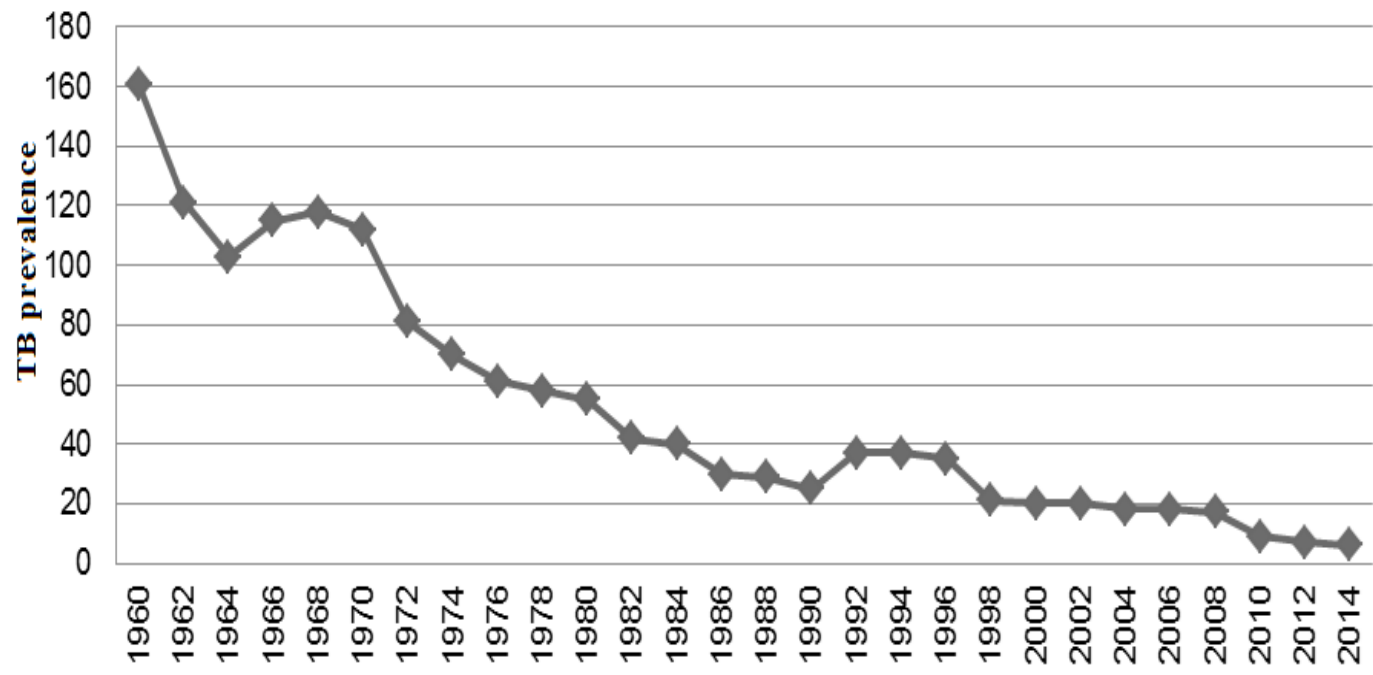


Fig. 2 TB cases during the years 1988 to 2014 (adapted according to National TB Registry, 2014)

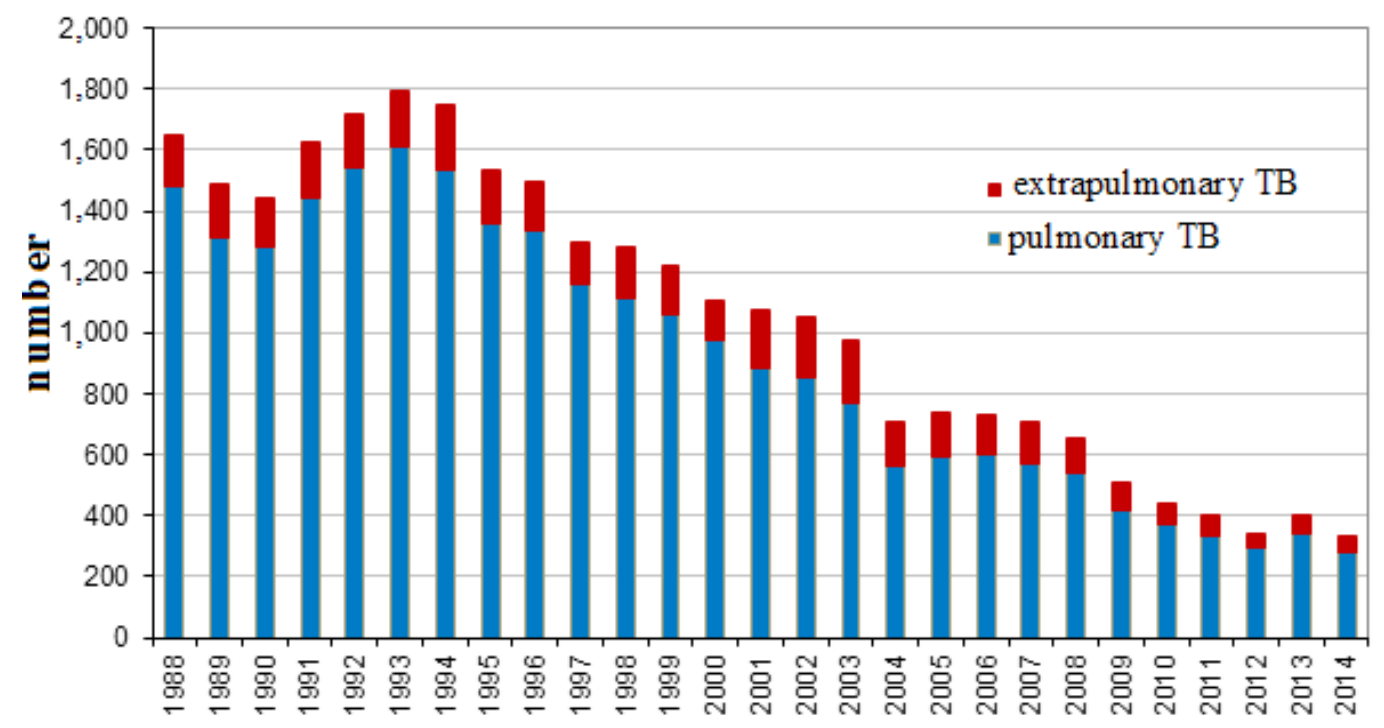

Fig. 3 The TB cases by age and sex, 2014 (adapted according to National TB Registry, 2014)

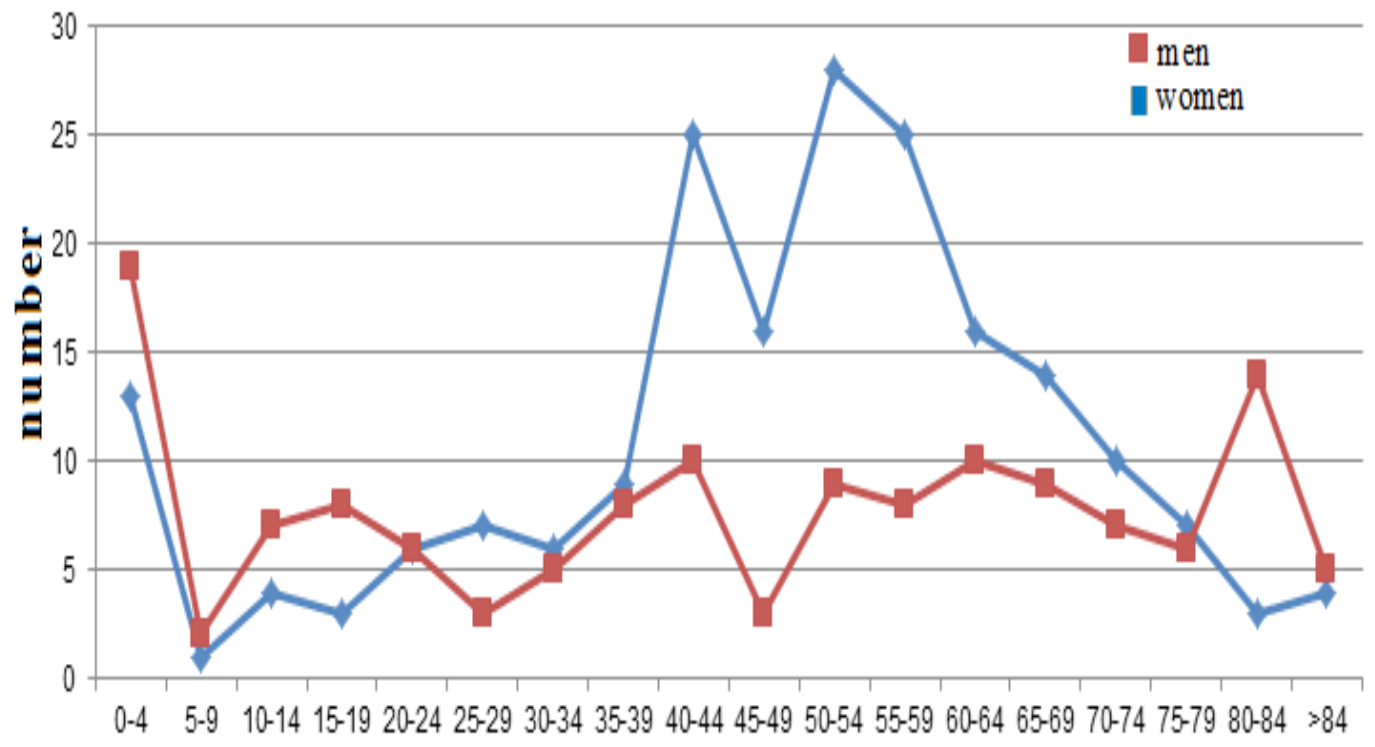

The most common methods of TB detection in patients included visiting out-patient departments for problems (220 cases), TB contacts examinations (50 cases), preventive medical checks (18 cases) and checking the registered TB patients (16 cases) (Fig. 4).
The highest TB prevalence was in the Presov Region (PO, 13.07/100,000 population) and in the Kosice Region (KE, 8.05/100,000 population) in Eastern Slovakia with the highest proportion of Roma population; and the lowest in the Trnava 
Fig. 4 Methods of TB patient detection, 2014 (adapted according to National TB Registry, 2014)

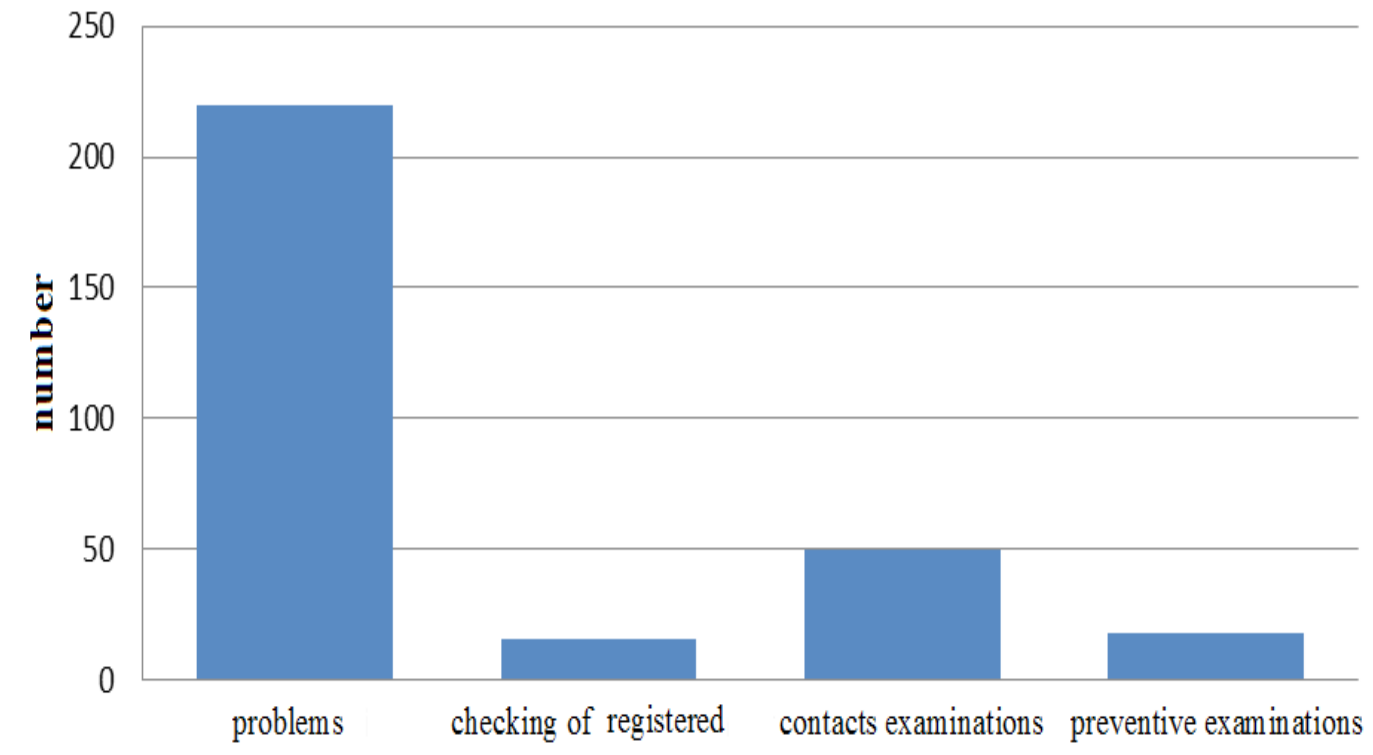

Region (TT, 3.23/100,000 population) (Fig. 5).

Over the years 2004 - 2014, the highest TB prevalence in the Presov Region was in 2007 (25.76/100,000 population) and the lowest in 2010 (12.64/100,000 population). In 2014, the TB prevalence in the Presov Region was 13.07/100,000 population (Fig. 6).

The highest TB prevalence in the Presov Region was in the Kezmarok District (24/100,000 population) and the lowest in the Levoca District (1/100,000 population). Over the years 2005 - 2014, the highest TB prevalence in the Presov Region was in the Presov District in the year 2006 (37/100,000 population) (Fig. 7).

The highest proportion of TB cases in the Roma population was in the Presov (51.4\%); Banska Bystrica (36.4\%); Kosice Regions (29.7\%) (Fig. 8).

The Roma population had $100 \%$ rate on the TB prevalence in the 5 - 9 years age group; followed by the 10 - 14 years age group (90\% rate); by the 15 - 19 years age group (81\% rate) (Fig. 9).
The TB prevalence in childhood has been increasing since 2010. In 2014, TB was diagnosed in 45 children, of which 39 cases were Roma children (Fig. 10).

The highest TB prevalence in childhood was in the Presov (PO, 22.24/100,000 population) and Banska Bystrica Regions (BB, 4.35/100,000 population). No childhood TB cases were recorded in the Trnava (TN), Zilina (ZA) and Bratislava (BA) Regions (Fig. 11).

Over the years 2003 - 2014 the highest TB prevalence in Slovak prisons was in the year 2007 (34 cases) (Fig. 12).

In 2014, the Slovak Republic achieved the highest rate of successful treatment $(85 \%)$ of newly diagnosed and microscopically confirmed TB cases in European countries. The lowest success in the TB treatment was in Croatia (only 12\%) (Fig. 13).

The most deaths in TB patients (with no TB cause of death) in Slovakia was in 2007 (47 cases) and the less in 2014 (13 cases). The most deaths caused by TB was in 2008 (10 cases) and the least in the years 2010 2012 (5 cases per year) (Fig. 14). 
Fig. 5 The TB prevalence by Regions in Slovakia and in neighboring countries (the number of cases per 100,000 population), 2014 (adapted according to National TB Registry, 2014)

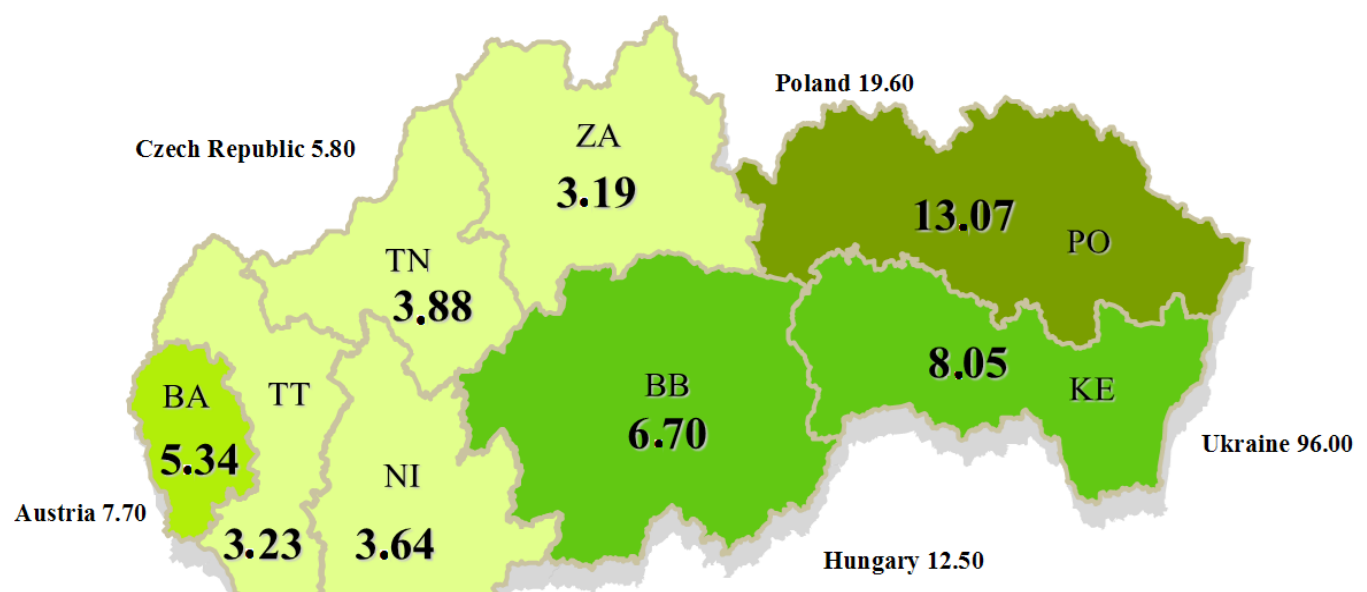

Fig. 6 The TB prevalence in the Presov Region, 2004 - 2014 (the number of cases per 100,000 population) (adapted according to National TB Registry, 2014)

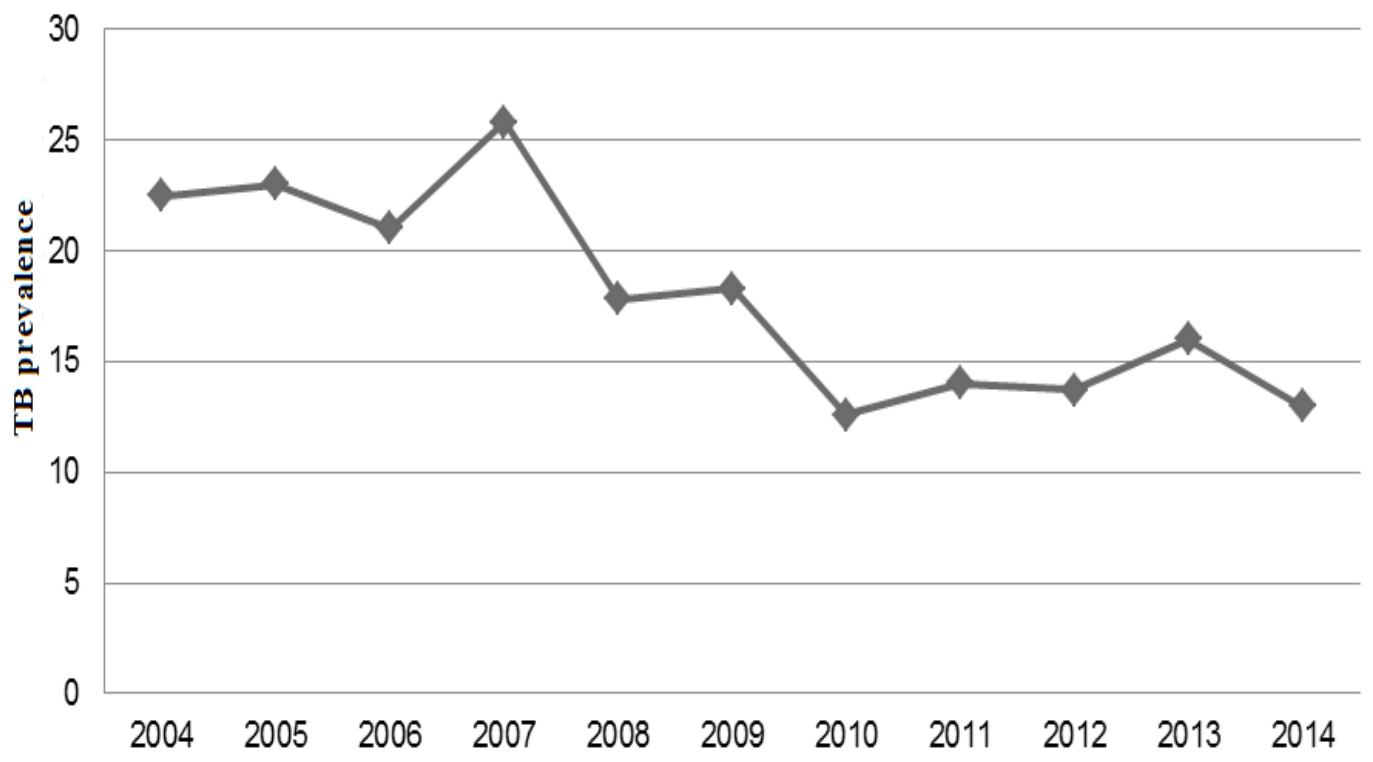


Fig. 7 The TB prevalence in the Presov Region, 2005 - 2014 (the number of cases per 100,000 population), (adapted according to National TB Registry, 2014)

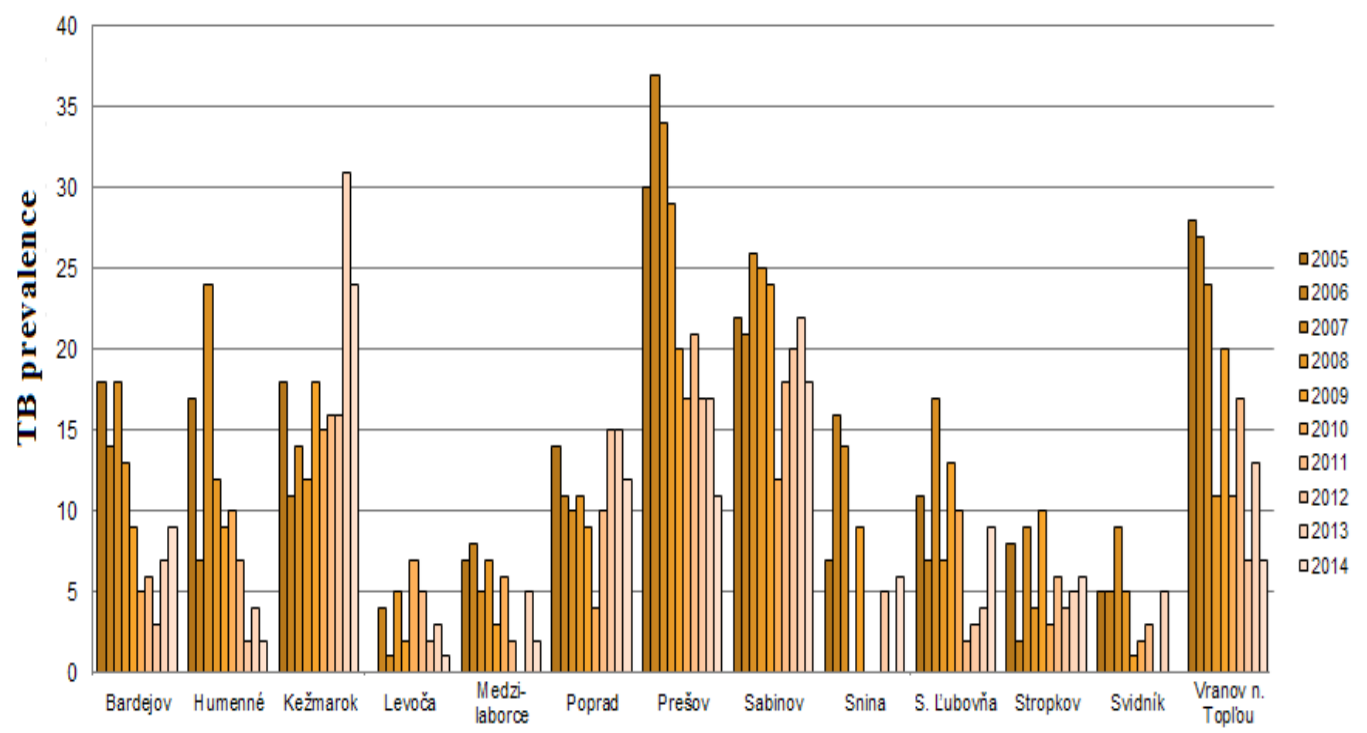

Fig. 8 The TB cases in the Roma population in Slovakia, 2014 (adapted according to National TB Registry, 2014)

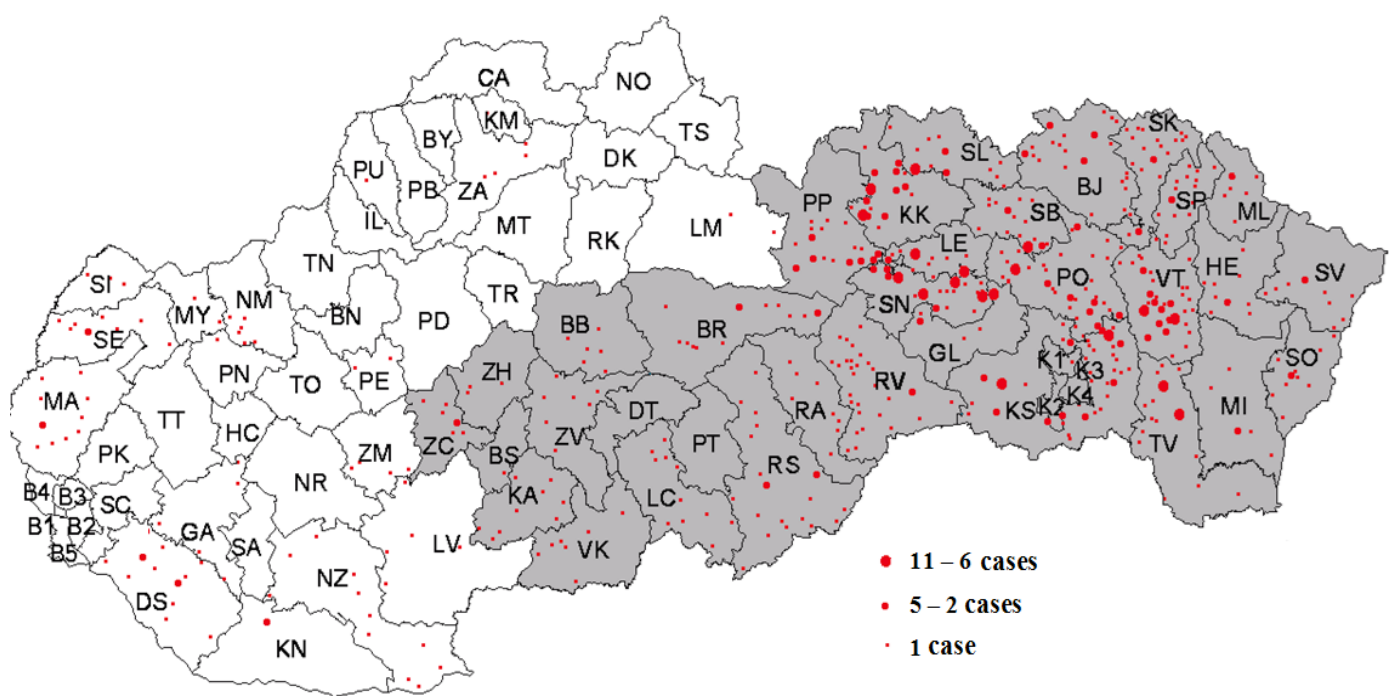


Fig. 9 The Roma ethnic group percentage in the TB prevalence, 2014 (adapted according to National TB Registry, 2014)

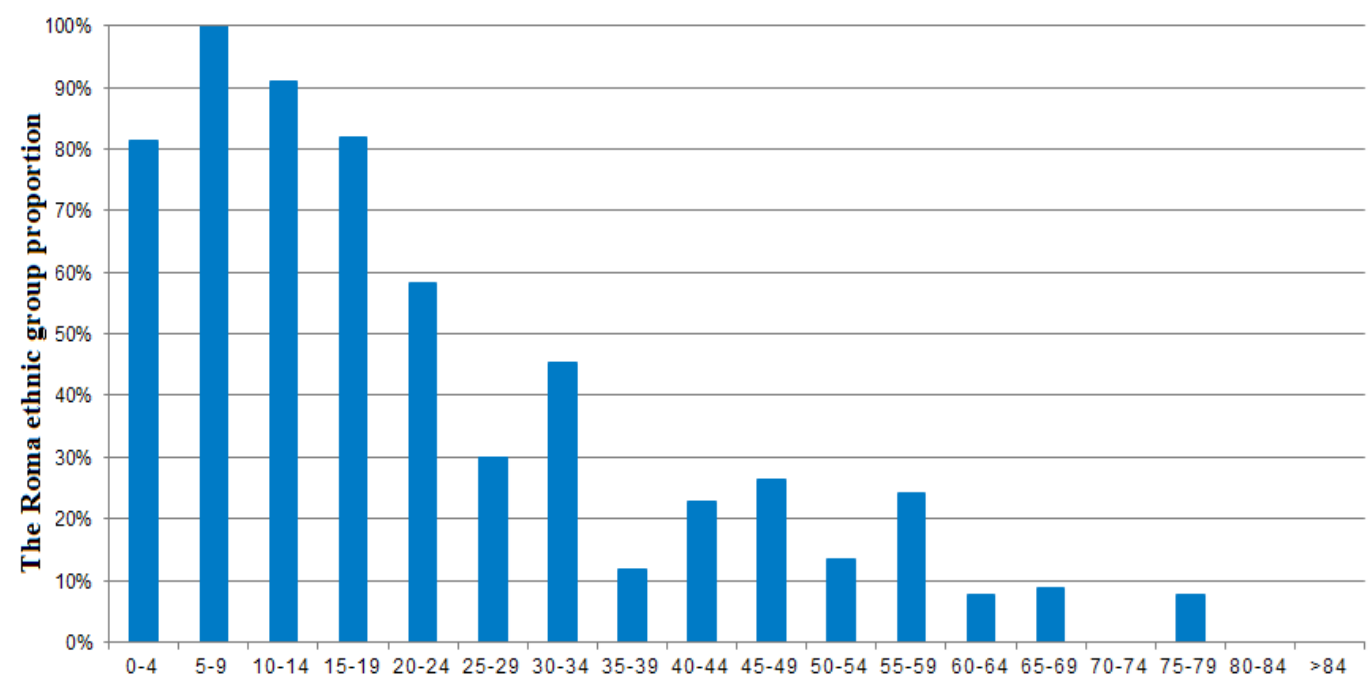

Fig. 10 The TB cases in childhood, 2014 (adapted according to National TB Registry, 2014)

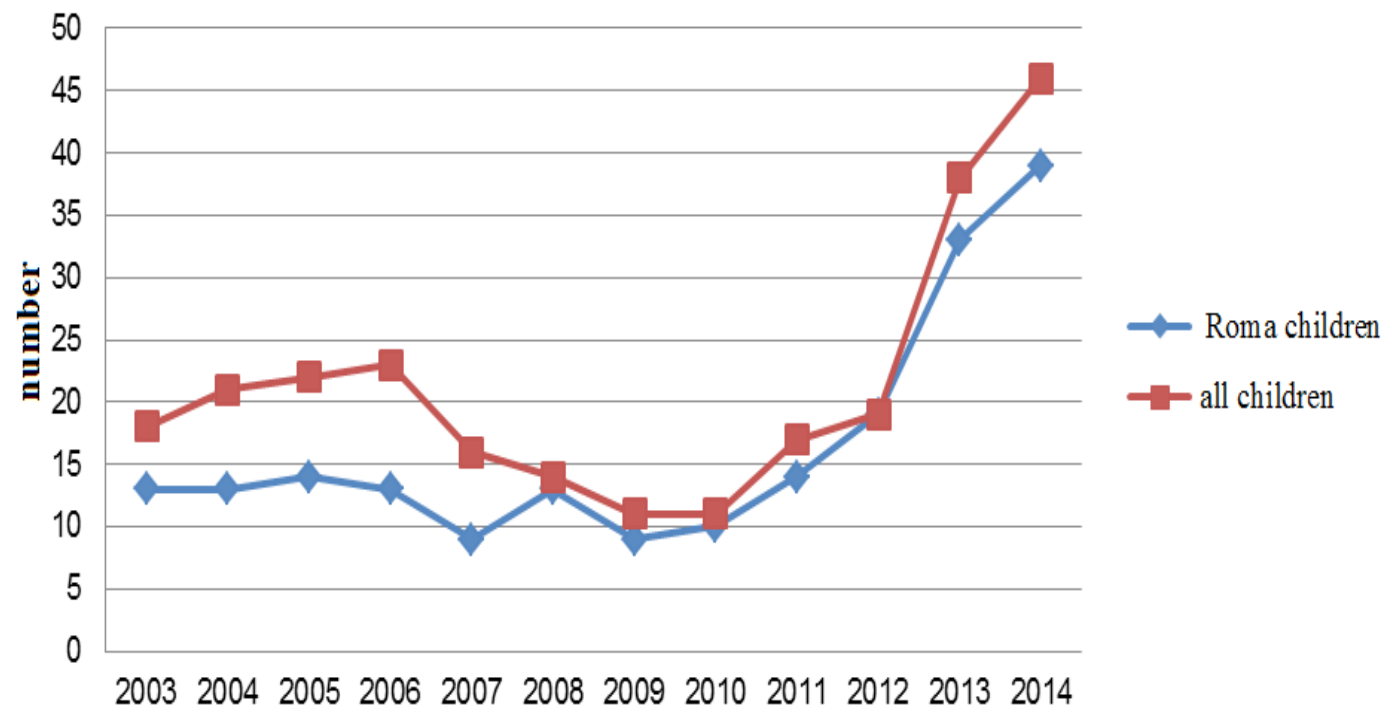


Fig. 11 The TB prevalence in childhood in Slovakia Regions, 2014 (adapted according to National TB Registry, 2014)

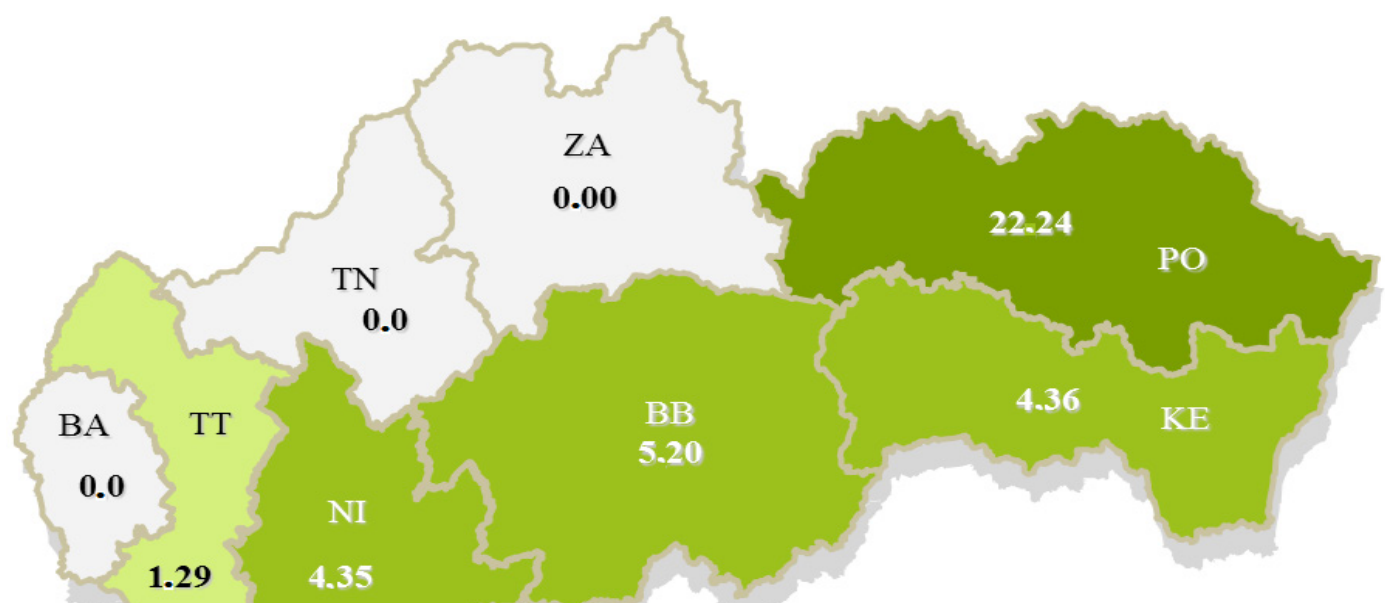

Fig. 12 The TB cases in Slovak prisons, 2003 - 2014 (adapted according to National TB Registry, 2014)

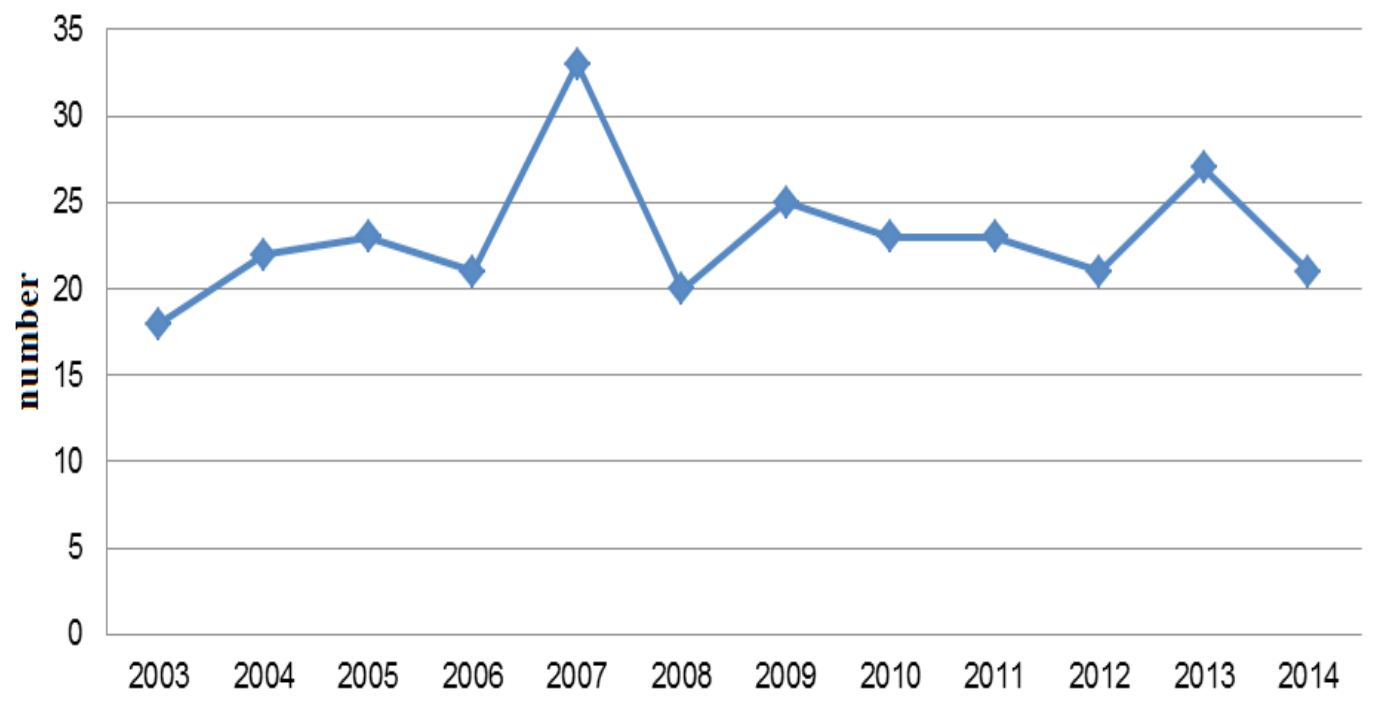


Fig. 13 The successful TB treatment rate (\%) in selected European countries, 2014 (adapted according to National TB Registry, 2014)

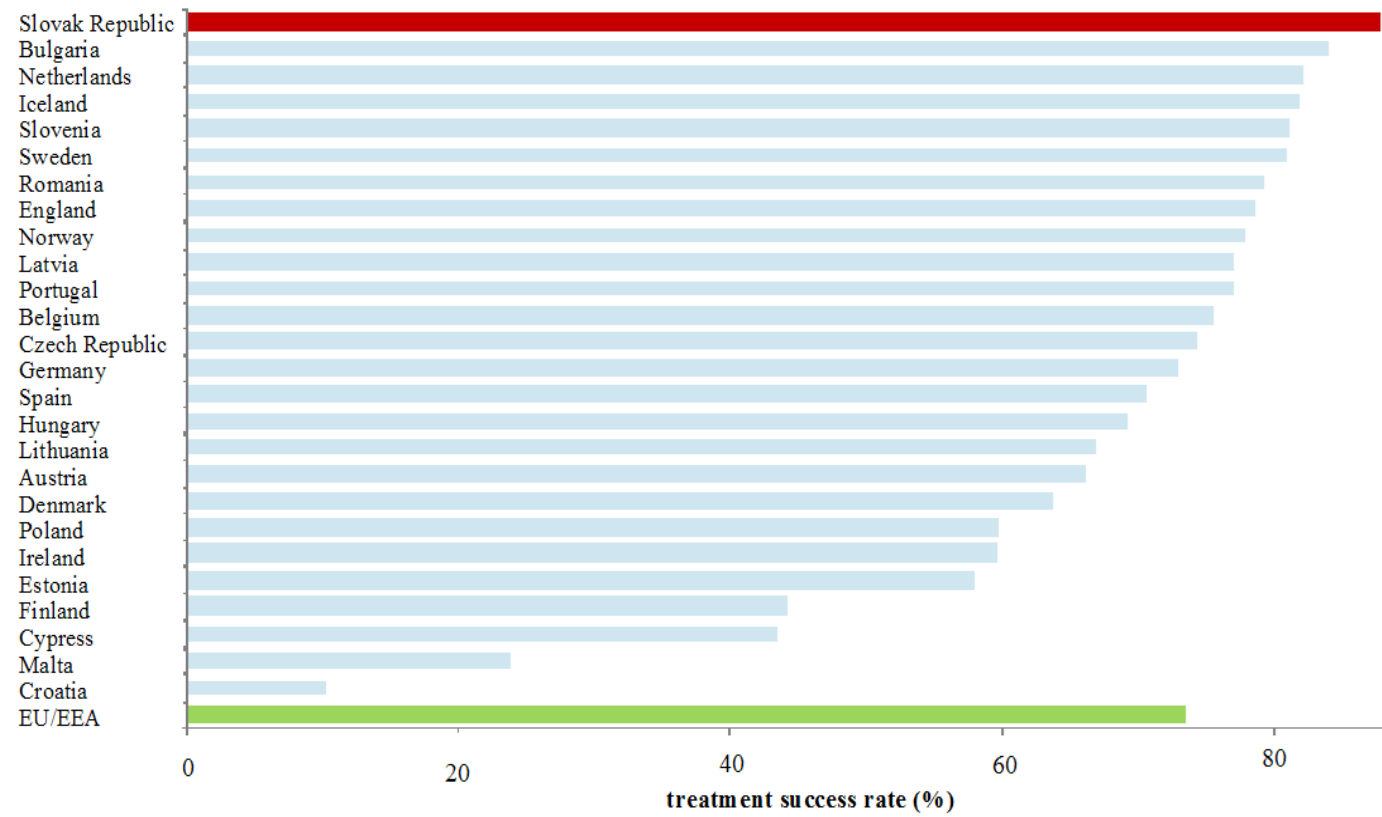

Fig. 14 The number of deaths in TB patients in Slovakia, 2007 - 2014 (adapted according to National TB Registry, 2014)

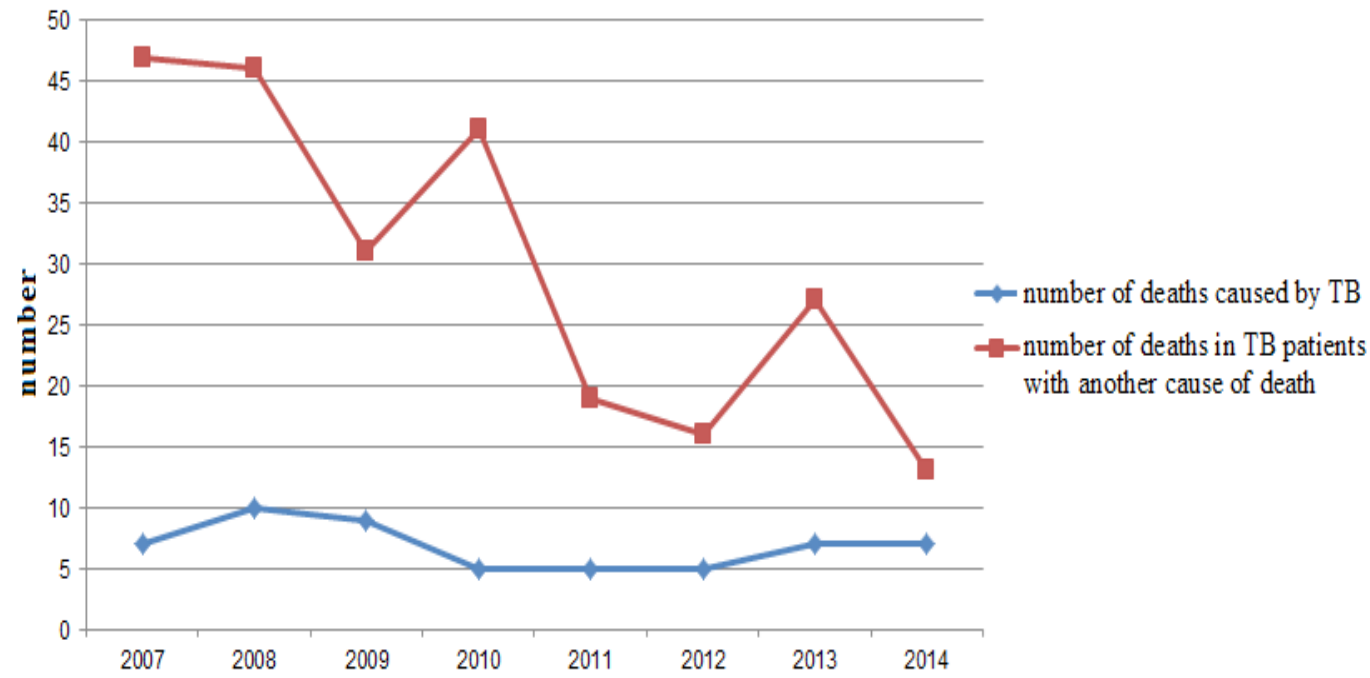


The highest TB prevalence in the elderly $(65+)$ was in the Presov Region (PO, 21.21/100,000 population) and in the Bratislava Region (BA, 16.54/100,000 population), the lowest in the Zilina Region (ZA, 4.53/100,000 population) (Fig. 15). in the Presov and Kosice Regions (in the eastern part of Slovakia with the highest proportion of Roma people) and the lowest in the Trnava Region. The highest TB prevalence in the Presov Region was in the Kezmarok District and the lowest in the Levoca

Fig. 15 The TB prevalence in the elderly (65+) in Slovakia, 2014 (adapted according to National TB Registry, 2014)

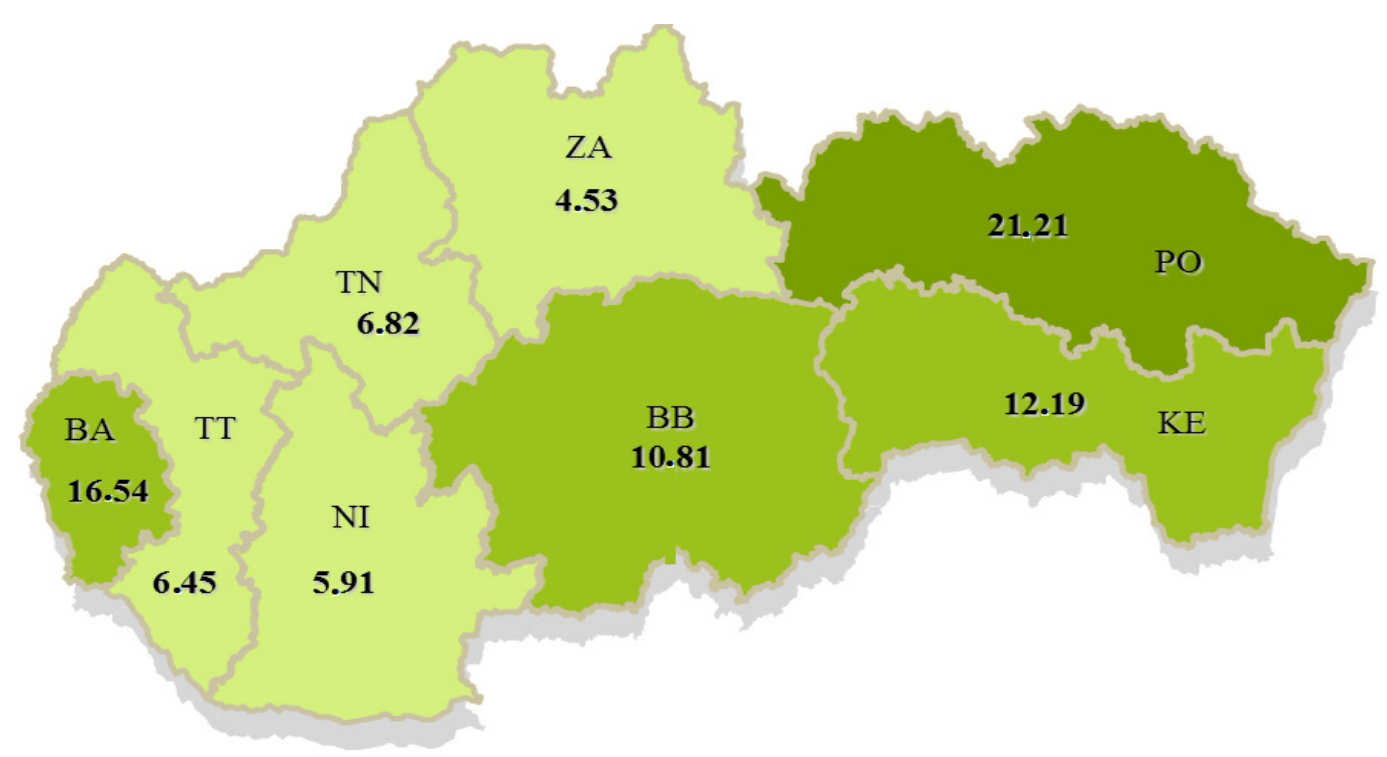

\section{Conclusion}

The epidemiology of TB in the Slovak Republic in the year 2014 was analyzed. Since 1960, TB prevalence has been reduced. The percentage of pulmonary TB occurrence was $95 \%$, with the highest prevalence in 1993. The TB prevalence decreased by $1.21 / 100,000$ compared to the year 2013.

The most common methods of TB detection in patients included visiting out-patient departments for health problems; TB contacts examinations; preventive medical checks; and checking the registered TB patients.

In 2014, the highest TB prevalence was
District. The highest TB prevalence in children was in the Presov and Banska Bystrica Regions. The Trnava, Zilina and Bratislava Regions have not reported any TB cases in children.

The Slovak Republic achieved the highest rate of successful TB treatment (85\%) in Europe. Tuberculosis is an airborne disseminated illness. It is a curable disease, however, in neglected cases and/or cases treated too late with severely attacked lung or other organs, TB can be fatal. Multi-resistant forms with their increasing incidence are problematic.

In the Slovak Republic, the TB incidence has a decreasing tendency in recent years, but nevertheless, more attention 
should be paid to finding and treating the patients, particularly in high-risk population groups.

\section{References}

1. AHLBURG D (2000) The economic impact of tuberculosis. Geneva: World Health Organization.

2. DYE C, SCHEELE S, DOLIN $\mathrm{P}$ et al (1999) Consensus statement. Global burden of tuberculosis: Estimated incidence, prevalence, and mortality by country. WHO Global Surveillance and Monitoring Project. JAMA 282: 677-686.

3. DYE C (2006) Global epidemiology of tuberculosis. Lancet 367(9514): 938-940.

4. European Center for Disease Prevention and Control (2010) World Health Organization.

5. Tuberculosis surveillance and monitoring in Europe (2012) Stockholm: European Center for Disease Prevention and Control.

6. FRIEDEN TR, STERLING TR, Munsiff SS et al (2013) Tuberculosis. Lancet 362: 887899.

7. GLAZIOU P, FALZON D, FLOYD K et al (2013)Global epidemiology of tuberculosis. Semin' Respir Crit Care Med. 34(1): 3-16.

8. GUPTA R, ESPINAL MA, RAVIGILONE MC (2004) Tuberculosis as a major global health problem in the 21 st century: A WHO perspective. Semin Respir Crit Care Med. 25:245-253.
9. MAHER D, RAVIGLIONE M (2005) Global epidemiology of tuberculosis. Clin Chest Med 26: 67-182.

10. MATHEMA B, KUREPINA NE, Bifani PJ et al (2006) Molecular Epidemiology of Tuberculosis: Current Insights. Clin Microbiol Rev.19(4): 658-685.

11. Regional Public Health Administration (2014) March 24th - World Tuberculosis Day. [online] RPHA: Trencin. [updated 2014 November; cited April 9, 2015]. Available at: http://www.ruvztn.sk/SDT_2014. pdf.

12. SOLOVIC I (2014) Tuberculosis at the beginning of the 21 st century - a practical view. Via Practica 4: 215-219.

13. SOLOVIC I, BANSKA K, BARBORICOVA Z et al (2008) Tuberculosis - selected Chapters. Vysne Hagy: ITLD\&TS 198 p. ISBN 978-80-970024-4-2.

14. ZANOVA E, KOZAKOVA D, RYBAR I et al (2012) The conversion of quantiferon TB gold test during biological treatment by anti-TNF preparations. In Annual European Congress of Rheumatology. Berlin: Rheumatology European Congress p. 1.

15. ZANOVA E, KOZAKOVA D, POLANOVA $M$ et al (2012) Diagnosis of latent tuberculosis before starting biologic treatment. Annual Meeting Proceedings 56th congress of Czech-Slovak Rheumatologists. Prague: Czech Rheumatological Society ISBN 97880-260-2901-1 p 1. 


\section{Burnout syndrome in neurological nursing}

Z. Slezáková1,2, G. Vörösová', G. Mičinová

Original Articles

${ }^{1}$ Constantine the Philosopher University in Nitra, Faculty of Social Sciences and Health Care, Department of Nursing, Kraskova no. 1, 94974 Nitra, Slovak Republic

${ }^{2}$ St. Elizabeth University of Health and Social Work in Bratislava, Slovak Republic

\section{Correspondence to:}

Constantine the Philosopher University in Nitra, Faculty of Social Sciences and Health Care, Department of Nursing, Kraskova no. 1, 94974 Nitra, Slovak Republic;

e-mail: gvorosova@ukf.sk, zuzana.slezakova@health.gov.sk, zlezakova@ukf.sk, tel. no. +421904247049

Submitted: 7.5.2016

Revised: 25.6.2016

Accepted: 18.8 .2016

\section{Reviewers:}

E. Grey

Department of Social Work, St. Elizabeth University of Health and Social Work in Bratislava, Slovak Republic

V. Tkac

Charles University in Prague, Faculty of Law, Czech Republic

\section{Key words:}

burnout, Maslach Burnout Inventory - MBI, Nursing, Neurological Nursing, Oncological Nursing

CSWHI 2016; 7(2): 36-46 @ 2016 Clinical Social Work and Health Intervention

\section{Abstract:}

Objective: To ascertain the incidence of burnout syndrome in Nurses working in Neurological Nursing. Burnout Syndrome (SV) often occurs in Neurological Nursing, where the Nurses are in circumstances associated with suffering and death. Design: For the diagnosis of burnout syndrome we used the Maslach Burnout Inventory (MBI). Respondents consisted of Nurses $n=120$ working at the Neurological Department, in a hospital and ambulances belonging to those wards in Slovakia. Results: In our study, out of $n=120$ Nurses working at the Departments of Oncology 50, 83\% showed high levels of burnout in their degree of emotional burnout (EE). We found that the age of Nurses has an impact on the formation of burnout syndrome: where the age range was 31-40 years old, $62.16 \%$ showed high degrees of burnout in the degree of depersonalization (DP); $64.86 \%$ showed a medium degree in the degree of personal satisfaction (PAT). The relation between seniority in 
neurological care and burnout syndrome is not confirmed. However the relation between the total length of practice and the degree of burnout is confirmed. Concusions: Based on the findings, the management of Neurological and Oncological Nursing it can be recommended that more focus be placed on programs of preventive measures in the field of burnout among Nurses.

\section{Introduction}

The concept of the term "burnout" begins to appear for the first time in the 1970s. Herbert Freudenberger, who defined this term in 1974 is considered its Founder. Several authors clarified the definition, for example Edelwich, Brodsky (1980), Pines, Aronson (1981) Sarros, Densten (1989), Glozier (2002), Kraft (2006), as a feeling of fatigue and exhaustion, or a whole range of physical challenges from recurring headaches, respiratory distress through gastrointestinal problems, to depression and insomnia. It not only affects psychosomatic areas, but also the realms of Psychology and the behavioral sphere. Many authors in our study looked at burnout syndrome among the helping professions, e.g. Venglářová et al (2011), Vorlíček, Abrahámová, Vorlíčková et al (2012), Klimeková (2007), Eliášová (2010), Sorková and Zvaríková (2003), Heftyová (2002) and others. Aronson, et al (1985) differentiates between burnout syndrome and exhaustion. Even though these phenomena are similar they have different causes. The cause of exhaustion may lay in any prolonged stress (physical, mental, emotional), but it does not mean that the situation of a completely exhausted person cannot be based on a sudden change in his life, e.g. as a result of some current trauma. The typical symptom of exhaustion is that the negative aspects of a person are permanently in predominance than positive aspects. The person feels unappreciated and worthless. The burnout syndrome is also manifested by physical, emotional and mental fatigue, but everything is due to chronic stress which is associated with long-term commitment toward other people. A 'Helper', as described by Andrasiova (2006), is a syndrome formed by combining characteristic personality traits from social assistance and rigid life form at the expense of one's personal development.

A 'Helper, is highly oriented to the ideal, self and needs and capacity to receive help.

This ideal, however, can only be sustained with a denial of reality, and in time, will necessarily result in feelings of frustration, failure and subsequent burnout. Burnout can be understood as a complete fatigue of one's work which was previously perceived positively, but today only gives a sense of non-satisfaction and excessive sacrifice that comes to nothing. The work of a Nurse in Oncology Nursing is very demanding in terms of mental composure and professionalism. As reported by Hnatova and Kovalcikova (2010), a Nurse is in constant confrontation with suffering, dying and death and is one of the main causes of burnout. Patient care, especially in the last stage of life is indeed stressful for Nurses, but may bring some sense of satisfaction for them. 


\section{Materials and methods}

We used the standardized Maslach Burnout Inventory (MBI) Questionnaire to map the neurological impact on Nurses of their nursing practice; its impact as well as prevention of the occurrence of burnout syndrome in the conditions of Neurological Nurses in Slovakia. The sample consisted of $n=120$ respondents $(92.50 \%$ women and $7.50 \%$ men): the age of Nurses under 30 years of age $n=27(22.50 \%) ; 31-40$ years of age $n=37(30.83 \%) ; 41-50$ years of age $\mathrm{n}=31(25.83 \%) ; 51$ years old and older $\mathrm{n}=25$ (20.84\%); by education, $25 \%$ secondary education, $15.83 \%$ secondary vocational education, 38.34\% Bachelor (Bc.) Degree and 20.83\% Master Degree (Mgr.); from these, 29.17\% with Specialization and Certification studies. The length of nursing practice under 10 years $n=61(50.83 \%) ; 11-20$ years $\mathrm{n}=50(41.17 \%) ; 21-30$ years $\mathrm{n}=5(4.17 \%)$ and 31 years and older $n=4(3.33 \%)$. The sample consisted of Nurses working at the Inpatient Department of Neurology, Clinical and Radiation Oncology, Primary Care Clinics belonging to those Departments in Slovakia $n=58(48.33 \%)$ in Hospitals with Health Centers, or Teaching Hospitals, $n=62(51.67 \%)$ from specialized institutes.

For the diagnosis of burnout syndrome, we used the Maslach Burnout Inventory (MBI) whose authors are Christina Maslach and Susan Jackson (1981,1986). The MBI has been modified three times; the last correction in 1996; and at present, is used in this form (Maslach, Jackson, Leiter 1996; Bakker, Demerouti, Schaufeli 2002; Bartošíková 2006).

We found several studies in the available databases in which MBI was verified in the helping professions, for example, Kalliath et al (2000), Gil-Monte (2005), Aguayo et al (2011), Chirkowska-Smolak, Kleka (2011), Córdoba et al (2011), Sabbah et al (2012), Mészáros et al (2014),
Figueiredo-Ferraz, Gil-Monte, Grau-Alberola (2013), Dyrbye et al (2013), Chen et al (2014) and others. The MBI Questionnaire used is according to Kebza and Šolcová (2003). Several studies have verified it in terms of psychometric properties including Leiter, Schaufeli (1996), Schutte et al ( 2000), Rothmann, Vuuren (2002), Rothmann, Malan (2003), Campbell, Rothmann (2005), Córdoba et al (2011), Aguayo et al (2011) where many other parameters for EE (Emotional exhaustion-emotional burnout) moved the alpha coefficient from 0.81 0.92 for DP (Depersonalization) 0.57-0.82 and PA (Personal accomplishment-personal satisfaction) from 0,50-0,86. According to Maslach, Jackson (1981,1986), Maslach, Jackson, Leiter (1996), Venglářova (2011), Aguayo et al (2011), Chen et al (2014) the MBI Questionnaire made up of 22 questions is divided by different dimensions into three subscales. The first subscale is made up of nine questions and is focused on emotional burnout (EE) characterized by emotional tension and inability to meet requirements. The second subscale consists of five questions that assess depersonalization (DP), the feeling of a decrease of competence and poor performance. The third subscale contains eight questions focused on personal satisfaction or job satisfaction (PA); characterized by numbness, impersonality, and negativism. Since SV is a complicated psychological construct, the various subscales are combined in order to affect as many areas as possible. The total score is not measured (Table 1).

In a statistical analysis, we used the chisquare test of independence for the pivot table. According to Chráska (2007), this test of significance can be utilized when deciding whether there is a correlation between the two phenomena. We are reviewing the test by comparing values calculated and values from the table. Values from the table are 
Table 1 Spot evaluation of MBI subscales

\begin{tabular}{|c|c|c|c|}
\hline \multirow{2}{*}{$\begin{array}{c}\text { FACTOR } \\
(\text { dimension })\end{array}$} & low & medium & high \\
\cline { 2 - 4 } & $0-16$ & $17-26$ & 27 and more \\
\hline EE & $0-6$ & $7-12$ & 13 and more \\
\hline DP & 39 and more & $38-32$ & $0-31$ \\
\hline
\end{tabular}

seen thanks to the significance level $(\alpha)$ and the degree of freedom (f). Significance level $(\alpha)$ was at 0.05 .

Degree of freedom (f) is calculated based on data from the pivot Table. It applies that $\mathrm{f}=(\mathrm{r}-1)(\mathrm{s}-1)$, where (r) is the number of rows and (s) is the number of columns of the pivot Table.

\section{Results}

Based on statistical analysis, we present the data obtained in the individual components of MBI (Table $2 \boldsymbol{\&} 3$ ), comparison by years of experience in the Oncology Department and overall experience (Table 4,5 \& 6), by type of workplace (Table $7 \& 8$ ) and the age of Nurses (Table $9 \& \mathbf{1 0}$ ).

\section{Discussion}

Aiken et al (2001) reported that as a result of their study between 1998-1999 on a sample 43,329 Nurses who where investigated using MBI, they realized that the rate of burnout in the emotional area (from Pennsylvania 13 471/43.2\%; from Canada 17 450/36\%; from England 5 006/36.2\%; from Scotland 4 721/29.1\%; from Germany $2681 / 15.2 \%$ ). In our study of n-120 Nurses working at the Department of Neurology, we showed a high rate of burnout in the Emotional Burnout Dimension (EE) - 50.83\%. We agree with Mr. Kmet (2010) who states that the risk of emotional exhaustion and feelings of inner emptiness arise if the Nurse treats eight patients instead of four patients; the risk of $\mathbf{S V}$ increases by $23 \%$ allocated to each additional patient. The Nurses are exposed to excessive physical and mental stress. Similarly our findings compared (Table 5) with the Spanish Study, showed that in the Intensive Care Departments (Iglesias et al 2010, In Preventing...2014), Nurses had the highest level of burnout in Emotional Burnout Level; a medium level in depersonalization; and a low level of personal satisfaction. The study of Catalana et al (1996 In Balbay et al 2011), which compared the level of burnout among the oncology professionals and personnel working with HIV positive people: the oncology staff was found with a high level of burnout $4 \%$, which was although less $4 \%$ of the working staff with HIV positive patients indicates a high tendency for oncology center professionals for the formation of burnout syndrome.

We found that the type of health facility can affect the rate of burnout among Nurses (Table7 \& 8) where there is confirmed a relationship between the monitored facility and the rate of burnout in the degree of emotional burnout; $33.33 \%$ of Nurses working in specialized institutions vs. $17.50 \%$ in a Hospital or University Hospital. The length of service is an important factor in the burnout process. According to Aronsona 
Table 2 Comparison of the degree of burnout in various dimensions of MBI

\begin{tabular}{|c|c|c|c|c|c|c|}
\hline \multirow{2}{*}{$\begin{array}{c}\text { Degree of } \\
\text { burnout }\end{array}$} & \multicolumn{2}{|c|}{ EE } & \multicolumn{2}{c|}{ DP } & \multicolumn{2}{c|}{ PA } \\
\cline { 2 - 7 } & $\mathrm{n}$ & $\%$ & $\mathrm{n}$ & $\%$ & $\mathrm{n}$ & $\%$ \\
\hline low & 25 & 20.8 & 25 & 20.83 & 41 & 34.17 \\
\hline medium & 34 & 28.33 & 44 & 36.67 & 58 & 48.33 \\
\hline high & 61 & 50.83 & 51 & 42.50 & 21 & 17.50 \\
\hline Total & 120 & 100 & 120 & 100 & 120 & 100 \\
\hline
\end{tabular}

Table 3 Statistical dependence between dimensions MBI

\begin{tabular}{|c|c|c|c|c|}
\hline Dimension & $\chi^{2}{ }_{\text {calc.. }}$ & $\mathbf{f}$ & $\chi^{2}{ }_{\text {tab.0,05 }}$ & Evaluation \\
\hline EE, DP, PA & 31.587 & 4 & 9.488 & $\chi_{\text {vyp. }}^{2} \boldsymbol{\chi}_{\text {tab. } 0,05}^{2}$ \\
\hline
\end{tabular}

Table 4 Experience in Neurological Nursing in relation with dimension MBI

\begin{tabular}{|c|c|c|c|c|c|c|c|c|c|c|c|}
\hline \multirow{2}{*}{\multicolumn{2}{|c|}{$\begin{array}{c}\text { Years of } \\
\text { Experience }\end{array}$}} & \multicolumn{2}{|c|}{ Under $10 \mathrm{r}$. } & \multicolumn{2}{|c|}{$11-20$ r. } & \multicolumn{2}{|c|}{$21-30$ r. } & \multicolumn{2}{|c|}{$31+$} & \multicolumn{2}{|c|}{ Total } \\
\hline & & $\mathbf{n}$ & $\%$ & $\mathbf{n}$ & $\%$ & $\mathbf{n}$ & $\%$ & $\mathbf{n}$ & $\%$ & n & $\%$ \\
\hline \multirow{3}{*}{$\mathbf{E E}$} & Low & 16 & 13.33 & 9 & 7.50 & 0 & 0.00 & 0 & 0.00 & 25 & 20.83 \\
\hline & Medium & 19 & 15.83 & 14 & 11.67 & 1 & 0.83 & 0 & 0.00 & 34 & 28.33 \\
\hline & High & 26 & 21.67 & 27 & 22.50 & 4 & 3.33 & 4 & 3.33 & 61 & 50.83 \\
\hline \multirow{3}{*}{ DP } & Low & 13 & 10.83 & 11 & 9.17 & 1 & 0.83 & 0 & 0.00 & 25 & 20,83 \\
\hline & Medium & 24 & 20.00 & 14 & 11.67 & 2 & 1.67 & 0 & 0.00 & 40 & 33.34 \\
\hline & High & 24 & 20.00 & 25 & 20.83 & 2 & 1.67 & 4 & 3.33 & 55 & 45.83 \\
\hline \multirow{3}{*}{ PA } & Low & 5 & 4.17 & 14 & 11.67 & 0 & 0.00 & 4 & 3.33 & 23 & 19.17 \\
\hline & Medium & 31 & 25.83 & 20 & 16.67 & 3 & 2.50 & 0 & 0.00 & 54 & 45.00 \\
\hline & High & 25 & 20.83 & 16 & 13.33 & 2 & 1.67 & 0 & 0.00 & 43 & 35.83 \\
\hline
\end{tabular}

et al (1985), in the care of people with seniority there is a proportional decrease in the sense of satisfaction from their work. Dimunová a Nagyová (2012) examined the effect of the length of service in their work on SV in a cohort of 844 Nurses. In the final assessment, they did not confirm the statistical significance of the relationship.
Analysis of the various dimensions of the relationship in the practice in the Neurology Department shows in Table 4 where we see the highest rate of burnout in Emotional Burnout: $22.50 \%$ indicates Nurses with 11 20 years of service; in Table 5 we see that there is no relationship between the length of experience in Neurological Nursing and 
Table 5 The statistical calculation in dependence of length of work in Neurological Nursing and MBI

\begin{tabular}{|c|c|c|c|c|}
\hline dimensions & $\chi_{\text {calc. }}^{2}$ & $\mathbf{f}$ & $\chi_{\text {tab.0,05 }}^{2^{2}}$ & Evaluation \\
\hline EE & 7.995 & 6 & 12.592 & $\chi^{2}{ }_{\text {vyp. }}<\chi_{\text {tab. } 0.05}^{2}$ \\
\hline DP & 8.921 & 6 & 12.592 & $\chi^{2}{ }_{\text {vyp. }}<\chi_{\text {tab. } 0.05}^{2}$ \\
\hline PA & 15.433 & 6 & 12.592 & $\chi_{\text {vyp. }}^{2}>\chi_{\text {tab. } 0.05}^{2}$ \\
\hline
\end{tabular}

Table 6 The statistical correlation between total length of nursing practice and MBI

\begin{tabular}{|c|c|c|c|c|}
\hline dimension & $\chi^{{ }^{2}}$ vyp. & $\mathbf{f}$ & $\chi_{\text {tab.0,05 }}^{2}$ & Evaluation \\
\hline EE & 13.57 & 6 & 12.592 & $\chi_{\text {vyp. }}^{2}>\chi_{\text {tab. } 0.05}^{2}$ \\
\hline DP & 18.100 & 6 & 12.592 & $\chi_{\text {vyp. }}^{2}>\chi_{\text {tab. } 0.05}^{2}$ \\
\hline PA & 13.295 & 6 & 12.592 & $\chi_{\text {vyp. }}^{2}>\chi_{\text {tab. } 0.05}^{2}$ \\
\hline
\end{tabular}

Table 7 Comparison by type of workplace

\begin{tabular}{|c|c|c|c|c|c|c|c|}
\hline \multirow{2}{*}{\multicolumn{2}{|c|}{ Type of institution }} & \multicolumn{2}{|c|}{$\begin{array}{l}\text { Hospital with Out } \\
\text { Patient Clinic/ } \\
\text { University Hospital }\end{array}$} & \multicolumn{2}{|c|}{$\begin{array}{l}\text { Specialized } \\
\text { Institutions }\end{array}$} & \multicolumn{2}{|c|}{ Total } \\
\hline & & $\mathbf{n}$ & $\%$ & $\mathbf{n}$ & $\%$ & $\mathbf{n}$ & $\%$ \\
\hline \multirow{3}{*}{$\mathbf{E E}$} & Low & 15 & 12.50 & 10 & 8.33 & 25 & 20.83 \\
\hline & Medium & 22 & 18.33 & 12 & 10.00 & 34 & 28.33 \\
\hline & High & 21 & 17.50 & 40 & 33.33 & 61 & 50.83 \\
\hline \multirow{3}{*}{ DP } & Low & 15 & 12.50 & 10 & 8.33 & 25 & 20.83 \\
\hline & Medium & 24 & 20.00 & 20 & 16.67 & 44 & 36.67 \\
\hline & High & 19 & 15.83 & 32 & 26.67 & 51 & 42.50 \\
\hline \multirow{3}{*}{ PA } & Low & 23 & 19.17 & 18 & 15.00 & 41 & 34.17 \\
\hline & Medium & 28 & 23.33 & 30 & 25.00 & 58 & 48.33 \\
\hline & High & 7 & 5.83 & 14 & 11.67 & 21 & 17.50 \\
\hline
\end{tabular}

degree of burnout in dimensional burnout (EE) and depersonalization (DP).

The question in the study on the degree of personal satisfaction (PA) confirmed this relationship. We confirmed this relationship with the study by Iglesias et al (2010) which states that respondents with a seniority of 10 years are more prone to emotional burnout and depersonalization and personal dissatisfaction (PA). We can say that if the Sister has over 10 years of experience she has increasing risk of $\mathrm{SV}$.

We verified that the age of Nurses will affect SV. According Erikson, Grove (2008), age plays an important role in situations where they need to suppress or evoke 
Table 8 Statistical dependence according to workplace

\begin{tabular}{|c|c|c|c|c|}
\hline dimensions & $\chi_{\text {calc. }}{ }^{2}$ & $\mathbf{f}$ & $\chi_{\text {tab.0,05 }}$ & Evaluation \\
\hline EE & 9.736 & 2 & 5.991 & $\chi_{\text {vyp. }}^{2}>\chi_{\text {tab. } 0,05}^{2}$ \\
\hline DP & 4.549 & 2 & 5.991 & $\chi_{\text {vyp. }}^{2} \chi_{\text {tab. } 0,05}^{2}$ \\
\hline PA & 6.973 & 2 & 5.911 & $\chi_{\text {vyp. }}^{2}>\chi_{\text {tab. } 0,05}^{2}$ \\
\hline
\end{tabular}

Table 9 Comparison of Nurses by age

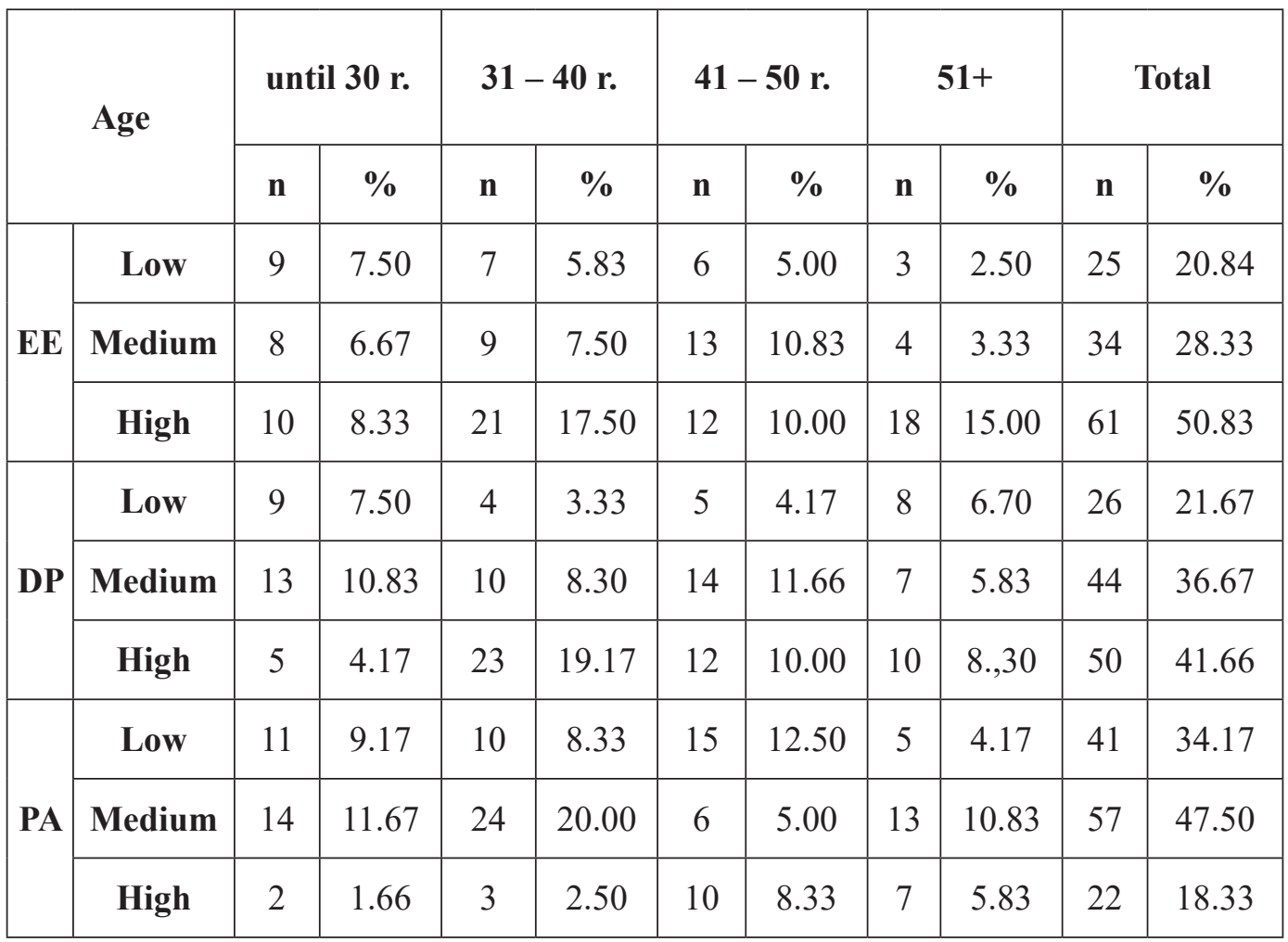

Table 10 Statistical differences according to age of Nurses

\begin{tabular}{|c|c|c|c|c|}
\hline dimension & $\chi^{{ }^{2} \text { vyp. }}$ & $\mathbf{f}$ & $\chi_{\text {tab.0,05 }}^{2}$ & Evaluation \\
\hline EE & 10.735 & 6 & 12.592 & $\chi_{\text {vyp. }}^{2}<\chi_{\text {tab. } 0.05}^{2}$ \\
\hline DP & 16.078 & 6 & 12.592 & $\chi_{\text {vyp. }}^{2} \chi_{\text {tab. } 0.05}^{2}$ \\
\hline PA & 18.808 & 6 & 12.592 & $\chi_{\text {vyp. }}^{2}>\chi_{\text {tab. } 0.05}^{2}$ \\
\hline
\end{tabular}


emotions that are appropriate to the situation. In our survey, the largest representation of Nurses were aged 31-40 years old $(30.83 \%)$. According to a study conducted on a sample of 843 Nurses in the United States, the age of Nurses has an effect on the formation of SV. In this study, Grove (2008) divided Nurses by age into two groups, before 30 and more than 30 years old. They focused on the survival of positive and negative emotions in relation to age and SV. They found that were no differences between age groups in experiencing positive emotion; among Nurses up to 30 years old significantly more experiences were reported such as frustration, agitation and anger, and therefore these Nurses burned out earlier than their older colleagues who are better able to manage their emotions.

The relationship between the age of Nurses (31-40) and dimension of emotional burnout is not confirmed; but the degree of depersonalization $(62.16 \%)$ and the degree of personal satisfaction $(64.86 \%)$ has been shown.

Confirmed was the relationship in the degree EE and age and the relationship and degree in age in $72 \%$ of Nurses over 51 years of age and degree of $52 \%$ for a younger age. Therefore, the older the nurse, the more the feeling of satisfaction from her work disappears. Of course, there are many external factors including the currently decreasing status of nursing in society and inadequate salary.

In our study, burnout in older Nurses can be compared with a study of Erikson and Grove (2008), which claims that by thirty years of service Nurses will experience burnout.

The result may be influenced by the different social status of Nurses abroad compared to the status of Nurses in our country. According Maslachova (in Kebza, Šolcová, 2003) in burnout syndrome, we are dealing with systemic rather then personal issues, and the occurrence of SV in an employee signals something that is not good, or does not work well in the organization. Therefore, we wanted to find out how to influence the employer toward prevention of the occurrence of SV on Nurses. Since the Labor Code obliges employers to provide employees working in the third risk group recovery stays or reduced working time, we wanted to find out whether this regulation is observed on Neurological and Oncological Departments as compared to working with carcinogenic substances according to law changing into a third risk group. Therefore, we considered recovery stays an important component in the prevention of the formation and development of SV. From n $=120$ of respondents (120) said that their employer provides recovery stays. Of these only $1.65 \%$ said that their employer offer recovery stays beyond the laws; $79.34 \%$ of respondents have reduced working hours and $76.86 \%$ reported supplemental leave.

For prevention, most Nurses $90.08 \%$ use various social activities; $82.65 \%$ seek recreational activities; $28.1 \%$ of Nurses engage in sports; $66.12 \%$ go to culture events such as cinema or theater. According Andrášiova (2006), important parts of preventing burnout are adequate and regular rest; ability to relax; purposefully eliminate stressors and raise salutors. Employers should provide psychological support programs for staff in hazardous work places that would allow health professionals to cope with their congested emotions; according to Andrášiova (2006)there is very low support in such work places and institutions. In statistical analysis, we confirmed the relationship between preventive measures and the rate of burnout in all three dimensions of the MBI Questionnaire.

\section{Conclusion}

We can say that the risk of burnout at different levels for Nurses not only will threaten but according to the research is already 
really present in this profession in all three dimensions.

In agreement with other authors, we affirm that Nurses in Neurological and Oncological Nursing have the highest rates of emotional burnout. An interesting finding was that even though we confirmed the relationship of age to the degree of burnout in depersonalization, personal satisfaction had no effect on burnout on an emotional level. Preventing burnout is not only an internal matter, but also has to be carried out at the level of organization to ensure balance between the level of competence, accountability and effective teamwork. We think that management is not aware of all the possibilities and forms of prevention that would be effective to protect against burnout. Therefore. in the future it would be appropriate to focus research on the possibility of preventative measures in relationship to burnout.

\section{References}

1. AGUAYO R, PECINO CV, DE LAFUENTE SOLANA EI, FERNÁNDEZ LML (2011). A meta-analytic reliability generalization study of the Maslach Burnout Inventory. Int $J$ Clin Health Psychol. 11(2): 343-361.

2. AIKEN LH, CLARKE SP, SLOANE DM, SOCHALSKI JA, BUSSE R, CLARKE H et al (2001). Nurses'reports On Hospital Care In Five Countries. In Health Aff. 20(3): 43-53.

3. ANDRÁŠIOVÁ M (2006). Burnout syndrome in medical practice, the possibilities for its management and prevention. In Viapractica. 3(12): 559-561.

4. ARONSON E \& LIDZEY G (1985). The Handbook of Social Psychology. New York: RandomHause, ISBN 0-7167-5715-X.

5. BAKKER AB, DEMEROUTI E, SCHAUFELI WB (2002). Validation of the Maslach Burnout Inventory -General Survey: An Internet Study across Occupations. Anxiety, Stress \& Coping. 15(4): 245-260.
6. BALBAY O A, ISIKHAN V, BALBAY EG, ANNAKKAYA AN, ARABAK PM (2011). Burnout status of health care personnel working in onkology and their coping methods. In HealthMED. 5(4): 730-740.

7. BARTOŠÍKOVÁ I (2006). The burnout syndrome for nurses. Brno: National Centre of Nursing and Other Health unions, ISBN 80-7013-439-9, 86 p.

8. CAMPBELL C \& ROTHMANN S (2005). A psychometric assessment of the Maslach Burnout Inventory (General Survey) in a customerservice environment. Management Dynamics. 14(2): 16-28.

9. CATALAN J, BURGESS A, PERGAMI A, HULME N, GAZZARD B, PHILLIPS R (1996). The psychological impact on staff of caring for peoplewith serious diseases: the case of HIV infection and oncology. $J$ Psychosom Res. 40(4): 425-435.

10. CÓRDOBA L, TAMAYO JA, GONZÁLEZ MA, MARTÍNEZ MI, ROSALES A, BARBATO SH (2011). Adaptation and validation of the Maslach Burnout Inventory-Human Services Survey in Cali, Columbia. Columbia Médica. 42(3): 286-293.

11. DIMUNOVÁ L \& NAGYOVÁ I (2012). The relationship between burnout syndrome and seniority among nurses and midwives in Slovakia. Profession on-line. 5(1): 1-4.

12. DYRBYE LN, THOMAS MR, MASSIE FS, POWER DV, EACKER A, HARPER $\mathrm{W}$, et al (2008). Burnout and suicidal ideation among U.S.medical students. Ann Intern Med. 149(5): 334-341.

13. EDELWICH J \& BRODSKY A (1980). Burn-Out: Stages of Disillusionment in the Helping Profesions. New York, NY: Human Sciences Press.

14. ELIÁŠOVÁ A (2001). Burnout syndrome. Health. 1(9): 38-41.

15. ERICKSON R \& GROVE W (2008). Why Emotions Matter:Age, agitation, and burnout among registered nurses. Online Journal of Issues in Nursing. 13(1). http://www. nursingworld.org/MainMenuCategories/ 
ANAMarketplace/ANAPeriodicals/OJIN/ TableofContents/vol132008/No1Jan08/ ArticlePreviousTopic/WhyEmotionsMatterAgeAgitationandBurnoutAmongRegisteredNurses.html.

16. FIGUEIREDO-FERRAZ H, GIL-MONTE PR, GRAU-ALBEROLA E (2013). Psychometric properties of the „Spanish Burnout Inventory" (SBI): Adaptation and validation in a Portuguese-speaking sample. Revue européenne de psychologie appliquée. 63(1): 33-40.

17. GIL-MONTE P (2005). Factorial validity of the Maslach Burnout Inventory (MBI-HSS) among Spanish professionals. Rev Saúde Pública. 39(1): 1-8.

18. GLOZIER N (2002). Mental ill health and fitnes for work. J Occup Environ Med. 59(10): 714-720.

19. HEFTYOVÁ E (2002). Threatens nurses burnout syndrome? Nurse. 1(2): 44-46.

20. HNÁTOVÁ I \& KOVALČÍKOVÁ N (2010). The issue of burnout in the provision of palliative care. Palliative medicine and pain treatment. 3(2): 57-58.

21. CHEN WS, HANIFF J, SIAU CH-S, SEET W, LOH S-F, JAMIL MHA (2014). Pilot Study of the Malay Maslach Burnout Inventory and Malay Work-Related Quality of Life Scale in Malaysia. Studies in Asian Social Science. 11: 20-26.

22. CHIRKOWSKA-SMOLAK $\mathrm{T} \&$ Kleka $P$ (2011). The Maslach Burnout Inventory-General Survey: validation across different occupational groups in Poland. Polish Psychological Bulletin. 42(2): 86-94.

23. CHRÁSKA M (2007). Methods of Educational Research. Praha: Grada, ISBN 97880-247-1369-4, 272 p.

24. IGLESIAS MEL, BECERRO DE BENGOA VALLEJO R, Salvadores Fuentes P. 2010. Reflections on the burnout syndrome and its impact on health care providers. Ann Afr Med. 9(4): 197-198.

25. KALLIATH, T, O'DRISCOLL MP, GILLESPIE DF, BLUEDORN AC (2000). A test of the Maslach Burnout Inventory in three samples of healthcare professionals. Work \& Stress. 14(1): 35-50.

26. KEBZA V \& ŠOLCOVÁ I (2003). Burnout syndrome. 2nd expanded and supplemented edition. Praha: State Health Institute, ISBN 80-7071-231-7, $25 \mathrm{p}$.

27. KLIMEKOVÁ A (2007),,,Burnout“" or where to share our elan vital. In Lichner J, Švanter P, editors. Military education. Bratislava: The personnel office OSSR, ISBN 978-80-969458-4-9, p. 92-105.

28. KMEŤ L' (2010). The possibilities of the prevention of burnout syndrome in the healthcare environment. In Selko D, Durka R, editors. The psychology of health. Bratislava: National institute of heart and vascular diseases, Bratislava, ISBN 978-80968092-6-4, p. 72-79.

29. KRAFT U (2006). Burned out: your job is extremely fulfilling. It is also extremely demanding - and you feel overwhelmed. You are not alone. Scientific American Mind. 17: 28-33.

30. LEITER MP \& SCHAUFELI WB (1996). Consistency of the burnout construct across occupations. Axiety Stress Coping. 12(9): 229-243.

31. MASLACH C \& JAKSON S (1981). The Maslach Burnout Inventory. Research ed. Palo Alto, CA: Consulting Psychologists Press.

32. MASLACH C \& JAKSON S (1986). The Maslach Burnout Inventory Manual. 2nd ed. Palo Alto, CA: Consulting Psychologists Press.

33. MASLACH C, JAKSON S, LEITER M (1996). The Maslach Burnout Inventory Manual. 3rd ed. Palo Alto, CA: Consulting Psychologists Press.

34. MESZÁROS V, ADÁM S, SZABÓ M, SZIGETI R, URBÁN R (2014). The Bifactor Model of the Maslach Burnout Inventory-Human Services Survey (MBI-HSS)-An Alternative Measurement Model of Burnout. Stress Health. 30(4): 82-88. 
35. PINES A, ARONSON E, KAFRY D (1981). Burnout: From Tedium to personal Growth. New York: Free Press.

36. Preventing and Reducing Burnout Among Staff Nurses: A Literature Review FS20101278. (2014). http://nursing.missouri.edu/ academics/master-of-science/pdf/msn exam_burnout. pdf.

37. ROTHMANN S \& MALAN H (2003). Koherensiesin, selfdoeltreffendheid, lokus van beheer en uitbranding by maatskaplike werkers. SA Journal of Industrial Psychology. 29(4): 43-51.

38. ROTHMANN S \& VUUREN JA (2002). Sence of Coherence, Self-Efficacy, Locus of control, Coping and Burnout of Senior managers in a Manufacturing Industry. Paper presented at the $1 *$ South African Burnout Conference, Potchefstroom.

39. SABBAH, I, SABBAH H, SABBAH S, AKOUM H, DROUBI N (2012). Burnout among Lebanese nurses: Psychometric properties of the Maslach Burnout Inventory-Human Services Survey (MBI-HSS). Health. 4(9): 644-652.
40. SARRO JC \& DENSTEN IL (1989). Undergraduate students stress and coping strategies. Higher Education Research \& Development. 8(1): 47-57.

41. SCHUTTE N, TOPPINEN S, KALIMO R, SCHAUFELI W (2000). The factorial validity of the Maslach Burnout Inventory General Survey (MBIGS) across occupational groups and nations. Journal of Occupational and Organizational Psychology. 73(1): 53-66.

42. SORKOVÁ T \& ZVARÍKOVÁ M (2003). Effective communication and coping with the workload in the teaching process. Vydavatel'stvo: Technical university, ISBN 97880-807-3015-4, $105 \mathrm{p}$.

43. VENGLÁŘOVÁ M et al (2011). Nurses in distress. Praha: Grada, 2011. ISBN 978-80247-3174-2, $192 \mathrm{p}$.

44. VORLÍČEK J, ABRAHÁMOVÁ J, VORLÍČKOVÁ H et al (2012). Clinical oncology for nurses. 2nd expanded and supplemented edition. Praha: Grada, ISBN 978-80-247-3742-3, $450 \mathrm{p}$. 


\section{An objective view of homeopathy in Slovakia}

\section{J. A. Spinelli III}

University of Scranton, Department of Health Administration

and Human Resources, USA

\section{Correspondence to:}

University of Scranton, Department of Health Administration, and Human Resources, 800 Linden St, Scranton, PA 18510, USA

Submitted: 16.5 .2015

Revised: 17.3 .2016

Accepted: 1.8 .2016

\section{Reviewers:}

S. Szydlowski

University of Scranton school of Education, USA

V. Okoth

Adjunct lecturer Catholic University of Eastern Africa, Nairobi, Kenya

\section{Key words:}

Alternative Medicine, Homeopathy, Healthcare

CSWHI 2016; 7(2): 47-49 @ 2016 Clinical Social Work and Health Intervention

\section{Abstract:}

Complementary and Alternative Medicine and specifically Homeopathy, have both supporters and those who feel that they have no part in the delivery of healthcare.

\section{Complementary and alternative medicine}

Complementary and Alternative Medicine (CAM) has been around for centuries. The most popular uses in Europe include acupuncture, chiropractic medicine, reflexology, the use of herbal supplements, and homeopathy (CAMDOC, 2010). Homeopathy, while not a viable replacement for clinical medicine, has gained much support and also scrutiny in recent years. The general population has become more health conscious in recent times and the holistic approach used by homeopathic practitioners is a major reason that it has gained in popularity in this author's opinion.

Proponents of homeopathy point to a few key reasons for the use of this technique. As stated, homeopathy looks at preventing and 
curing illnesses by focusing on the whole person, that is, how the mental, physical, emotional, and spiritual elements of an individual are interconnected to maintain health. There are two main principles at the heart of homeopathy, developed by Dr. Samuel Hahnemann in Germany in the $18^{\text {th }}$ Century and they are "Like Cures Like," or the Similarity Principle, and "The Law of Minimum Dose." The Similarity Principle states that a disease can be cured by a substance that produces similar symptoms in healthy people and the Law of Minimum Dose, contrary to the prescribing of pharmaceuticals, proposes that the lower the dosage of medication, the greater the effectiveness. Homeopathic doctors aim to treat each person using an individualized approach. It is their belief that no two people will react the same way to a treatment, pathogen, or stressor. By using this individualized approach, homeopathic doctors look at each person's symptoms, disease, build, temperament, and genetic predispositions (ECH, 2010). Whether one feels that these principles hold true or not, it is used by $65 \%$ of Europeans (CAMDOC, 2010) and an understanding of this branch of CAM from an objective perspective is beneficial to formulating an opinion.

Regulation of CAM, the practice of Homeopathy, and homeopathic drugs in Central Europe varies by country. There are three models that are used in regulating the practice of medicine:

Direct government-administered regulation - In most European countries, the government authorizes, registers, and supervises health professionals. In this type of regulation, the authorities can withdraw the authorization of health professionals if the law is broken.

Government-sanctioned self-regulation - In this form of regulation, the government relies on national medical associations to authorize, register, and supervise health professionals in particular disciplines.

Independent self-regulation - Self-regulation relies on the associations of individual therapies to develop their own statistics, educational and research programs, and standards of competence. (CAMDOC, 2010).

The legal status of homeopathy is unclear in Slovakia at this time (wholehealthnow.com). The practice of Homeopathy is not regulated by the government. However, homeopathic remedies that have been labeled as "drugs" are subject to government regulation.

A number of CAM and homeopathic associations exist that offer education and resources:

CAMDOC Alliance, consisting of The European Committee for Homeopathy, The European Council of Doctors for Plurality in Medicine, The International Council of Medical Acupuncture and Related Techniques, The International Federation of Anthroscopic Medical Associations.

The Slovak Homeopathic Society

The European Central Council of Homeopaths

The World Homeopathy Awareness Organization.

There are also side effects and risks involved with homeopathic remedies. Homeopaths as well as those opposed to the use of Homeopathy cite its lack of empirical data showing its effectiveness and also cited is the lack of fundamental concepts of chemistry and physics.

The National Institutes of Health in the United States lists these risks as well (nih. gov):

Homeopathic vaccination have been promoted by some supporters but these lack any data to show that they are a viable substitute for conventional immunizations. 
Many homeopathic remedies contain large amounts of active ingredients that can have adverse effects.

Replacing an effective conventional remedy with an ineffective homeopathic remedy can have adverse effects.

Many questions surround the use of Homeopathy and will continue to do so until clinical research can prove the effectiveness of many of its remedies. More research is certainly needed. Still, supporters of Homeopathy believe that it is a safe, cost-effective, and sustainable way to complement the delivery of healthcare.

\section{References}

1. CAMDOC Alliance (2010). The Regulatory Status of Complementary and Alternative Medicine for Medical Doctors in Europe.

2. European Committee for Homeopathy (2010). Homeopathic Care in a Medical Context. Brussels, Belgium.

3. Homeopathy in Slovakia, 1860 to present. (n.d.). Retrieved from http://www.wholehealthnow.com/homeopathy_pro/slovakia. html

4. Homeopathy: An Introduction | NCCAM. (n.d.). Retrieved from http://nccam.nih.gov/ health/homeopathy 


\section{Mobbing experienced by nurses in health care facilities}

\section{E. Zacharová, I. Bartošovič}

Original Articles

St. Elizabeth University of Health and Social Work in Bratislava, Slovak Republic

\section{Correspondence to:}

St. Elizabeth University of Health and Social Work, Department of Social Work in Skalica, Nám. slobody 3, P. O. Box 104, 810 00, Bratislava, Slovak Republic; eva.zacharova@seznam.cz

Submitted: 8.4.2016

Revised: 13.7.2016

Accepted: 4.8 .2016

\section{Reviewers:}

V. Kozon

Vienna General Hospital - Medical University Campus, Vienna, Austria

Urbanus M. Ndolo

Catholic university of Eastern Africa, Nairobi, Kenya

\section{Key words:}

Mobbing. Health care facilities. Stress. Nurse. Conflict.

CSWHI 2016; 7(2): 50-61 ๔ 2016 Clinical Social Work and Health Intervention

\section{Abstract:}

The article deals with the issues of mobbing in health care facilities. Nurse is one of the professions excessively exposed to the mobbing behaviour. Compared to other sectors, the risk of occurrence of this negative phenomenon in health care sector is up to seven times higher. The empirical part of the paper includes an analysis and a comparison of the results of the research carried out as a descriptive study with the aim to determine the extent to which mobbing is experienced by nurses, its emotional and physiological effects on the respondents and the steps taken by the individual persons to escape from the mobbing. It focuses also on the possible links between the nurses' personal traits and their vulnerability to mobbing. In order to get the necessary data, a quantitative method - through a questionnaire survey - has been used. The creation of the questionnaire has drawn inspiration from the research carried out by Nursing Administration Department, Florence Nightingale School of Nursing, Istanbul University in 2005, the respondents being nurses working in health care facilities in Turkey [1]. In order to determine the personal characteristics, the $M$. Hřebíčková and T. Urbánek's NEO Five-Factor Inventory has been applied, based on the NEO Five-Factor Inventory developed by P. T. 
Costa and R. R. McCrae. The inventory identifies the levels of individual differences. It determinates the level of neuroticism, extraversion, openness to experience, agreeableness and conscientiousness. In order to obtain the statistical analysis of the data received, parametric tests have been used, i.e. the student's two-tailed t-test with the equal dispersion and Pearson correlation. The data have been processed by the STATISTICA version $10 \mathrm{CZ}$ programme. All the data have also been verified by the non-parametric tests. The research results point out problems that might occur in the health care facilities, drawing the attention of the facilities' management to emerging problems concerning the staff. It is necessary to define clear rules and procedures in order to prevent the negative behaviour practices from developing among the health care staff and to help establishing well-being in the workplace.

\section{Introduction}

The term of mobbing is derived from the English word ,to mob" = to bully, to offend, to attack or to assail somebody. Professional literature offers various definitions of the term, examples being the following: „Mobbing is a range of negative communicative behaviour of one or more individuals targeted towards a person for a longer period (for six months minimum and at least once a week).“ [2: p. 15]; ,Mobbing is a systematic, intentional and above all repetitive attack towards a person, using degradating approach, excessive criticism, mocking, minor or more serious attacks. It might also very well use a material influence." [3: p. 13]; „Mobbing is a kind of psychic torment in the workplace where very hostile and unethical forms of communication are used, as well as the attacks on a person's, ,integrity [4: p. 14]; ,The term of mobbing can be used only when it regards a systematic, recurring and long-term activity, systematic and recurring persecution and torment of a victim, where the roles of an aggressor and a victim are strictly separated and the bullying is no longer a reaction to a real or fictitious offence by a victim, but becomes a goal itself.“ [5: p. 14]; ,Mobbing - a psychic torment - is a systematic, intentional and above all repetitive attack towards a person, using degradating approach, excessive criticism, mocking, minor or more serious intrigues“ [6: p. 73]; ,Mobbing means not being integrated into a team." [4: p. 14].

A large part of his career was dedicated to this subject by Heinz Leymann (19321999), a German professor, who lived and worked in Sweden since 1955 where he specialized namely in patients suffering from communication and relation problems in the workplace. He considers mobbing to be a psychological terror in the workplace and defines it as follows: „Psychological terror or mobbing in working life involves hostile and unethical communication which is directed in a systematic manner by one or more individuals, mainly toward one individual, who, due to mobbing, is pushed into a helpless and defenceless position“" [7]. Prof. Leymann finds the time aspect to be the most important factor to distiguish between mobbing and other conflicts. To be considered as a mobbing, the actions must occur on a frequent basis (at least once a week) and over a long period of time (at least six months' duration). Because of the 
high frequency and long duration of hostile behaviour, this maltreatment results in a lot of problems, both in personal and professional life of the individual concerned. As a consequence of a social pressure, there is also mental misery such as posttraumatic stress disorder, depression, loss of concentration, mistrust, suicidal thoughts or suicide attempts, as well as psychosomatic problems such as headaches, backaches, indigestion, state of anxiety or sleep disorder. [7]. According to the International Labour Organization it is the psychological abuse that is the most serious problem in the workplace at the beginning of the new millennium.

The profession of nurse belongs to the professions which are exposed to the risk of mobbing behaviour to a significantly higher extent than other professions, the rate in the health care and social sectors being up to seven times higher. The progress of medicine knowledge and the changes in the society affect also the functions of the hospital. There are new, narrowly specialized diagnostic and therapeutic centres in hospitals, which imply the need of additional specialized training for the doctors and nurses. As a consequence, they become specialized in certain diseases. The working conditions to ensure high-quality treatment include not only spatial arrangement of the workplace, physical, chemical and biological factors which might lead to inter alia occupational disease, but also the physical and mental burden affecting the workers. While performing her occupational duties, the nurse has several roles to play: e.g. a hospital attendant, an assistant, a communicator, an instructor, an advisor, a patients' rights defender, a manager. All the professional roles are interconnected and complementary and their performance places demands not only on the nurses' professional competence but also on their personal qualities. Working in the health care sector means working in a team. Therefore, cooperation and communication with other nurses, doctors, patients and their relatives is an essential part of work. The ability to effectively evaluate a situation, choose the right words and adequately react and address a problem is a prerequisite for managing the role of a nurse. The relations between nurses and doctors are very important aspects of the overall atmosphere at work. When assessing their satisfaction at work, the nurses attribute great importance to these relations. When there is an atmosphere full of tension and conflicts, there is growing dissatisfaction, the quality of work is on the decrease, there is a frequent job changing and the nurses lose their interest in self-development. Both the doctors and nurses should be willing to mutually respect their roles and the relating responsibilities and encourage each other to meet the common goal of taking care of the patients. A well treated patient is also an objective for the work executed by the nurses. In order to meet this objective, the nurses must perform team work. That is why it is indispensable for the nurses to establish close relations at the workplace. If the team work is not respected by a nurse, the coexistence is disrupted and the efforts to meet the main objective end in failure. The same applies also to the relations between a nurse and a patient: there is a strong interdependence as regards good personal contacts. An appropriate communication may prevent a lot of conflict situations. The nurse must inspire the patient's faith in his/ her expert knowledge; he/she must show tact and patience, be aware of the patient's concerns and acknowledge his/her moods, depressions or particularities. The nurse's role requires a great deal of understanding, sympathy and kindness. Compared to other professions, the work in health care sector involves more stress. The stress factors can be non-specific (e.g. shift work, being pressed for time, role conflicts, information 
overload), as well as specific ones (being in contact with pain and death, dealing with quarrelsome patients etc.) An excessive stress increases the risk of incorrect actions and decisions, job-related injuries and psychosomatic disorders, as well as alcohol and other drugs addictions, thus worsening the state of health and work productivity of the medical staff and negatively affecting their family life. It is often difficult for nurses - as a profession assisting in somatic medicine - to meet the professional requirements as a health care specialist and at the same time provide the patients with positive energy, encourage them and listen to them. These requirements might be very exhausting for the nurses lacking an emotional balance.

\section{Defining a research problem}

This research has been carried out as a descriptive study with the aim to determine the extent to which mobbing is experienced by nurses, its emotional and physiological effects on the respondents and the steps taken by the individual persons to escape from the mobbing. Another subject of the research is the relation between personal traits and the vulnerability to mobbing.

\section{General objective}

To determine the occurrence of the mobbing experienced by nurses and the relation between mobbing and personal traits.

\section{Specific objectives}

1. To determine the occurrence of the mobbing experienced by nurses and the most frequent types of behaviour showing signs of mobbing.

2. To identify the most frequently reported physiological and emotional reactions of the nurses facing mobbing.
3. To determine the most frequent ways of dealing with the mobbing incidents experienced by nurses.

4. To find out if there is a link between the number of years of employment in nursing and the extent of the reported mobbing.

5. To find out if there is a link between the age of the nurse and the extent of the reported mobbing.

\section{Hypotheses}

H1: Within the monitored group of nurses there is a statistically significant positive link between the extent of the reported mobbing and the height of scores in the scale of neuroticism in the questionnaire NEO Big five.

$\mathrm{H} 2$ : Within the group of nurses there is a statistically significant positive link between the extent of the reported mobbing and the height of score of extraversion in the questionnaire NEO Big five.

\section{Research sample}

For the purposes of the research, the questionnaires were distributed among nurses in three hospitals in the following regions: Moravian-Silesian Region, Olomouc and Zlín. Out of 195 questionnaires which were distributed, 125 questionnaires returned back (64\%). After processing it was necessary to exclude 12 more questionnaires for their incompleteness. Therefore there were processed 113 questionnaires $(58 \%)$. For the purposes of this research, the sample of 113 nurses was considered $100 \%$.

\section{Methods}

To obtain the necessary data a quantitative research method through a questionnaire survey was conducted. The questionnaires were distributed personally with the 
Table 1 Absolute frequency of nurses, their average age and average length of time employed in nursing.

\begin{tabular}{|c|c|c|c|}
\hline & $\begin{array}{c}\text { Absolute } \\
\text { frequency }\end{array}$ & $\begin{array}{c}\text { Average } \\
\text { age }\end{array}$ & $\begin{array}{c}\text { Average } \\
\text { length of } \\
\text { time em- } \\
\text { ployed }\end{array}$ \\
\hline Nurses & 113 & 35.5 & 13.9 \\
\hline
\end{tabular}

reassurance of anonymity. Although the research was carried out with the consent of the managers of the individual hospitals and hospital departments, due to the sensitivity of the issue and the difficulty of collecting the data, the names of all medical facilities where the survey took place were not stated.

The creation of the first questionnaire drew the inspiration from the research carried out by Nursing Administration Department, Florence Nightingale School of Nursing, Istanbul University in 2005, the respondents being nurses working in health care facilities in Turkey [1]. This questionnaire had four sections. In the first section the participants' demographic information were requested. In part A questions about mobbing behaviours were asked. In part B there were questions focused on the physiological and emotional reactions to mobbing incidents and the questions in part $\mathrm{C}$ focused on the actions taken in order to escape from the mobbing. The research participants were asked to indicate the frequency of mobbing behaviours they had faced in the last six months. In the determination of frequency a six-choice type of scale from $0=$ have never faced, $1=$ have faced only once, 2 = have faced several times, $3=$ I face sometimes, $4=$ I frequently face, $5=$ I constantly face was used.

The second part of the survey consisted of the NEO Five-Factor Inventory by $M$. Hřebíčková and T. Urbánek based on the NEO Five-Factor Inventory developed by
P. T. Costa and R. R. McCrae. The inventory identifies the level of individual differences. It determines the level of neuroticism, extraversion, openness to experience, agreeableness and conscientiousness. In each of the sixty questions a respondent decided on a five-point scale from 0 "not described" to 4 "well described". The level of each personal trait expresses the sum of gross score. Each of the characteristics is measured by 12 items; the maximum score in each range is 48. The inventory asks about five personality dimensions. A dimension of neuroticism - emotional stability - examines a scale of adaptation or emotional instability. A dimension of extraversion - introversion examines quality and quantity of interpersonal reactions, the level of activation and a need for stimulation. A dimension of openness to experience detects active search for new experiences, tolerance to the unknown and its discovery. A dimension of agreeableness detects interpersonal orientation. A dimension of conscientiousness affects that kind of self-control which applies to the organization, motivation and perseverance to the goal-oriented behaviour.

In order to obtain the statistical analysis of the data received, parametric tests were used - the student's two-tailed t-test with the equal dispersion and Pearson correlation. The data were processed by the STATISTICA version $10 \mathrm{CZ}$ programme. All the data were also verified by the non-parametric tests.

\section{Results}

The first specific objective was to detect the rate of occurrence of mobbing among the nurses and what were the most frequent types of mobbing behaviours. Such questions were answered in part A of the questionnaire "The occurrence of unwanted (unfriendly) behaviour in the workplace (mobbing)". This part was focused on the description of unwanted 
behaviour in the workplace, which the respondents could have encountered within the last twelve month. The respondents commented on the 33 statements. Each of the statement was evaluated on the scale from 0 to 5 (have never faced - I constantly face). The average score of the examined sample of 113 nurses in the part A was 0.67. Within the monitored group of nurses there are 31 (27\%) of them who evaluated one of the 33 items in part A by score 4 (I often face) or 5 (I constantly face). The average score of these nurses in part A was 1.24 in contrast with the nurses, who did not evaluate any items in part A by score 4 or 5 and whose average score was 0.43 .

The second specific objective was the statements. The average score within the monitored group of 113 nurses in part B was 0.74 . Within this group of nurses there were 37 of them (33\%) who evaluated one of the 34 statements in part B by score 4 (I experience most of the time) or 5 (I experience all the time). The most commonly experienced reactions to mobbing behaviours were feelings of tiredness and stress, headaches and restless sleep. It can be said that physiological reactions were the most frequent reactions of the nurses to mobbing behaviours.

The third specific objective tracked possible ways of solving mobbing problems which the nurses had encountered. In part $\mathrm{C}$

Table 2 Most frequent types of mobbing behaviours within the monitored group of nurses.

\begin{tabular}{|l|c|c|}
\hline Statement & $\begin{array}{c}\text { Absolute } \\
\text { frequency N }\end{array}$ & $\begin{array}{c}\text { Relative } \\
\text { frequency \% }\end{array}$ \\
\hline Making me feel as if I and my work are being inspected. & 16 & $14 \%$ \\
\hline $\begin{array}{l}\text { Holding me alone responsible for the negative results of } \\
\text { work carried out by others. }\end{array}$ & 11 & $10 \%$ \\
\hline Having untrue things said about me. & 11 & $10 \%$ \\
\hline Blaming me for things that are not my responsibility. & 8 & $9 \%$ \\
\hline Not informing me about organized social meetings. & 8 & $7 \%$ \\
\hline $\begin{array}{l}\text { Having my decisions and recommendations criticized and } \\
\text { rejected. }\end{array}$ & 7 & $6 \%$ \\
\hline Being verbally threatened. & 7 & $6 \%$ \\
\hline Questioning my professional competency for every job I do. & & \\
\hline
\end{tabular}

detection of the most frequent physiological and emotional reactions to mobbing incidents. This was monitored in part B of the questionnaire, in which the respondents were asked to evaluate their emotional and physiological reactions to mobbing behaviours they had experienced in the last 12 months. The respondents evaluated the 34 of the questionnaire, the nurses were asked to indicate what they had done in situations they had faced the mobbing. The average score within the monitored group of 113 nurses in part $\mathrm{C}$ was 0.99 . Within this group of nurses there were 49 (43\%) of them who evaluated one of the 8 statements in part $\mathrm{C}$ by score 4 (I experience most of the time) or 
5 (I experience all the time). Out of 8 offered solutions the most frequent ones were: "I am working more carefully to avoid being criticized for my work" and "I am working harder and more organized". of time employed and the level of indicated mobbing.

The fifth specific objective was focused on the relationship between the age of each individual respondent and the level

Table 3 Most frequent reactions to mobbing within the monitored group of nurses.

\begin{tabular}{|l|c|c|}
\hline Statement & $\begin{array}{c}\text { Absolute } \\
\text { frequency N }\end{array}$ & $\begin{array}{c}\text { Relative } \\
\text { frequency } \%\end{array}$ \\
\hline My sleep regularity is disturbed. & 18 & $16 \%$ \\
\hline I have headache. & 16 & $14 \%$ \\
\hline I feel tired and stressed. & 14 & $12 \%$ \\
\hline I think I am depressed. & 13 & $11.5 \%$ \\
\hline I have stomach and intestinal problems. & 11 & $10 \%$ \\
\hline $\begin{array}{l}\text { My work life negatively affecting my life away from work } \\
\text { (my marriage and family). }\end{array}$ & 11 & $10 \%$ \\
\hline I am afraid when I go to work, I do not want to be at work. & 11 & $10 \%$ \\
\hline
\end{tabular}

Table 4 Most frequent types of solutions to mobbing situations within the monitored group of nurses

\begin{tabular}{|l|c|c|}
\hline Statement & $\begin{array}{c}\text { Absolute } \\
\text { frequency N }\end{array}$ & $\begin{array}{c}\text { Relative } \\
\text { frequency \% }\end{array}$ \\
\hline $\begin{array}{l}\text { I am working more carefully to avoid being criticized } \\
\text { for my work }\end{array}$ & 45 & $40 \%$ \\
\hline I am working harder and more organized. & 39 & $35 \%$ \\
\hline I am seriously thinking about quitting work. & 12 & $11 \%$ \\
\hline
\end{tabular}

The task of the fourth specific objective was the existence of relationship between the length of time employed and the rate of mobbing that the individual respondent showed. The resulting correlation values were compared with the tabulated value, in which the critical value for the monitored group of nurses $(\mathrm{N}=113)$ of the Pearson's correlation coefficient at a significance level of 0.05 was 0.214 . Within the monitored group of nurses was not found a statistical significant relationship between the length of indicated mobbing. The resulting correlations were compared with the tabulated value, in which the critical value for the monitored group of nurses $(\mathrm{N}=113)$ of the Pearson's correlation coefficient at a significance level of 0.05 was 0.214 . The results of the relationship between the age and mobbing were equal to the results of the relationship between the length of time employed and mobbing. Within the monitored group of nurses was not found a statistically significant relationship be- 
Table 5 Relationship between the length of time employed and the indicated level of mobbing within the monitored group of nurses, $\mathrm{N}=113$

\begin{tabular}{|l|c|c|c|}
\hline & $\mathrm{A}$ & $\mathrm{B}$ & $\mathrm{C}$ \\
\hline $\begin{array}{l}\text { The length of } \\
\text { time employed }\end{array}$ & 0.1356 & 0.1723 & 0.1855 \\
\hline & $\mathrm{p}=.353$ & $\mathrm{p}=.236$ & $\mathrm{p}=.202$ \\
\hline
\end{tabular}

tween the age and the level of indicated mobbing.

Based on the information from the study [8] that being exposed to the mobbing behaviours relates with individual personal traits such as neuroticism, that victims of mobbing at working place appear to be submissive, anxious and neurotic, lacking the social skills and self-confidence [9], that victims of bullying reach higher results on the scales of anxiety, worry and sensitivity on average [9] and that victims show symptoms of anxiety and depression even before

Table 6 Relationship between the age and the level of indicated mobbing within the monitored group of nurses, $\mathrm{N}=113$

\begin{tabular}{|l|c|c|c|}
\hline & $\mathrm{A}$ & $\mathrm{B}$ & $\mathrm{C}$ \\
\hline Age & 0.0703 & 0.145 & 0.1423 \\
\hline & $\mathrm{p}=.631$ & $\mathrm{p}=.320$ & $\mathrm{p}=.329$ \\
\hline
\end{tabular}

the beginning of mobbing [10], a hypothesis was formulated.

Hypothesis 1: Within the monitored group of nurses exists a statistically significant positive link between the level of indicated mobbing and the height of the score of neuroticism in the questionnaire NEO Big five. With the help of Pearson's correlation at the significance level $\mathrm{p}<.05000$ the following facts were found:
Table 7 Correlation between the scale of neuroticism and individual parts of the questionnaire Mobbing within the monitored group of nurses $(\mathrm{N}=113)$

\begin{tabular}{|c|c|c|c|}
\hline & $\mathrm{A}$ & $\mathrm{B}$ & $\mathrm{C}$ \\
\hline Neuroticism & 0.0331 & 0.2342 & 0.0495 \\
\hline & $\mathrm{p}=.822$ & $\mathrm{p}=.105$ & $\mathrm{p}=.735$ \\
\hline
\end{tabular}

There was not proved a statistically significant correlation of monitored parameters. The hypothesis 1 was not confirmed.

Out of conducted researches [11] results the information about lower levels of independence and extraversion of the victims of mobbing. In accordance with this idea a lot of the victims said that their problems had been supported by the lack of skills for managing conflict situations and the low level of self-confidence or shyness. On the basis of these statements a hypothesis was formulated.

Hypothesis 2: Within the monitored group of nurses there was a statistically significant positive correlation between the level of the indicated mobbing and the height range of scores in extraversion in the NEO Big Five questionnaire. With the help of the Pearson's correlation at a significance level $\mathrm{p}<.05000$ the following facts were found: There was not proved a statistically significant correlation of monitored parameters. The hypothesis 2 was not confirmed.

Table 8 Correlation between Extraversion and individual parts of the questionnaire Mobbing within the monitored group of nurses $(\mathrm{N}=113)$

\begin{tabular}{|l|c|c|c|}
\hline & $\mathrm{A}$ & $\mathrm{B}$ & $\mathrm{C}$ \\
\hline Extraversion & -0.0754 & -0.183 & -0.0763 \\
\hline & $\mathrm{p}=.606$ & $\mathrm{p}=.208$ & $\mathrm{p}=.602$ \\
\hline
\end{tabular}




\section{Discussion and verification of hypotheses}

This research has been carried out as a descriptive study with the aim to determine the extent to which mobbing is experienced by nurses, its emotional and physiological effects on the respondents and the steps taken by the individual persons to escape from the mobbing. Another subject of the research is the relation between personal traits and the vulnerability to mobbing.

The overall results as well as the analysis of particular items of nurses' teams show that among the most frequent types of mobbing behaviour belong 'making me feel as if I and my work are being inspected', 'holding me alone responsible for the negative results of work carried out by others', 'having untrue things said about me' and 'blaming me for things that are not my responsibility'. The nurses in their answers consider the personal aspect of communication as the most demanding. This fact might be influenced by one of the essential traits in nurses' job which is cooperation in the team. The nurse has often to rely on help of other nurses therefore it is necessary for them to trust each other to be able to take care of their patients effectively. It might be the reason why the nurses are more susceptible to the personal attacks.

The research, which was conducted at Istanbul University in 2005 with the purpose of determining the mobbing experienced by nurses who work in healthcare facilities in Turkey, shows similar results. It was found out that the most common mobbing behaviour experienced by the participants was determined to be 'having someone speak about me in a belittling manner in the presence of others' $(55.2 \%)$. The second most common mobbing behaviour experienced by the nurses was 'being blamed for things I am not responsible for' $(50.5 \%)$ and the third was 'having me feel like me and my work were being controlled' (50.1\%). A larger percentage of these results is caused by using the participants' answers of one (I have faced once) and above which were taken for evaluation.

In this study a more exacting criterion had been chosen and only the participants' answers of four (I frequently face) and five (I constantly face) were taken for evaluation.

The second specific objectives aims to identify the most frequently reported physiological and emotional reactions of the nurses facing mobbing. The most frequent reactions included disturbance of sleeping regularity, feeling tiredness and stress and having headaches. It can be said that physiological reactions were the most frequent reactions of the nurses to mobbing behaviours. These results stand in line with Yildirim A. and Yildirim D. (2007) who indicated as the two most common reactions also feeling tiredness and stress and having headaches. According to the Istanbul University research other frequent reactions were very similar - eating excessively or not having an appetite (in the Turkish research $53.5 \%$ ) and having gastrointestinal complaints (in the Turkish research 52.9\%). Moreover, there were quite a lot of participants reporting depression as a significant trait of their reaction to the working environment.

Among the emotional reactions there were mainly mentioned these describing participants' fears when they enter the workplace as well as their feeling that their life outside work is negatively affected by mobbing. These results also stand in line with Yildirim A. and Yildirim D. (2007). It was proved that most of people as a reaction to the stressful situations are stressed, tired and have headaches. In addition, if the people experience some wrong and injustice they often suffer from extreme sadness. That is why the reactions of the nurses 
facing to mobbing are understandable and expectable.

The third specific objective aims to determine the most frequent ways of dealing with the mobbing incidents experienced by nurses. The most common things the nurses did to escape from mobbing were 'to work more carefully to avoid criticism' and 'to work harder and more organized'. As well as previous results these findings also stand in line with Yildirim A. and Yildirim $D$. (2007). In addition, there were quite a lot of participants who seriously thought about changing workplaces. These results contradict with Yildirim A. and Yildirim D. (2007) who did not indicate this answer at all. This distinction might be caused by different opportunities for women in the labour market in the Czech Republic and in Turkey.

The fourth specific objective aims to find out if there is a link between the number of years of employment in nursing and the extent of the reported mobbing. No statistically significant relationships were found with the total years of service in the nursing profession and the extent of the reported mobbing.

The fifth specific objective aims to find out if there is a link between the age of the nurse and the extent of the reported mobbing. Again no statistically significant relationships were found with the nurses' age and the extent of the reported mobbing. Similar findings are reported by Yildirim A. and Yildirim D. (2007) who also did not prove this relationship. As can be seen, it is quite possible for the healthcare workers and nurses to face mobbing behaviours regardless to their age.

Mobbing behaviours at workplace are influenced by the combination of lots of factors in one particular moment in time. As the main factors can be considered the personality of an aggressor, the personality of a victim, working environment, quality of management, structure of the organization, overworking stress, reorganization, existential uncertainty, boredom or monotony. It is evident that mobbing behaviour is not significantly connected with one specific trait, for example with the age of nurse or the number of years of employment in nursing. Even a new member of the staff can adapt himself/herself to the working process if working environment is positive, willing to cooperate and pass along information, open to discussion and is able to solve all the problems immediately.

Hypotheses $\mathrm{H} 1$ and $\mathrm{H} 2$ dealt with a statistically significant relation between the extent to which mobbing is experienced and the total score on the scale Neuroticism and Extraversion measured by the NEO Big Five Test. Statistically significant relation between the monitored parameters was not proved in this study although lots of previous researches had been confirmed it. This relation was confirmed for example in Coyne I. and Seigne E. study which examined the extent that workplace victim status can be predicted from personality traits. Victims tended to be less independent and extroverted, less stable, and more conscientious than non-victims. Significance of mobbing at the workplace is mentioned by Niedl [1] who observed 368 employees working in Austrian public hospitals. He found out that the victims of mobbing suffered more from anxiety, depression, irritation and psychosomatic problems than people who were not exposed to mobbing behaviours. In Ireland O'Moore, Seigne, McGuire and Smith [9] found out that the victims of mobbing achieved in average lower results than the reference group at Catell's 16PF related to emotional stability and dominance as well as higher results at the scale of anxiety, fears and sensitivity. Although the findings in this study, which might be influenced by a lower number of the participants, have not confirmed similar results mentioned above, it can be said - according to results based 
on the previous research, that the victims of mobbing at the workplace show signs of submissiveness, anxiety, neuroticism, lack of social skills and self-confidence but on the other hand they are characterized by the behaviour focused on effort to succeed. The presence and frequency of mobbing behaviours faced in the facilities can be an indicator of the awareness that the most valuable presence in the facility is human resources. Present development of the society, individual's entering the labour market and a pressure on his/her career growth as well as incorrectly solved interpersonal conflicts among the co-workers might be the reason of occurrence of the attitudes and behaviours which first can cause tension at the workplace and finally lead to mobbing behaviours. In this study it was found that all nurses, regardless of their age, educational status and position, can be exposed to mobbing behaviours at the workplace. As can be seen at every workplace in the world it is very important both for the employees and for the institutions to prevent hostile behaviours at the workplace. Solving long-term unresolved interpersonal conflicts with appropriate conflict resolution strategies can help decrease the development of workplace violence. In addition, mobbing behaviours at the work place need to be defined and appropriate rules and procedures need to be specified and shared with all employees to prevent the development of these mobbing behaviours. Managers are expected to adopt an open managerial approach to prevent the development of these behaviours.

\section{Conclusion and recommendations to the clinical practice}

The purpose of the research presented in this study was to determine the occurrence of mobbing experienced by nurses, its emotional and physiological effects on the respondents and the steps taken by the indi- vidual persons to escape from the mobbing. It dealt with the research focused on the relation between personal traits and the extent to which mobbing is experienced.

The sample involved a total of 113 participants. $31(27 \%)$ of the nurses who participated in the research had faced mobbing behaviours within the last six months and they marked these behaviours on a sixpoint scale four (I frequently face) and five (I constantly face). The nurses stated attacks to personality as the most serious problem. The nurses' reactions to mobbing behaviours included feeling tired and stressed, having headaches and disturbance of sleeping regularity. The most common things the nurses did to escape from mobbing were 'to work more carefully to avoid criticism' and 'to work harder and more organized'. No statistically significant relationships were found with the nurses' age or the total years of service in the nursing profession and the extent of the reported mobbing. Moreover, no statistically significant relation was between the extent to which mobbing is experienced and the total score on the scale Neuroticism and Extraversion measured by the NEO Big Five Test.

This study pointed out a large number of problems connected with mobbing behaviours which could occur at the workplace. To prevent the development of these behaviours and avoid the negative consequences stemming from poor atmosphere at the workplace it is recommended to support communication among the employees, for example by organizing supervisor seminars. Supervision focused on the employee provides the opportunity to discuss and express personal problems connected with the work as well as to get the feedback, acknowledgment and support. Supervision also provides professional and personal development of the employees, creates a safe place for solving personal problems, encourages the 
employees to realistically reflect their own limits and possibilities, offers necessary social support and develops team interaction. These days supervision has become a very important part of work which can offer improving professional competences, support in the complicated working situations, reflection on the work, analysis of the professional topics and knowledge about the work style not only to particular employees but also to a work team or to the whole facility. These recommendations seem to be very important for nurses' teams where a higher rate of psychical and physical burdens is. These recommendations also can prevent negative forms of communication as well as support mental health all the participants.

To sum up, it must be said that mobbing is a part of daily clinical practice in health care facilities. It is recommended:

- mobbing behaviours in the work place need to be defined;

- appropriate policies and procedures need to be developed and shared with all employees to prevent the development of mobbing behaviours;

- managers should adopt an open managerial approach.

\section{References}

1. BEDNÁŘ, M., BEŇO, P.: Patology of working relations or mobbing again: Psychological bullying at work is illegal. Sondy, 2000, 11 , is. 2, p. 14.

2. COYNE, I., SEIGNE, E., RANDALL, P.: Predicting workplace victim status from personality. European Journal of Work and Organizational Psychology, 2000. 9, p. 335-349.
3. GLASO, L., MATTHIESEN, S. B., NIELSEN, M. B., EINARSEN, S.: Do targets of workplace bullying portray a general victim personality profile? Scandinavian Journal of Psychology, 2007. 48, p. 313-319.

4. JANOUŠEK, V.: Mobbing, current problem [online], January-March 2004, [cit.27.02.2011]. Available on www: $<$ http://www.zenain.cz/rubrika.asp?id$\mathrm{c}=8431 \& \mathrm{id}=2>$ a (http://www.zena-in.cz/ rubrika.asp?idc $=8603 \& i d=2$ ).

5. KRATZ, H. J.: Mobbing, how to recognize it and how to face it. Praha: Management Press, 2005, 131 s. ISBN 80-7254-953-0.

6. LEYMANN, H. 1996. [cit.27.2. 2011]. Available on: www. <http://www.leymann. se/English /frame.html>.

7. NOVÁK, T., CAPPONI V.: Alone against agressoion. Prague: Grada, 1996. 128 s. ISBN 80-7169-253-0.

8. NOVÁK, T., RICHTEROVÁ, I.: Bullying terrorizing - aggression - all these can be experienced at the workplace or mobbing in different ways. Sondy, 1999, 10, is. 22, p. 1.

9. VARTIA, M.: Consequences of workplace bullying with respect to the well-being of its targets and the observers of bullying. Scandinavian Journal of Work Environment and Health, 2001. 27, p. 63-69.

10. YILDIRIM, A., YILDIRIM, D.: Mobbing in the workplace by peers and managers: mobbing experienced by nurses working in healthcare facilities in Turkey and its effect on nurses. Journal of Clinical Nursing, 2007. 16, 8, p.1444-1453.

11. ZAPF, D.: Organisational, work group related and personal causes of mobbing/bullying at work. International Journal of Manpower. 1999. 20, p. 70-85. 


\title{
Analysis of psychometric features of the Mini-Mental State Examination and the Montreal Cognitive Assessment methods
}

\author{
0. Kabátová, S. Puteková, J. Martinková, M. Súkenníková
}

Original Articles

Trnava University, Faculty of Health and Social Work, Department of Nursing, Trnava, Slovak Republic

\section{Correspondence to:}

Trnava University in Trnava, Faculty of Health Sciences and Social Work,

Univerzitné nám. 191843 Trnava, Slovak Republic; E-mail: olga.kabatova@truni.sk

Submitted: 23.2.2016

Revised: 13.7.2016

Accepted: 5.8.2016

\section{Reviewers:}

J. Nzau Mavole

The Catholic University of Eastern Africa, Nairobi, Kenya

M. Bartkovjak

Hospital in Marial Lou, AAA organization, South Sudan

\section{Key words:}

Cognitive disorders. Screening. MMSE. MoCA. Analysis.

CSWHI 2016; 7(2): 62-69 @ 2016 Clinical Social Work and Health Intervention

\section{Abstract:}

This study aim was to analyse selected psychometric features of the Mini-Mental State Exam (MMSE) and the Montreal Cognitive Assessment (MoCA) methods. The Montreal Cognitive Assessment (MoCA) was developed to enable earlier detection of mild cognitive impairment (MCI) relative to familiar multi-domain tests like the Mini-Mental State Exam (MMSE). Clinicians need to better understand the relationship between MoCA and MMSE scores. The analysis was performed on a sample of 84 geriatric patients. We have found a concurrent validity by calculation of Pearson's correlation coefficient between the test scores of the MMSE and the MoCA methods $(\mathrm{r}(84)=0.77, \mathrm{P}<0.001)$. Based on the correlation analysis, it may be stated that the MMSE test score is in a very tight positive correlation with the test score of the MoCA. We have also performed reliability analysis of both screening methods by calculation of internal consistency. The internal consistency of the MMSE method was represented by Cronbach's alpha at the level of 0.78 , and the MoCA method at the level of 0.81 ; those are considered to be optimum 
values. The MMSE sensitivity was good, and that was at the level = 0.83 with a confidence interval $95 \%$ from 0.62 to 0.95 . The MoCA sensitivity was very good, and that was at the level $=0.98$ with $95 \%$ of the confidence interval from 0.80 to 0.99 . The MMSE specificity was very good, and that was at the level $=0.99$ with $95 \%$ of the confidence interval from 0.92 to 0.99 . The MoCA specificity was good, and that was at the level $=0.85$ with $95 \%$ of the confidence interval from 0.73 to 0.91 . We have demonstrated a good internal consistency for both of the methods, and that means these screening methods are stable at the time and they provide reliable measuring of cognitive deficit.

\section{Introduction}

Cognitive disorders and dementia represent a serious health issue of older population. Due to high financial costs and social consequences they are becoming an issue of the whole society as well. Their prevalence is high in old age: $5-10 \%$ of dementias, $17 \%$ of mild cognitive impairment, and app. 20\% of benign age-influenced changes (Mauk, 2013). With the mean life expectancy rising, incidence of cognitive disorders will also be rising (Smith, Bondi, 2013). Despite this fact, $49 \%$ of the general practitioners do not examine cognitive functions in elderly patients at all or only occasionally, other $18 \%$ of them would perform this examination but they do not know how, and $12 \%$ of them do not have time for this diagnostics. Standardised tests are known only to $8 \%$ of the general practitioners and only half of them use it. Therefore, the alarming $60-70 \%$ of geriatric patients with dementia in higher age are not usually diagnosed (Topinková, Jirák, Kožený, 2002). Cognitive examination performed by screening tests is a necessary part of cognitive disorders diagnostics. In appropriate usage, the screening tests of cognitive functions may reveal partial stage of cognitive deficit. The results of screening methods should be in compliance with the information about the patient's problems which are communicated by conversation with the patient and persons in their proximate surrounding. However, complex neuropsychological examination is essential for thorough specification of cognitive deficiency. The same applies not only to mild cognitive impairment study but mainly for pre-clinic study of neurodegenerative diseases leading to cognitive deficit, when the first cognitive problems might occur, which are sensed subjectively by the patient $(\mathrm{Tu}-$ okko, Hultsch, 2013). Cognitive disorders assessment in context of recognition need is a part of complex assessment of a geriatric patient and it is based on the data gained by various methods. It does not replace clinic examination and it is understood as a supplementary method to other methods of data collection (Barker, Board, 2012). The most widespread short screening test is the Test MMSE - Mini-Mental State Examination, which evaluates orientation, extent of attention, attention and calculation, memory and language (Folstein, Folstein, McHugh, 1975). Due to low sensitivity, however, it is rather inappropriate in mild cognitive impairment diagnostics and it is particularly applied in dementia syndrome diagnostics. Low sensitivity in patients with mild cognitive impairment is caused by relative simplicity of the test in relation to memory and low representation of items which test the memory, and also by absence of tasks for frontal functions such as planning, 
decision-making, attention and others. The second mostly used short screening test for cognitive functions evaluation is the MoCA - Montreal Cognitive Assessment (Nasreddine et al., 2005). Out of the cognitive skills, the MoCA is focused on visuospatial functions, naming, and memory including delayed recall, attention, language, abstraction and orientation. It means that it encompasses greater spectrum of tasks demanding of executive functions and in all it is more difficult test than the MMSE. Advantage of the MoCA is sensitivity rise of the test in patients with mild cognitive impairment without significant impact on specificity, and at the same time still relatively short period of administration.

\section{Patients and Methods}

Analysis of psychometric features of the MMSE and MoCA methods was performed on a sample of 84 geriatric patients. With regard to gender, the examined group was formed by 29 men $(35 \%$ of $\mathrm{N}=84)$ and 55 women $(65 \%$ of $\mathrm{N}=84)$. The mean age of the examined group was $77(\mathrm{SD}=3.9)$ with the variation span of 12 years; the minimum age of $71(\mathrm{~N}=10)$ and maximum age of 83 years $(\mathrm{N}=4)$. In the group of men the mean age was $76.5(\mathrm{SD}=4.4)$ and in the group of women 77.2 ( $\mathrm{SD}=3.6)$. The selection criteria for geriatric patient classification into the examined group were: the age of 65 and more, willingness and ability to cooperate, the language kept, fine motor movement, sight and hearing. The data collection was taking place from July 2015 to February 2016. We found the concurrent validity by calculation of Pearson's correlation coefficient between the test scores of the MMSE and MoCA methods. We have also performed reliability analysis of both screening methods by calculation of internal consistency of both screening methods. We determined the sensitivity and specificity based on dementia diagnosis in comparison with the critical cut off score of 26 points, and that was both for the MMSE methodology as well as the MoCA, so called gained test score of 25 and less represented cognitive deficit.

\section{Results and Discussion}

First, we analysed the concurrent, or also so called diagnostic, validity which is represented by Pearson's correlation coefficient between the test scores of the MMSE and MoCA methods; $r(84)=0.77, \mathrm{P}<$ 0.001 . Based on the correlative analysis, we can state that the test score of the MMSE is in a very tight positive correlation with the test score of the MoCA which is graphically illustrated by the means of correlation diagram (Graph 1). In the graph, there are geriatric patients marked by red who had dementia diagnosis confirmed and there are geriatric patients without dementia diagnosis marked by blue.

Also, we have performed reliability analysis of both screening methods. Internal consistency of the MMSE method was represented by Cronbach's alpha at the level of 0.78 and the MoCA method at the level of 0.81 . The optimum value of Cronbach's alpha, which points to sufficient internal consistency of the method, is considered the value from 0.7 up to 0.9 (see e.g. Tavakol, Dennick, 2011). We determined the sensitivity and specificity based on dementia diagnosis in comparison with the critical cut off score $=26$ points for both the MMSE method as well as the MoCA method, the so called gained test score of 25 points and less represents cognitive deficit or dementia. The MMSE sensitivity was good, and that was at the level $=0.83$ with $95 \%$ of the confidence interval from 0.62 to 0.95 . The MoCA sensitivity was very good, and that was at the level $=0.98$ with $95 \%$ of the confidence interval from 0.80 to 0.99 . The 
Graph 1 Correlation diagram score of the MMSE with the MoCA

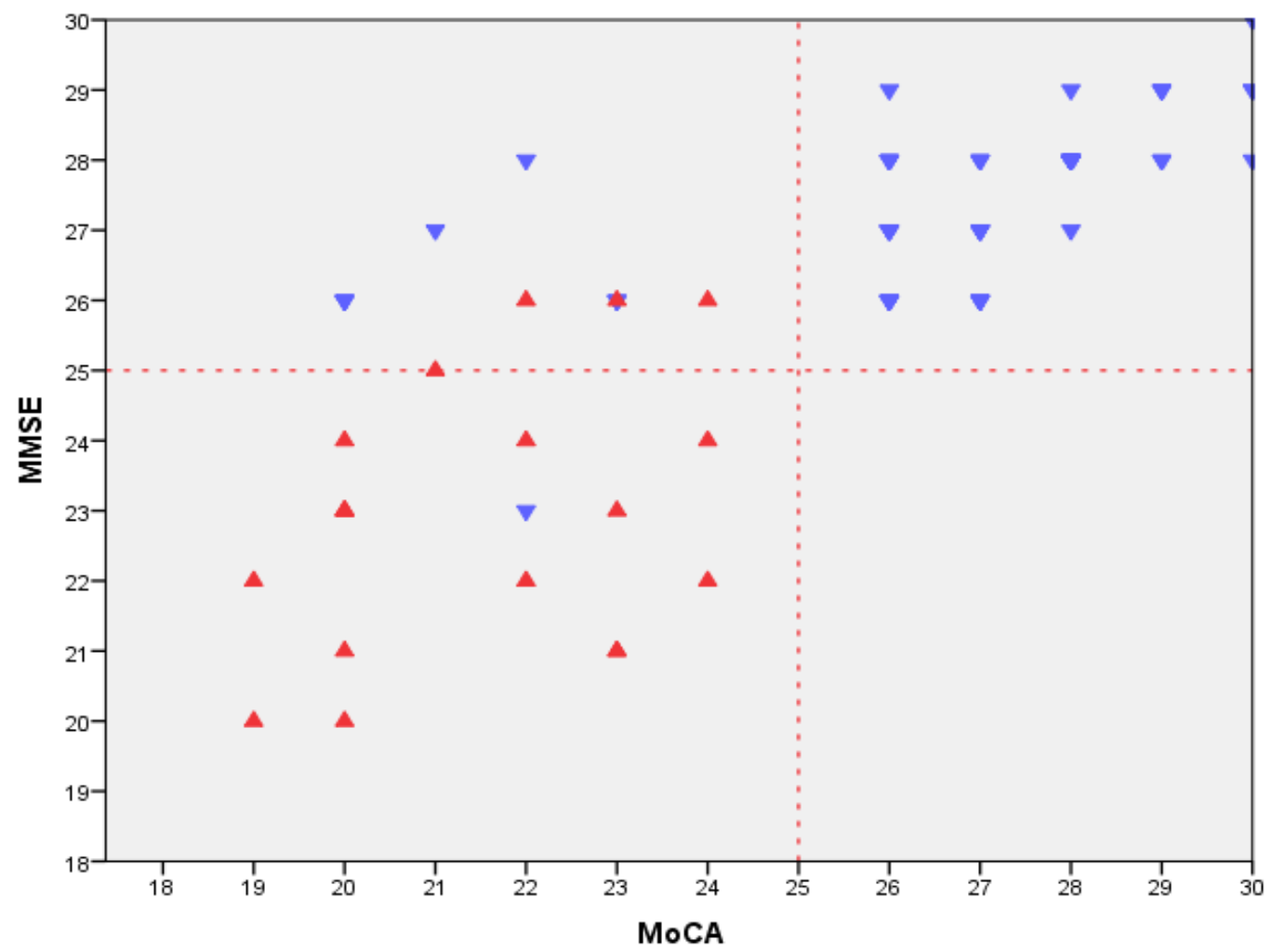

Table 1 Contingency table for the MMSE and the MoCA cut off with dementia diagnosis

\begin{tabular}{|c|l|c|c|c|c|}
\hline \multirow{2}{*}{2} & \multicolumn{2}{c|}{ MMSE } & \multicolumn{2}{c|}{ MoCA } \\
\cline { 3 - 6 } \multicolumn{2}{|c|}{} & $\begin{array}{c}\mathbf{2 5} \text { and } \\
\text { less }\end{array}$ & $\mathbf{2 6}$ and more & $\begin{array}{c}\mathbf{2 5} \text { and } \\
\text { less }\end{array}$ & \\
\hline \multirow{2}{*}{ Dementia diagnosis } & No & 64 & 1 & 55 & 10 \\
\cline { 2 - 6 } & Yes & 3 & 16 & 0 & 19 \\
\hline \multicolumn{2}{|c|}{ Total } & $\mathbf{6 7}$ & $\mathbf{1 7}$ & $\mathbf{5 5}$ & $\mathbf{2 9}$ \\
\hline
\end{tabular}

MMSE specificity was very good, and that was at the level $=0.99$ with $95 \%$ confidence interval from 0.92 to 0.99 . The MoCA specificity was good, and that was at the level $=0.85$ with $95 \%$ of the confidence interval from 0.73 to 0.91 .

In accordance with the foreign studies (Amieva et al., 2014; Imtiaz et al., 2014;
Trzepacz et al., 2015), we have demonstrated a good internal consistency for both methods, which means that these screening methods are stable at the time and they provide reliable measurements of cognitive deficit. Further on, the MoCA had a very good concurrent validity with the MMSE. This result has been expected because both 
of the tests are overlapped to a certain extent (there are the same tasks and some of them very similar). Based on our findings, we may state that the MMSE as well as the MoCA are adequately reliable screening tests. The alpha value found by us (the MMSE $\alpha=0.78 /$ the MoCA $\alpha=0.81$ ) is lower than the value specified by the MoCA method author $(\alpha=0.83)$ (Nasreddine et al., 2005); but despite that, these reliability values are sufficient and they are also in accordance with the research findings of the performed psychometric studies (Roalf et al., 2013; Saczynski et al., 2015).

Sensitivity and specificity of the MMSE are different in various stages depending on the cut off used. The original limit value was determined for 23 points and less - none of the examined persons without cognitive deficit from Folstein's study had less than 24 points. Later studies showed low sensitivity of this critical value (around (0.6), but high specificity (over 0.96) (Arevalo-Rodriguez et al., 2015; Kukull et al., 1994). Other studies showed that the cut off $24 / 23$ reaches 0.8 of the sensitivity for individuals with variously serious dementia, but the sensitivity of 0.54 for mild form of dementia (Schramm et al., 2002). Similarly, also in individuals with university education (having been educated for more than 16 years) the original cut off was shown to be a little sensitive (0.66). Nasreddine et al. (2005) found the sensitivity of only 0.18 with the critical score of 26 points for detection of mild cognitive impairment. With the same cut off, the sensitivity for dementia detection of Alzheimer's type was 0.78 and the specificity was 1 . The MMSE is also used as a classical screening tool for cognitive disorder diagnostics in Parkinson's disease. For this purpose, however, the MMSE seems to be a little specific tool. Hoops et al. (2009) recommend increasing of the limit value for the best ratio of sensitivity and specificity of the test in order to record cognitive disability in subjects with Parkinson's disease for the cut off of 28/29 points (sensitivity $=0.78$; specificity $=0.63$ ). The data about the MoCA sensitivity and specificity differ in various studies. The original work of the method author specifies the MoCA sensitivity with the cut off of $26 / 25$ points for mild cognitive impairment 0.9 and 1 for dementia. Specificity is specified at 0.87 (for dementia detection). In contrast with the MMSE, within the MoCA there are almost no patients with mild cognitive impairment or patients with dementia do not have the score over 25 points (Nasreddine et al., 2005). Some studies confirmed original psychometric features of the test (Litvan et al., 2012; Steenoven et al., 2014). Rossetti et al. (2011) found that the limit value of 26 points for specification of cognitive pathology may be strict a little and it is necessary to decrease it. Due to the fact that the MoCA is still only a supplementary test to the MMSE being used as a routine, Koski et al. (2011) tried to combine both of the tests and verify their diagnostic value. The use of the MoCA showed to be as the most convenient to the diagnostics of mild cognitive deficits with addition of 5 most difficult items from the MMSE (repetition of 3 words, recollection of 3 words, a sentence repetition, writing, and drawing of a pentagon). Thanks to some studies, from the results of the MoCA it is possible to easily assess a probable score of the MMSE (Saczynski et al., 2015). Our findings about sensitivity and specificity of both screening methods are comparable with the previous studies. Sensitivity of the MMSE was good at the level of 0.83 and sensitivity MoCA was very good at the level of 0.98 . Specificity of the MMSE was very good at the level $=0.99$ and specificity of the MoCA was good at the level $=0.85$ (Nasreddine et al., 2005). Even though the results of our study are significantly consistent with 
the previous findings, it is also necessary to mention limitations of our research. With regard to non-random selection, we are aware of our examined group limitation that it may not be generalisable. The gained examined group is relatively small and non-representative in terms of the Slovak population of geriatric patients, which was caused by occasional and non-random selection of subjects. The selection method was defined particularly with regard to its feasibility in practice and also it was influenced by our economic and temporal possibilities.

\section{Conclusion}

Cognitive functions evaluation by measuring tools has become a part of clinical practice not only in geriatrics, geriatric psychiatry, but also in the field of nursing research and practice. The measuring tools are predominantly recommended for the area of assessment and diagnostics in the literature. Screening tests provide information about a global cognitive status of a person without demanding neuropsychological examination. They are frequently used in research as a criterion classifying the persons who are examined into individual groups. They are appropriate for routine verification of the health status of certain populations with higher likelihood of certain disease incidence. Some methods are developed for global cognitive deficit diagnostics, some for specific disorders diagnostics and others are relevant only for differential diagnostics. Most of the methods serving for dementia detection are designed for all-purpose examination of cognitive deficit (Barker, Board, 2012). Due to reduction of load being laid on the patient as well as efficiency of measuring tools usage it is not necessary to use several measuring tools, between which there is a strong scale of correlation, and it is appropriate to choose a representative tool. Based on our as well as previous research findings, the MoCA method seems to be more effective for cognitive disorders screening of geriatric patients.

\section{References}

1. AMIEVA, H. - MOKRI, H. - LE GOFF, M. - MEILLON, C. - JACQMIN-GADDA, H. - FOUBERT-SAMIER, A. - ORGOGOZO, J.-M. - STERN, Y. - DARTIGUES, J.-F. Compensatory mechanisms in higher-educated subjects with Alzheimer's disease: a study of 20 years of cognitive decline. Brain, 2014. vol. 137, pp. 1167-1175. ISSN 0006-8950.

2. AREVALO-RODRIGUEZ, I., SMAILAGIC, N., ROQUE, I.F.M., CIAPPONI, A., SANCHEZ-PEREZ, E., GIANNAKOU, A., PEDRAZA, O.L., BONFILL COSP, X., CULLUM, S. Mini-Mental State Examination (MMSE) for the detection of Alzheimer's disease and other dementias in people with mild cognitive impairment (MCI). Cochrane Database Syst Rev. 2015, vol. 3, no. 1, p. 72. ISSN 1469-493X.

3. BARKER, S. - BOARD, M. Dementia Care in Nursing. 1. vyd. Cambridge: SAGE Publications, 2012. 184 s. ISBN 9780857258014.

4. FOLSTEIN, M.F. - FOLSTEIN, S.E. MCHUGH, P.R. "Mini-mental state": a practical method for grading the cognitive state of patients for the clinician. J Psychiatr Res, 1975. vol. 12.

5. HOOPS, S. - NAZEM, S. - SIDEROWF, A.D. - DUDA, J.E. - XIE, S.X. - STERN, M.B. - WEINTRAUB, D. Validity of the $M o C A$ and MMSE in the detection of MCI and dementia in Parkinson disease. Neurology, 2009. vol. 73 , no. 21, pp. 1738-1745. ISSN 0028-3878.

6. IMTIAZ, B. - TOLPPANEN, A.-M. - KIVIPELTO, M. - SOININEN, H. Future directions in Alzheimer's disease from risk factors to prevention. Biochemical Pharmacology, 
2014. vol. 88, no. 4, pp. 661-670. ISSN 0006-2952.

7. KOSKI, L. - XIE, H. - KONSZTOWICZ, $\mathrm{S}$. Improving precision in the quantification of cognition using the Montreal Cognitive Assessment and the Mini-Mental State Examination. Int Psychogeriatr, 2011. vol. 23, no. 7, pp. 1107-1115. ISSN 1041-6102.

8. KUKULL, W.A. - LARSON, E.B. - TERI, L. - BOWEN, J. - MCCORMICK, W. PFANSCHMIDT, M.L. The Mini-Mental State Examination score and the clinical diagnosis of dementia. J Clin Epidemiol, 1994. vol. 47, no. 9, pp. 1061-1067. ISSN 0895-4356.

9. LITVAN, I. - GOLDMAN, J.G. - TROESTER, A.I. - SCHMAND, B.A. WEINTRAUB, D. - PETERSEN, R.C. - MOLLENHAUER, B. - ADLER, C.H. MARDER, K. - WILLIAMS-GRAY, C.H. - AARSLAND, D. - KULISEVSKY, J. RODRIGUEZ-OROZ, M.C. - BURN, D.J. - BARKER, R.A. - EMRE, M. Diagnostic criteria for mild cognitive impairment in Parkinson's disease: Movement Disorder Society Task Force guidelines. Movement Disorders, 2012. vol. 27, no. 3, pp. 349-356. ISSN 0885-3185.

10. MAUK, K.L. Gerontological Nursing. 2. vyd. Massachusetts: Jones \& Bartlett Learning, LLC, 2013. 1062 s. ISBN 9781449694647.

11. NASREDDINE, Z.S. - PHILLIPS, N.A. - BEDIRIAN, V. - CHARBONNEAU, S. - WHITEHEAD, V. - COLLIN, I. - CUMMINGS, J.L. - CHERTKOW, H. The montreal cognitive assessment, MoCA: A brief screening tool for mild cognitive impairment. Journal of the American Geriatrics Society, 2005. vol. 53, no. 4, pp. 695-699. ISSN 0002-8614.

12. ROALF, D.R. - MOBERG, P.J. - XIE, S.X. - WOLK, D.A. - MOELTER, S.T. - ARNOLD, S.E. Comparative accuracies of two common screening instruments for the classification of Alzheimer's disease, mild cognitive impairment and healthy aging. Alzheimer's \& Dementia: The Journal of the Alzheimer's Association, 2013. vol. 9, no. 5, pp. 529-537. ISSN 1552-5260.

13. ROSSETTI, H.C. - LACRITZ, L.H. - CULLUM, C.M. - WEINER, M.F. Normative data for the Montreal Cognitive Assessment (MoCA) in a population-based sample. Neurology, 2011. vol. 77, no. 13, pp. 12721275. ISSN 0028-3878.

14. SACZYNSKI, J.S. - INOUYE, S.K. GUESS, J. - JONES, R.N. - FONG, T.G. - NEMETH, E. - HODARA, A. - NGO, L. MARCANTONIO, E.R. The Montreal Cognitive Assessment: Creating a Crosswalk with the Mini-Mental State Examination. Journal of the American Geriatrics Society, 2015. vol. 63, no. 11, pp. 2370-2374. ISSN 0002-8614.

15. SCHRAMM, U. - BERGER, G. - MULLER, R. - KRATZSCH, T. - PETERS, J. - FROLICH, L. Psychometric properties of Clock Drawing Test and MMSE or Short Performance Test (SKT) in dementia screening in a memory clinic population. Int $\mathrm{J}$ Geriatr Psychiatry, 2002. vol. 17, no. 3, pp. 254260. ISSN 0885-6230.

16. SMITH, G.E. - BONDI, M.W. Mild Cognitive Impairment and Dementia: Definitions, Diagnosis, and Treatment. 1 ed. London: OUP USA, 2013. 403 pp. ISBN 9780199764181.

17. STEENOVEN, I. - AARSLAND, D. HURTIG, H. - CHEN-PLOTKIN, A. DUDA, J.E. - RICK, J. - CHAHINE, L.M. - DAHODWALA, N. - TROJANOWSKI, J.Q. - ROALF, D.R. - MOBERG, P.J. - WEINTRAUB, D. Conversion between Mini-Mental State Examination, Montreal Cognitive Assessment, and Dementia Rating Scale-2 scores in Parkinson's disease. Movement Disorders, 2014. vol. 29, no. 14, pp. 1809-1815. ISSN 1531-8257.

18. TAVAKOL, M. - DENNICK, R. Making sense of Cronbach's alpha. Int J Med Educ, 2011. vol. 2, pp. 53-55. 
19. TOPINKOVÁ, E. - JIRÁK, R. - KOŽENÝ, J. Short battery neurocognitive screening for dementia in clinical practice: a seven-minute screening test. Neurology for Practice, 2002. vol. 6, no. 2, p. 323-328.

20. TRZEPACZ, P.T. - HOCHSTETLER, H. WANG, S. - WALKER, B. - SAYKIN, A.J. Relationship between the Montreal Cognitive Assessment and Mini-mental State Examination for assessment of mild cognitive impairment in older adults. BMC Geriatrics, 2015. vol. 15, no. 1, pp. 1-9. ISSN 1471-2318.
21. TUOKKO, H.A. - HULTSCH, D.F. Mild Cognitive Impairment: International Perspectives. 1 ed. New York: Taylor \& Francis, 2013. 336 pp. ISBN 9781134953820. 


\section{Management of diabetic individuals with emphasis on prevention of foot amputation}

M. Korintušová, V. Kozoň, E. Zacharová

Original Articles

St. Elizabeth University of Health and Social Work in Bratislava, Ph.D. Programm, Slovak Republic

\section{Correspondence to:}

St. Elizabeth University of Health and Social Work, Department of Social Work in Skalica, Nám. slobody 3, P. O. Box 104, 810 00, Bratislava, Slovak Republic

Submitted: 19.2 .2016

Revised: 5.7 .2016

Accepted: 4.8 .2016

\section{Reviewers:}

I. Bartosovic

Tropic team of st. Elizabeth, Slovak Republic

V. Okoth

Adjunct lecturer Catholic University of Eastern Africa

\section{Key words:}

Diabetes mellitus, diabetic, quality of life, preventive measures.

CSWHI 2016; 7(2): 70-80 @ 2016 Clinical Social Work and Health Intervention

\section{Abstract:}

Goal: The purpose of this work was to determine whether the duration of the disease in diabetic patients and their age have an effect on the quality of their life in relation to this disease. Determine the preference in measures aimed at the prevention of the diabetic foot complications in diabetic patients. Methods: The research population included 172 patients from Trenčín region in Slovakia. The research was based on a questionnaire developed by amending the standardized questionnaire of the WHO - WHOQOL-BREF to include additional items focusing on the choice of preventive measures related to the prevention of the complications of a diabetic foot. Results: No association was demonstrated between the duration of the disease in diabetic patients and their quality of life. However, the results demonstrated that there is an association between the age of the patients and their quality of life. We also found statistically significant differences in the choice of the most important areas of preventive measures preventing the complications of diabetic foot between men and women. 
Conclusion: Diabetic patients are not only passive recipients of care but also individuals who are active, independent and jointly responsible for the achieved results. Very important aspect is the knowledge of the preventive measures focused especially on the prevention of the complications of diabetic foot.

\section{Introduction}

Diabetes mellitus (DM) is one of the frequent, medically serious and high-cost chronic diseases. As a result of acute and chronic complications, this condition significantly contributes to morbidity, mortality and poor quality of life of patients.

An important means to improve the quality of life of diabetic patients, is their effective education and knowledge of preventive measures. Through education, diabetic patients are expected to become co-authors and be jointly responsible for the proper control of diabetes, thus contributing to the improvement of their quality of life (Holmanová, 2002, p. 53-54).

A much feared chronic complication of diabetes mellitus is the diabetic foot syndrome (DFS). Fard et al. (2007, p. 1931) claim, that up to $20 \%$ of diabetic patients are hospitalized with DFS. The World Health Organization defines DFS as the ulceration or destruction of deep tissues of the foot associated with neurological abnormalities and varying degrees of ischaemia. Diabetic ulcerations affect $15 \%$ of diabetics during their life and they also represent a risk of amputation of the affected part of the foot, with prevalence of $0.5-1 \%$ of diabetics. More than $85 \%$ of amputations in diabetics are accelerated by the development of ulcers, infection and gangrene (Jirkovská, 2006 , p. 297). The education of diabetics and their families is an integral component of the nursing process, a systematic and rational method of providing care.

\section{Objectives}

The objective of the work was to contribute to the improvement in the area of care for patients with diabetes with emphasis on the prevention of foot amputations and to assess their quality of life and their position on preventive measures. This objective was split in two tasks:

1. Determine whether the duration of the disease in diabetic patients and their age have an effect on the quality of their life in relation to this disease.

2. Determine the preference in measures aimed at the prevention of the diabetic foot complications in diabetic patients.

\section{Methods}

In the research project we focused our attention on the specification of the differences in the perception of the quality of life of people with diabetes and on the assessment of the preventive measures from the viewpoint of certain sociodemographic factors.

The subject matter of the research was the perception of the quality of life in 
people with diabetes and preference of preventive measures with respect to the prevention of diabetic foot complications.

The object of the research were the patients with diabetes in selected out-patient diabetology practices in Trenčín region in Slovakia. The research population consisted of 172 subjects. Data was collected using a questionnaire consisting of two parts. In the first part of the questionnaire, the subjects assessed their quality of life using an independent standardized questionnaire of the World Health Organization WHOQOL-BREF containing 26 items, where two separate items were related to the overall evaluation of the quality of life and satisfaction with health and 24 items were grouped in four domains (physical health, psychological health, social relations and environment). The results of WHOQOL-BREF are expressed in four domain scores, and a mean gross score for the two separate items, assessing the overall quality of life and health. The rating scale for individual items is $1-5$ and for domains 4-20. This part of the questionnaire was evaluated using the method of the authors of the standardized questionnaire Dragomirecká, Bartoňová (2006).

In the second part of the questionnaire, the subjects responded on preventive measures related to the prevention of diabetic foot complications. The subjects had the opportunity to choose 5 out of 16 areas of prevention that they consider the most important from the viewpoint of prevention of complications of a diabetic foot.

The questionnaire was also used to acquire identification and demographic information from the subjects - age, gender, highest achieved education and approximate diagnosed duration of diabetes. The data from the subjects was processed and analysed using mathematical-statistical methods at the level of descriptive and inductive statistics.

\section{Results}

Out of 172 subjects who were included in the research, 110 were women $(64 \%)$ and 62 were men (36\%). From the viewpoint of the highest achieved education, the largest was the subgroup with high-school education - consisting of 106 subjects (61.6\%), 44 subjects (25.6) had elementary education and 22 subjects (12.8\%) had university education. With respect to age, the subjects were divided into five subgroups. Subgroups aged below 40 years included 24 subjects (14\%), 41-50 years: 18 subjects (10.5\%), 51-60 years : 26 subjects (15.1\%). Most numerous were the subgroups 61-70 years $(33.7 \%)$ and $70+$ years $(26.7 \%)$.

The subjects had the opportunity to record in the questionnaires the approximate diagnosed duration of the disease - by marking one of the four ranges ( $0-5$ years, 6-10 years, $11-15$ years and $15+$ years). According to the responses, $56(32.5 \%)$ had been diagnosed with this condition for up to 5 years, 59 subjects (34.3\%) 6-10 years, 29 subjects $11-15$ years and 28 subjects $(16.3 \%)$ stated that they have been diagnosed with the condition for more than 15 years.

With respect to the defined partial objectives, the research results can be summarized into two areas:

\section{Quality of life of the patients with diabetes}

Table 1 presents the mean score of 26 items of this part of the questionnaire for our research population $(\mathrm{N}=172)$ and mean score of the set of individuals selected from standard population (marked *) according to the authors Dragomirecká, Bartoňová (por. 2006, p.22). Pilot testing was carried out on a research sample of 310 subjects, of which 161 were women (51.94\%) and 149 men $(48.06 \%)$ aged 18 to 58 years, whereas 
$8 \%$ of subjects were considered ill in this population. It is necessary to point out that this was a Czech population as no results of a similar research have so far been published in the Slovak Republic. However, we expect that the circumstances regarding this are similar in the Czechia and in Slovakia.

The first two items (marked as Q1 and Q2) are independent items related to overall assessment of the quality of life and satisfaction with health. For all two items, the subjects in the research

Table 1 Mean score for individual items for the research population and for standard population

\begin{tabular}{|c|c|c|c|c|c|c|c|c|}
\hline & Item & Question & $\mathbf{N}$ & Mean & SD & $\mathbf{N}^{*}$ & Mean* & SD ${ }^{*}$ \\
\hline 1. & Q1 & How would you rate your quality of life? & 172 & 3.22 & 0.83 & 310 & 3.82 & 0.72 \\
\hline 2. & Q2 & How satisfied are you with your health? & 172 & 2.77 & 0.88 & 310 & 3.68 & 0.85 \\
\hline 3. & q3 & $\begin{array}{l}\text { To what extent do you feel that physical } \\
\text { pain prevents you from doing what you } \\
\text { need to do? }\end{array}$ & 172 & 2.91 & 0.97 & 310 & 4.03 & 1.05 \\
\hline 4. & $\mathrm{q} 4$ & $\begin{array}{l}\text { How much do you need any medical } \\
\text { treatment to function in your daily life? }\end{array}$ & 172 & 2.61 & 1.07 & 310 & 4.16 & 0.95 \\
\hline 5. & q5 & Do you enjoy life? & 172 & 3.43 & 1.23 & 310 & 3.83 & 0.90 \\
\hline 6. & q6 & $\begin{array}{l}\text { To what extent do you feel your life to be } \\
\text { meaningful? }\end{array}$ & 172 & 3.62 & 1.13 & 310 & 3.86 & 0.85 \\
\hline 7. & q7 & How well are you able to concentrate? & 172 & 3.27 & 0.94 & 310 & 3.55 & 0.88 \\
\hline 8. & q8 & How safe do you feel in your daily life? & 172 & 3.20 & 0.96 & 310 & 3.24 & 0.79 \\
\hline 9. & q9 & $\begin{array}{l}\text { How satisfied are you with the } \\
\text { environment where you live? }\end{array}$ & 172 & 3.20 & 1.00 & 310 & 2.85 & 0.92 \\
\hline 10. & q10 & $\begin{array}{l}\text { Do you have enough energy for everyday } \\
\text { life? }\end{array}$ & 172 & 2.98 & 0.89 & 310 & 3.62 & 0.93 \\
\hline 11. & q11 & $\begin{array}{l}\text { Are you able to accept your bodily } \\
\text { appearance? }\end{array}$ & 172 & 3.64 & 1.05 & 310 & 3.90 & 0.82 \\
\hline 12. & q12 & $\begin{array}{l}\text { Have you enough money to meet your } \\
\text { needs? }\end{array}$ & 172 & 2.54 & 0.97 & 310 & 2.87 & 1.08 \\
\hline 13. & q13 & $\begin{array}{l}\text { Do you have access to the information } \\
\text { that you need in your day-to-day life? }\end{array}$ & 172 & 3.22 & 0.91 & 310 & 3.87 & 0.77 \\
\hline
\end{tabular}




\begin{tabular}{|c|c|c|c|c|c|c|c|c|}
\hline 14. & $\mathrm{q} 14$ & $\begin{array}{l}\text { Do you have the opportunity for leisure } \\
\text { activities? }\end{array}$ & 172 & 3.00 & 1.01 & 310 & 3.33 & 1.00 \\
\hline 15. & $\mathrm{q} 15$ & How well are you able to get around? & 172 & 3.04 & 0.96 & 308 & 4.27 & 0.84 \\
\hline 16. & $\mathrm{q} 16$ & How satisfied are you with your sleep? & 172 & 2.94 & 1.03 & 308 & 3.61 & 0.99 \\
\hline 17. & $\mathrm{q} 17$ & $\begin{array}{l}\text { How satisfied are you with your ability } \\
\text { to perform your daily living activities? }\end{array}$ & 172 & 3.12 & 0.83 & 308 & 3.76 & 0.78 \\
\hline 18. & q18 & $\begin{array}{l}\text { How satisfied are you with your capacity } \\
\text { for work? }\end{array}$ & 172 & 2.91 & 0.97 & 308 & 3.76 & 0.80 \\
\hline 19. & q19 & How satisfied are you with yourself? & 172 & 3.30 & 0.95 & 308 & 3.57 & 0.76 \\
\hline 20. & $\mathrm{q} 20$ & $\begin{array}{l}\text { How satisfied are you with your personal } \\
\text { relationships? }\end{array}$ & 172 & 3.64 & 0.91 & 308 & 3.75 & 0.91 \\
\hline 21. & $\mathrm{q} 21$ & How satisfied are you with your sex life? & 172 & 3.14 & 0.99 & 308 & 3.64 & 1.07 \\
\hline 22. & $\mathrm{q} 22$ & $\begin{array}{l}\text { How satisfied are you with the support } \\
\text { you get from your friends? }\end{array}$ & 172 & 3.67 & 1.02 & 308 & 3.85 & 0.80 \\
\hline 23. & $\mathrm{q} 23$ & $\begin{array}{l}\text { How satisfied are you with the } \\
\text { conditions of your living place? }\end{array}$ & 172 & 3.86 & 0.87 & 308 & 3.54 & 0.86 \\
\hline 24. & $\mathrm{q} 24$ & $\begin{array}{l}\text { How satisfied are you with your access } \\
\text { to health services? }\end{array}$ & 172 & 3.41 & 0.95 & 308 & 3.70 & 0.79 \\
\hline 25. & $\mathrm{q} 25$ & $\begin{array}{l}\text { How satisfied are you with your } \\
\text { transport? }\end{array}$ & 172 & 3.22 & 0.99 & 308 & 3.19 & 1.07 \\
\hline 26. & $\mathrm{q} 26$ & $\begin{array}{l}\text { How often do you have negative } \\
\text { feelings? }\end{array}$ & 172 & 3.59 & 0.80 & 308 & 3.47 & 0.95 \\
\hline
\end{tabular}

population - as compared to standard (control) population - had lower values, i.e. they perceived their physical health and quality of life as worse. The remaining 24 items (marked q3 through q26) are split in four domains.

The first domain (Dom1) is identified as physical health and comprises seven items (q3, q4, q10, q15, q16, q17 and q18). This domain takes into consideration three aspects of physical health and four aspects of physical independence.
The second domain (Dom2) is identified as psychological health and comprises six items (q5, q6, q7, q11, q19 and q26). This domain contains five aspects of psychological health and one independent aspect focusing on spirituality.

The third domain (Dom3) focuses on three aspects of social relationships. It comprises three items (q20, q21 and q22) and is identified as social relationships.

The fourth domain (Dom4) is identified as environment, comprising eight items 
(q8, q9, q12, q13, q14, q23, q24 and q25) concerning the environment.

Table 2 presents the score of domains and items Q1 and Q2 according to the age of the subjects.

Based on the table 2, it appears that, considering the age, the overall evaluation of the quality of life (Q1) and overall evaluation of the satisfaction with health (Q2), were decreasing with increasing age.
Table 3 presents the score of individual domains and independent items Q1 and Q2 according to the diagnosed duration of diabetes.

With respect to the defined goals of our work, very important are the results of the analysis of correlation between socio-demographic variables (age and duration of the subjects' disease) and individual domains including independent items Q1 and Q2 as listed in table 4.

Table 2 Mean score of domains and items 01 and 02 according to the age of the subjects

\begin{tabular}{|l|l|c|c|c|c|c|}
\hline \multicolumn{2}{|c|}{ Domain } & $\begin{array}{c}\text { up to 40 } \\
\text { years } \\
(\mathbf{N = 2 4 )}\end{array}$ & $\begin{array}{c}\mathbf{4 1 - 5 0} \\
\text { years } \\
(\mathbf{N = 1 8})\end{array}$ & $\begin{array}{c}\mathbf{5 1 - 6 0} \\
\text { years } \\
(\mathbf{N = 2 6})\end{array}$ & $\begin{array}{c}\mathbf{6 1 - 7 0} \\
\text { years } \\
(\mathbf{N = 5 8})\end{array}$ & $\begin{array}{c}\mathbf{7 0 +} \text { years } \\
\text { (N=46) }\end{array}$ \\
\hline Domain 1 & Physical health & 15.57 & 11.81 & 12.66 & 11.65 & 9.19 \\
\hline Domain 2 & Psychological health & 15.61 & 13.85 & 14.97 & 14.23 & 12.00 \\
\hline Domain 3 & Social relations & 16.56 & 13.78 & 15.69 & 13.66 & 12.00 \\
\hline Domain 4 & Environment & 14.75 & 12.39 & 13.85 & 12.52 & 11.78 \\
\hline Q1 & Quality of life & 3.22 & 3.21 & 3.21 & 3.20 & 3.19 \\
\hline Q2 & Satisfaction with health & 2.77 & 2.77 & 2.76 & 2.76 & 2.75 \\
\hline
\end{tabular}

Table 3 Mean score of domains and items $\mathrm{Q} 1$ and $\mathrm{Q} 2$ according to the diagnosed duration of diabetes

\begin{tabular}{|l|l|c|c|c|c|}
\hline \multicolumn{2}{|c|}{ Domain } & $\begin{array}{c}\text { up to 5 } \\
\text { years } \\
(\mathbf{N = 5 6 )}\end{array}$ & $\begin{array}{c}\mathbf{6 - 1 0} \\
\text { years } \\
(\mathbf{N = 5 9 )}\end{array}$ & $\begin{array}{c}\mathbf{1 1 - 1 5} \\
\text { years } \\
(\mathbf{N = 2 6 )}\end{array}$ & $\begin{array}{c}\mathbf{1 5}+\text { years } \\
\text { (N=28) }\end{array}$ \\
\hline Domain 1 & Physical health & 11.43 & 12.32 & 11.31 & 11.43 \\
\hline Domain 2 & Psychological health & 13.76 & 14.55 & 12.40 & 14.43 \\
\hline Domain 3 & Social relations & 13.90 & 14.90 & 12.27 & 13.81 \\
\hline Domain 4 & Environment & 12.34 & 13.12 & 12.33 & 13.79 \\
\hline Q1 & Quality of life & 3.09 & 3.52 & 3.07 & 3.00 \\
\hline Q2 & Satisfaction with health & 2.54 & 3.05 & 2.73 & 2.71 \\
\hline
\end{tabular}


Table 4 Correlation of socio-demographic variables (age and duration of disease) and WHOQOL-BREF domains including independent questions Q1 1 and QQ2

\begin{tabular}{|l|c|c|c|c|c|c|}
\hline & $\begin{array}{c}\text { Q1 } \\
\text { Quality } \\
\text { of life }\end{array}$ & $\begin{array}{c}\text { Q2 } \\
\text { Satisfaction } \\
\text { with health }\end{array}$ & $\begin{array}{c}\text { Domain 1 } \\
\text { Physical } \\
\text { health }\end{array}$ & $\begin{array}{c}\text { Domain 2 } \\
\text { Psychologi- } \\
\text { cal health }\end{array}$ & $\begin{array}{c}\text { Domain 3 } \\
\text { Social } \\
\text { relations }\end{array}$ & $\begin{array}{c}\text { Domain 4 } \\
\text { Environ- } \\
\text { ment }\end{array}$ \\
\hline Age & -0.620 & -0.491 & -0.724 & -0.345 & -0.427 & -0.330 \\
\hline $\begin{array}{l}\text { Duration of } \\
\text { illness }\end{array}$ & -0.062 & 0.055 & -0.026 & -0.014 & -0.095 & 0.125 \\
\hline
\end{tabular}

From table 4 it is apparent that there is a statistically significant association between the diabetic patient's quality of life and their age. The quality of life and satisfaction with health decreases with increasing age. At the same time, the satisfaction with physical and psychological health, satisfaction with the quality of social relationships and environment is also decreasing. No statistically significant association was demonstrated between the quality of life of diabetic patients and duration of their disease. No association was demonstrated between the duration of the disease and the quality of their life. No association was found between the duration of the disease and variables that express the satisfaction with health, with physical and psychological health of the subjects, with the quality of their social relationships and the environment where they live.

\section{Key areas of preventive measures in relation to prevention of diabetic foot complications}

We evaluated the positions of the subjects on sixteen key areas of preventive measures aimed at the prevention of diabetic foot complications. We also compared the answers by gender. Chi-square test was used to compare the results in both populations (males/females) at significance level $\mathrm{P}=0.05$ (table 5).
Statistically significant differences in the preference in the most important areas of preventive measures aimed at the prevention of diabetic foot complications between men and women were confirmed in a total of 7 of 16 areas of preventive measures aimed at the prevention of diabetic foot complications. In nine areas statistically significant differences in the preferences of women and men were not confirmed.

\section{Discussion}

\section{Discussion about the quality of life of patients with diabetes}

According to Dragomerická and Bartoňová (2006, p. 9), nowadays, with increasing life expectancy and prevalence of chronic and lasting disorders, the main goal of medicine and nursing care is not the health or mere extension of the duration of life, but rather preservation or improvement of the quality of life. This is based on the definition of the World Health Organization that defines the quality of life as the subjective perception of the individual - of his/her position in life in the context of the cultural environment and in relation to his/her objectives, expectations, lifestyle and interests. Determination of the quality of life of a specific individual is a highly complex process based on various assessment scales, most commonly in 
Table 5 Comparison of responses in male/female populations (chi-square test)

\begin{tabular}{|l|l|c|c|c|}
\hline \multicolumn{1}{|c|}{ Areas of preventive measures } & chi & sv & P \\
\hline 1. & Regular inspection and checking of foot & 0.028 & 1 & 0.868 \\
\hline 2. & Care for foot skin and toenails & 4.195 & 1 & 0.041 \\
\hline 3. & Use of special toenail cutters (not manicure tools) & 0.198 & 1 & 0.656 \\
\hline 4. & $\begin{array}{l}\text { Provision of medicinal pedicure services (foot care services } \\
\text { provided by professional pedicurist) }\end{array}$ & 8.682 & 1 & 0.003 \\
\hline 5. & Regular washing of feet with lukewarm water & 1.284 & 1 & 0.257 \\
\hline 6. & Wearing cotton socks with medical rubber band & 0.259 & 1 & 0.611 \\
\hline 7. & No barefoot walking & 4.210 & 1 & 0.040 \\
\hline 8. & Using proper footwear & 1.890 & 1 & 0.169 \\
\hline 9. & Regular lower limb gymnastics (vascular gymnastics) & 12.120 & 1 & 0.000 \\
\hline 10. & Adequate overall physical activity & 0.198 & 1 & 0.656 \\
\hline 11. & Regular visits with diabetes specialist & 3.980 & 1 & 0.046 \\
\hline 12. & $\begin{array}{l}\text { Regular consulting and education of individuals with diabetes } \\
\text { on coping with the disease, with focus on prevention of foot } \\
\text { complications (such as injuries) }\end{array}$ & 1.186 & 1 & 0.276 \\
\hline 13. & Adherence to diet regimen & 1.697 & 1 & 0.193 \\
\hline 14. & Adherence to treatment regimen & 10.190 & 1 & 0.001 \\
\hline 15. & No smoking & 0.777 & 1 & 0.378 \\
\hline 16. & Increased care for diabetic patients by healthcare staff & 1 & 0.000 \\
\hline
\end{tabular}

the form of questionnaires (Cetlová et al., 2011, p. 7).

Using a standardized WHOQOL-BREF questionnaire, we compared the quality of life between our research population and a control set of common population according to the authors Dragomirecká, Bartoňová (2006, p. 22). On average, the overall quality of life and satisfaction with health was assessed by the subjects as lower than the population standard (table 1). Similar situation was observed also with respect to the domain of physical health, psychological health, social relationships and environment.

In our research, we found a significant association between the age and the quality of life of the patients (table 4). Correlation analysis of the acquired data demonstrated the inverse proportion (negative values of correlation coefficients) between the age and all areas of the patient's quality of life represented by domains - physical health $(-0.724)$, psychological health $(-0.345)$, social relationships $(-0.427)$ and environment (-0.330). A significant correlation was 
demonstrated also between age and overall quality of life (-0.620) and satisfaction with health $(-0.491)$.

Similar conclusions with respect to the quality of life in relation to the patient's age and with respect to the quality of life compared to population standard were reached also in the population subset of patients with diabetic foot syndrome in selected health centres in Moravian-Silesian region in the Czech Republic (Zeleníková et. al., 2014 , p. 4). When comparing the quality of life of the selected populations of diabetic patients and patients after lower limb amputation with the population norms, the authors - Bužgová, Hájková and Jasioková (2009, p. 249-250) point out the perception of reduced quality of life in these individuals compared to the common population. While the patients with a history of lower limb amputation demonstrated the lowest score of the quality of life in all areas, diabetic patients perceived reduced quality of life mainly in the area of physical health.

The research shows that the diabetic patients have lower quality of life compared to the patients without chronic disease (Yekta et al., 2011, p. 393). According to the French authors Valensi et al. (2005, p. 263), significant predicting factors of the reduced quality of life are the age, presence of type 2 diabetes and more advanced stage of diabetic ulcer. The presence of the diabetic foot syndrome reduces the patient's quality of life especially in the area of physical health.

\section{Discussion about the choice of the key areas of preventive measures in relation to prevention of diabetic foot complications}

Improved quality of life in diabetic patients is subject to their active involvement in their treatment (Závodná, 2005). Their interest in the collaboration with the team of diabetes specialists will initiate the effort to get their health under their control, preventing the need to treat complications. We were interested to know which areas of preventive measures aimed at the prevention of diabetic foot complications are the most important according to the subjects. Foot self-monitoring (regular inspection and checking of feet) is one of the most important areas according to the answers provided by the subjects in our research population. This area is preferred by up to $60.47 \%$ subjects $(61.29 \%$ male and $60.00 \%$ female $)$.

The importance of self-monitoring with respect to education of diabetic patients and subsequent improvement of diabetes control is also pointed out by Jirkovská (2006, p. 95-98).

We were also interested to know whether there are statistically significant differences in the choice of the most important areas of preventive measures preventing the complications of diabetic foot between men and women. In seven areas there are statistically significant differences in the preference for preventive measures between men and women (table 5). The men in our research population preferred especially the preventive measures related to no barefoot walking, adherence to treatment regimen and avoiding smoking. Women compared to men, more strongly preferred the care for skin and toenails of the foot, services of professional pedicurist, regular vascular gymnastics of lower limbs and regular visits with diabetes specialists. Men and women mostly agreed in the preference for regular inspection and checking of the feet.

The differences in the preference for individual preventive measures in relation to diabetes and in the extent of knowledge about this disease between men and women have been pointed out by authors Nemcová and Hlinková (2011, p. 8). They confirmed, that after education, women demonstrated 
a higher level of knowledge in the area of practising an inspection and care for the feet compared to men.

According to Poněšický (2003), men and women have different priorities, assign different importance to goals, and have differing skills, capabilities and techniques used to achieve these goals. In relation to their health, men overestimate themselves and engage in risky behaviour. This is one of the reasons for different views of diabetic patients - men and women on certain areas of preventive measures. As there are differences between men and women, appropriate techniques should be selected for nursing education based on these differences.

\section{Conclusion}

The search for options and methods aimed at improvement of the level of nursing care provided to diabetic patients with emphasis on the prevention of the amputation of the foot is not only a current topic attracting the attention of experts in different fields of research, it is also a topic associated with the improvement of the quality of life of people with this condition.

Diabetic patients are no more just passive recipients of care but also individuals who are active, more independent and jointly responsible for the achieved results. A very important aspect is the knowledge of the preventive measures focused especially on the prevention of the complications of a diabetic foot and access to quality education. Education in diabetes helps to take the attitude towards this incurable but very well controllable disease. The presented findings should be viewed as a contribution to the resolution of the problem of caring for people with diabetes, with emphasis on the prevention of foot amputation. The benefits of this work include not only the collected data on the quality of life of diabetic patients and their attitude towards preventive measures aimed at the prevention of diabetic foot complications but also the possibility of application of the outcomes in future research in similar areas.

\section{References}

1. BUŽGOVÁ R., HÁJKOVÁ M., JASIOKOVÁ A. (2009): Experience in measuring the quality of life with a questionnaire WHOQOL-BREF in selected groups of patients. Contact, no. 1, pp. 246-251, ISSN 1212-4117.

2. CETLOVÁ L., STANČIAK J., BĚHALOVÁ H. (2011): The quality of life in women with urinary incontinence. In Ižová M., Vicáňová M.: Family in health and disease. Proceedings of the international conference. Ružomberok: VERBUM, pp. 6-14, ISBN 978-80-8084-778-4.

3. DRAGOMIRECKÁ, E., BARTON, J. (2006): WHOQOL-BREF The WHO$Q O L-100$. User Manual for users of the Czech version of the Quality of Life Questionnaire of the World Health Organization. Prague: Prague Psychiatric Center, 88 pp. ISBN 80-85121-82-4.

4. FARD D. et al. (2007): Assessment and treatment of diabetic foot ulcers. International Journal of Clinical Practice, vol. 61, no. 11, pp. 1931-1938, ISSN 1742-1241.

5. HOLMANOVÁ E., ŽIAKOVÁ K., ČÁP J. (2002): The impact of education on the quality of life of diabetic patients. Diabetes and obesity, vol. 2, no. 4. pp. 52-59. ISSN 1335-8383.

6. JIRKOVSKÁ A. et al. (2006): The diabetic foot syndrome. Prague: Maxdorf, $397 \mathrm{pp}$. ISBN 80-7345-095-X.

7. NEMCOVÁ J., HLINKOVÁ E. (2011): Education in the prevention of diabetic ulceration and amputation. Nursing: Theory, research, education, vol. 1, no. 1, pp. 5-11.

8. PONĚŠICKÝ J. (2003): The phenomenon of femininity and masculinity. Praha: Triton, 204 pp. ISBN 80-4254-350-4. 
9. VALENSI P. et al. (2005): Quality of life and clinical correlates in patiens with diabetic foot ulcers. Diabetes \& Metabolism, vol. 31, no. 3, pp. 263-271, ISSN 1262-3636.

10. YEKTA Z. et al. (2011): Comparison of demographic and clinical characteristics influencing health-related quality of life in patients with diabetic foot ulcers and those without foot ulcers. Diabetes, Metabolic Syndrome and Obesity: Targets and Therapy, no. 4, pp. 393-399. ISSN 1178-7007.
11. ZÁVODNÁ V. (2005): Education in Nursing. 2nd ed., Bratislava: Osveta. 117 pp. ISBN 80-8063-193-X.

12. ZELENÍKOVÁ, R. et al. (2014): Evaluation of the quality of life of patients with diabetic foot syndrome in selected health facilities Region. Nursing and Midwifery, vol. 5, no. 1, pp. 2-8, ISSN 1804-2740. 


\section{Determinants characterizing the use of hormonal contraception regard to awareness}

K. Kotradyová', L. Rosková², M. Andrejiová3

Original Articles

${ }^{1}$ Catholic University, Faculty of Theology Kosice, Institute of Theology Spišské Podhradie, Slovak Republic

${ }^{2}$ University of South Bohemia in České Budějovice, Health and Social Sciences, Department of legal fields, Management and Economics, Czech Republic

${ }^{3}$ Technical University of Kosice, Faculty of Mechanical Engineering, Department of Applied Mathematics and Computer Science, Slovak Republic

\section{Correspondence to:}

Catholic University, Faculty of Theology, Kosice, Institute of Theology Spišské Podhradie, 04203 Košice, ul. Hlavná 91, Slovak Republic; e- mail: kotradyova@ku.sk

Submitted: 6.1.2016

Revised: 22.7.2016

Accepted: 14.8 .2016

\section{Reviewers:}

G. Herdics

Tropical Institute St. Elizabeth, Refugees Emergency Health Post Röszke, Vámosszabadi, Hegyeshalom, Hungary

Z. Szarota

Pedagogical University of Cracow, Poland

\section{Key words:}

Hormonal contraception, women, effects, awareness.

CSWHI 2016; 7(2): 81-90 @ 2016 Clinical Social Work and Health Intervention

\section{Abstract:}

In the last decade the number of women using hormonal contraceptives has raised, even though the views of its use are based on two mutually conflicting paradigms. The authors point to a number of serious health risks and aspects of hormonal contraceptive use, and are focused on a woman's free will decision with regard to her right of full awareness of the effects of combined hormonal contraceptives. In 2013 there was a research carried out in the south of the Czech Republic. It was dealing with the subjective perception of contraception by young women who used to take it, both in relation to their awareness of the negative and abortifacient effects of hormonal contraceptives. The present paper analyzes the acquired data. 


\section{Introduction}

In today's way of life when the question of sexual life has largely become acceptable, hormonal contraceptive use should be at the center of debates, especially among young people (Košč, 2013).

Lawren F. Winnerová sees the popularity of contraception in its easy availability as solutions to specific "problem". Avoid conception: "Stick it on the body, let it out of your mind ... It's so simple." (2007). According to Szarovska and Guillebaud there are more than 60 million women in the world who use hormonal contraceptives (1996). In this regard, Prochazka et al. state that the World Health Organization estimates the number of women using hormonal contraception for up to 100 million. The Czech and Slovak Republic, countries connected by historical and geopolitical line, recognize noticeable differences. While the Czech Republic is in the European average in the number of hormonal contraceptives users, Slovakia's at the end (2007).

\section{An insight into hormonal contraceptives use}

Hormonal contraception is based on the administration of synthetic hormonal substances having similar effects to those of natural sex hormones. It is of oestrogens ${ }^{1}$ and progesterone ${ }^{2}$. First theoretical considerations about the possibility of using hormonal contraceptives emerged in the 20 s of the 19th century and the first hormonal preparation appeared in 1931 (Kolářová, 2003). In the 50s and 60 s of the 20th century there was a big turning point in the research of hormonal contraceptives and there were the foundations for all three groups of known and used modern contraception methods laid - intrauterine method, progesterone method and combined hormonal method (Čepický, 2002).

Combined hormone preparations available at present act by several mechanisms - the inhibition of ovulation is the primary one; secondary effects must be divided into preimplantation (slowing the motility of the fallopian tubes and the ciliated epithelium in them) peri-implanation (affected endometrium prevents nidation) and post implantation (does not prevent the nidation itself but maintaining pregnancy). All three types of secondary effects are post fertilization, i.e. abortive - which occurs at the death of already fertilized egg. So far, there were not made any studies accurately quantifying the proportion of secondary effects in the final action of hormonal preparations (Andie, 2012).

Beneficial effects of combined hormonal contraceptives include in particular a highly effective and reversible pregnancy prevention allowing discretion on sexual activity. It also welcomes the reduction of blood loss during menstruation, but also controls irregular menstruation. Some users reach the improvement of acne and negligible is the prevention fact of ectopic pregnancy (Grindlay et al, 2013).

Britta Bürger, who is a specialist in gynecology and obstetrics, talks about the benefits of hormonal contraceptives on women particularly in the context of reducing some forms of inflammatory diseases, but also in the context of a lower risk of ovarian cystic change. The disadvantages of combined contraceptives include increased risk of thrombosis, especially if the woman smokes, water retention, which can raise the chest tension, blood pressure,

${ }^{1}$ Estrogens - are responsible for development of male sexual characteristics, support the construction of the uterus lining and the course of fertilization.

2 Progesterone - the group of female sex hormones, which include progesterone, are formed in the corpus luteum during the second half of the menstrual cycle. 
the occurrence of migraines, as well as increased risk of cervical cancer, breast cancer, and liver cancer. However, these risks, according to the authors, are considered to be low (2011).

Similarly, according to Sabine Balthasar hormonal products have many advantages, but they also have a range of side effects, so it is necessary to ensure the complete user history and rule out contraindications, as well as specific risk factors for thromboembolic disorders (2007). Hormonal contraceptives have many contraindications. Among the most serious thromboembolic events belong a family history of the user, resulting in deep vein thrombosis, pulmonary embolism, thromboembolism, stroke and myocardial infarction. Hereditary thrombophilia mutations have been known for over 20 years but the last decade raises immense manifestation of the disease. The reason is that millions of women, who take hormonal contraceptives daily, provided an update study material on which it is reliable to verify the number and incidence of coagulopathy disorders without any hormonal contraceptive use and their induction in the first and subsequent years of use (Hyánek, et al., 2010). Strunecká, Patocka present the results of a Danish study from 2010, which analyzed the medical records of 10, 4 million women aged 15-49 years from the period $1995-2005$. The analysis included 3.3 million women who use hormonal contraception at present, 2.3 million women who have used it in the past, and 4.8 million women who never used it. In this file, there were 4,213 cases of venous thrombosis, of which 2,045 were the users of contraception. According to the authors, the risk of venous thrombosis for women not taking hormonal contraceptives was 3 to 10000 , whereas for the hormonal contraceptive users the risk doubled at 6.26 to 10000 . Another input is the period of using where the occurrence of venous thrombosis occurs more often at young age, but it also increases with the age of women (2011). Similarly, the question of breast cancer risk with the use of contraceptives has not been clearly concluded. According to the latest data, long-term use of hormonal contraception at present and in the past (up to 5 years after discontinued) can increase the risk of pre-menopausal breast cancer 20\% (Habánová, Švikruhová, Sláviková, 2011).

It is true that with the development of medicine and pharmacy during the last few years there were reduced doses of estrogen in hormonal contraceptive formulations and thereby also reduced potential health complications resulting from its use. This does not change the fact that the health risks are still very severe and irreversible and that it is therefore important to truthfully inform the public about them. Citterbart considers depression, venous thromboembolism, cardiovascular disease, visual disturbances, hypertension, but also a rare risk of hepatocellular adenoma to be the most serious risks (2001). Čepický complements these side effects and talks about ovarian cysts, ectopic pregnancy and osteopenia (2002). Tesařová further adds intrauterine suppository cancer and breast cancer (2012). Anita Hardon in her scientific work "Women's Views and Experiences of hormones Contraceptives: What We Know and What We Need to Find Out" not only describes the side effects of hormonal contraceptives, but also highlights the differences in responses in the context of socio - cultural fields between the female respondents. In Netherlands, for example, from a sample of 1.200 women $58 \%$ of the asked were convinced that it is not healthy to take hormone pills every day (2007).

Indeed, some evidence suggests that hormonal contraceptives may negatively affect the choice of a partner, and thus has an indirect potential impact on healthy offspring (Welling 2013). The scientific study "Do the emotional side-effects of hormonal 
contraceptives come from pharmacologic or psychological mechanisms?" brings the evidence that hormonal contraception, especially its conscious use has its psychological reactions. The results of this study suggest that user's depression is not caused by substances that hormonal contraceptives include, but the very fact that the user is aware of taking hormonal contraceptives. The significant association results in fact that hormonal contraceptives mean psychological stress for women (Robinson, Dowell, Pedulla, McCauley, 2004). Rosa Sabatini and Raffele Cagiano point out in their study "Depression as Adverse Effect of Hormonal Contraception" that depression is associated with hormonal contraception more widely than we can ever imagine. They state that the study made by Parry in 2001 assumed that altered reproductive hormones may influence the temporal relationship, thereby contributing to the development of mood disorders in susceptible individuals (2010). In connection with hormonal contraceptives and their side effects, there comes a question whether potential users of hormonal contraceptives declare their informed consent for doctors who prescribe them hormonal contraceptives. Larimore deals with the effects of oral contraceptives in relation to the informed consent in the scientific study "Post fertilization effects of oral contraceptive and their relationship to inform." He predicts and assesses the available evidence of post fertilization hormonal contraceptives. He highlights the informed consent as a full note of the information about the abortifacient effect of contraception chosen, on the basis of which the patient voluntarily decides whether she wants to choose this way (2000).

\section{Theoretical - methodological basis}

Question dimension of awareness of hormonal contraceptives users of all the possible impact on human health, of all ethical and moral conflicts that come with hormonal contraceptives in relation to the previous theme, namely that nascent human life, but also life in the general sense, was the basis for conducting more extensive research. For the primary aim of our research we chose these three paradigms:

- Mapping the respondents' subjective perception of the effects of hormonal contraceptive use and its impact on the female body

- Mapping the awareness of respondents on the mechanism action of hormonal contraception and its abortive effect

- Identifying the link between faith in God and hormonal contraception.

\section{Methodology used}

Within our research, the primary means of collecting data was a questionnaire. In the quantitative analysis of the survey results analysis and discussion of the results is in some way defined by variables, the frequency and the relationships between them. The data obtained were classified by means of a single-stage and two-stage classification in tables of frequencies or relative frequencies. Each table dimension replied to classification in category by variables. While watching two categorical variables (e.g. the rate of hormonal contraceptive use and the level of awareness about the side effects of hormonal contraception, faith in God and opinions to the beginning of human life, etc.) the output were two-dimensional charts of frequencies (ie. pivot tables). For dichotomous variables those were called association tables. The relationship between the two variables selected was investigated by using Chi-square test of independence (ie. Pearson's independence test). We considered the result to be statistically irrelevant if the resulting p-value was less 
than the contemplated level of significance 0.05 . To assess the degree (degree, intensity) of dependence there are various factors used. In our case, we chose Pearson's contingency coefficient $\mathrm{Cp}$. The value close to zero meant variable independence. To measure the degree of dependence between two dichotomous variables, we have chosen odds ratio as another appropriate level, which allows you to compare the incidence of the phenomenon observed within two different groups.

\section{Results and discussion}

The research sample consisted of girls and young women aged 15-24 years. We decided for this age group due to the fact that young women and girls were confronted with the issue of hormonal contraceptives within the range of the present or within the last ten years, so we can get a realistic picture of the current state. In addition, due to the age they may express incalculable of their parents. Of course, that more extensive research could be also applied to women who are in middle age and it would be interesting to compare optional differences. Of the 400 responses there were 379 anonymous questionnaires evaluated, the remaining 21 questionnaires were not included into the evaluation because of the data incompleteness.

For the most common source of information on hormonal contraception (210 respondents, $55.4 \%$ ) is considered to be a doctor. Due to the high rate of hormonal contraceptive use we may infer that the medical community is inclined to oral contraceptive use, to the fact that the positive health impact, in their view, exceeds the negative impacts. The second most frequent source of information are girlfriends (185 respondents, 48.8\%). This fact is not surprising, because relations, sexuality and the future are one of the most common topics of talks among girls and young women. As a third source the respondents state the internet (171 respondents, 45.1\%). Due to the amount and in many cases, unverifiable information published on the internet, this source was considered unreliable. Another source of information are parents (155 respondents, $40.9 \%$ ). The last but not least source of information is school (88 respondents, 23.2\%), which runs classic sex education promoting rather the use of hormonal contraceptives.

$61.5 \%$ (233) of respondents state that they have taken or still are taking hormonal contraceptives and vice versa 38.5\% (146) of respondents have never used contraception, and they still don't. Reliable 95\% interval for the real share value of the population of girls and young women aged 15-24 years, who have taken or still take hormonal contraceptives, is from $56.1 \%$ to $65.9 \%$. The aim of the issue, where we investigated the reason of taking hormonal contraceptive, was to find out whether hormonal preparations can be used for another reason than to prevent pregnancy. $61.5 \%$ (233) of respondents stated unwanted pregnancy as the primary indication of taking hormonal contraceptive. Another reason is the harmonization of the menstrual cycle $(20.6 \%, 78$ respondents) and skin problems (13.7\%, 52 respondents).

$69.1 \%$ of respondents (161 of 233 users) inform their parents about taking hormonal contraceptives. Additional comments usually sounded in the meaning, that in connection with the opinion on the use of hormonal contraception is the mother (father exceptionally) for its use and it is trusted source of information. Because of that we can conclude that the use of hormonal contraceptives has been endorsed and supported by parents. 
$95 \%$ confidence interval for the real value of the population of girls and young women that inform their parents about the use of hormonal contraceptives is from $\mathbf{6 3 . 2 \%}$ to $\mathbf{7 5 . 0 \%}$. On the other hand, $30.9 \%$ of hormonal contraceptives users (72 respondents) do not consult given issue with the parents. According to them, "It's not their parents' business," "it is purely their thing" and "they would never discuss that topic with the parents." We believe that this speaks about the possible miscommunication between children and their parents and the possible disruption of social bonds in the family. $70.4 \%$ of users communicate about hormonal contraception with their practitioner (164 of 233 users). The fact that a higher number of respondents communicates with the doctor or parents is very important, since any ignorance of the practitioner (parent) can have serious consequences. $95 \%$ confidence interval for the true value of the population proportion of girls and young women that inform their doctor about taking hormonal contraceptives is from $\mathbf{6 4 . 5 \%}$ to $\mathbf{7 6 . 3 \%}$. More than $50 \%$ (123 of 233 users, $52.8 \%$ ) of those taking hormonal contraceptives have also consulted it with their sexual partners. As they reported in the additional comments, the partner should be informed, because it has to be a common decision. Only $15.8 \%$ (23) of respondents, who don't use hormonal contraception, still haven't lived sexual life, nor have they had a sexual partner. The remaining numbers of 123 respondents not using hormonal contraception, $97.6 \%$ of those (120) consult the issue of hormonal contraceptive use with the sexual partner and only $3(2.7 \%)$ respondents do not do so. It is gratifying that such a high percentage of girls and young women in both groups (taking a hormonal contraceptive, not taking a hormonal contraceptive) does not leave such a serious decision only on them but also share this responsibility with their partners. It is very interesting especially in the group of girls and young women not using hormonal contraception, which had evidently reached agreement between the partners on attitudes towards family planning.

In the next part of the research we were interested in whether the respondents are informed by a gynecologist about the mechanism of action of hormonal contraceptives, side effect, respectively, the negative health impact of hormonal contraceptives on the female body. Satisfaction with providing information on the mechanism of action of hormonal contraceptives was expressed by $55.4 \%$ (210) of respondents. Almost the same number (207 respondents, $54.6 \%$ ) is according to their subjective opinion well informed about the health impact of hormonal contraceptive use on the body. $58.0 \%$ (220) of respondents, of which 168 taking hormonal contraceptives, have been instructed about the possible side effects of hormonal contraceptives. The test results confirmed the relationship between awareness of the possible side effects by doctors and level of use, respectively nonuse of contraceptives $(p=0.001<0.05)$. The chances that respondents taking hormonal contraception are better informed about the possible side effects is almost 4.6 times higher than among respondents not using hormonal contraception. We can assume that awareness of the potential effects is associated with the use of hormonal contraceptives. The values of the Pearson contingency coefficient indicate that there is a slight dependency $(\mathrm{Cp}=$ 0.34). If we look at the answers of respondents, almost three quarters of respondents (72.5\%) taking hormonal contraceptives feel well informed about the side effects of hormonal contraceptives. This may also be inconsistent and biased presentation of information; respectively the girls and young women do not realize the negative impact 
of potential side effects and are not able to evaluate them well in relation to their health and their future. Up to $64.3 \%$ (94 of 146) of respondents not taking hormonal contraceptives do not feel well informed and instructed about the possible side effects of hormonal contraceptives by their doctor. This appreciation can be a reason for non-taking hormonal contraceptives. At this point, we must recognize the very strong personality in the notice of respondents, where a respondent may tend to "improve information" and thus appear in a better light. Only 45.6\% (173) of the respondents were instructed by their gynecologist about the increased risk of hormonal contraceptive use in the field of inherited thrombophilia mutations (higher blood clotting). Of those respondents who are taking hormonal contraception, only $22.3 \%$ (52) were examined for the presence of genetic thrombophilia mutations. This means that although $77.7 \%$ (181) of respondents did not attend any examination on the risk, their gynecologist / doctor still prescribes them a hormonal contraceptive. Of the 233 respondents who use hormonal contraception only 110 respondents are aware of their possible abortifacient effect. We believe that all girls and young women at this age that come in contact with hormonal contraceptive in any way should be truthfully and comprehensively informed of all the negative aspects and the impact of hormonal contraception so that they can make responsible decisions. A part of the research was also gathering the point of views of respondents to the life formation. According to 35.9\% (136) of respondents, human life begins at the moment of conception. 33.6\% (49) of that number are the respondents who do not use hormonal contraception and 37.3\% (87) are the users of hormonal contraceptives (Table 1). In this case we see a contradiction in taking hormonal contraception and opinion that human life begins at conception. Explanation may be twofold. Either the users of hormonal contraceptives do not mind possible abortifacient effect of hormonal contraceptives and don't think about the fact that their behavior can help eradicate already conceived life, or they are not sufficiently aware that hormonal contraceptives can have the abortifacient effect. In this case, we believe that the attention must be focused on the role of doctors and the information provided by them, regardless of their own ethical values and all other sources of information, where young women and girls may obtain objective information. The other results show that $23.0 \%$ (87) of respondents indicate the implantation of the

Table 1 Views on the beginning of human life

\begin{tabular}{|l|c|c|c|c|c|c|}
\hline & \multicolumn{2}{|c|}{$\begin{array}{c}\text { Use of hormonal } \\
\text { contraceptive }\end{array}$} & \multicolumn{2}{|c|}{$\begin{array}{c}\text { Non-use of hormonal } \\
\text { contraceptive }\end{array}$} & \multicolumn{2}{c|}{ Together } \\
\hline & $\mathrm{n}$ & $\%$ & $\mathrm{n}$ & $\%$ & $\mathrm{n}$ & $\%$ \\
\hline Conception & 87 & 37,3 & 49 & 33,6 & 136 & 35,9 \\
\hline Implantation (nidation) & 49 & 21,0 & 38 & 26,0 & 87 & 23,0 \\
\hline Heartbeat & 56 & 24,0 & 24 & 16,4 & 80 & 21,1 \\
\hline Fetal period & 35 & 15,0 & 31 & 21,2 & 66 & 17,4 \\
\hline Since birth & 6 & 2,7 & 4 & 2,8 & 10 & 2,6 \\
\hline Together & 233 & 100 & 146 & 100 & 379 & 100 \\
\hline
\end{tabular}


zygote in the endometrium as the moment of life formation. $21.1 \%$ (80) of respondents said the life begins at the moment when the heart begins to beat, so the third week after conception. $17.4 \%$ (66) of respondents agree the beginning of human life with fetal period (from the third month of pregnancy). $2.6 \%$ (10) of the respondents deem the last milestone, that moment of birth, as the beginning of human life. Anyway the last number is small, it is striking and the question is what causes their opinion. The analysis of research results show that the dependence between the views of a moment of human life and use, respectively not taking hormonal contraception was not confirmed $(\mathrm{p}=0.216>0.05)$.

$63 \%$ (242) of respondents indicated knowledge that hormonal contraceptives can make already fertilized egg lifeless. This fact is known by $81.5 \%$ (119) of the respondents who do not use hormonal contraceptives. Instead, only 52.8\% (123) of the users of hormonal contraception are aware of this fact and only 47.2\% (110) of the respondents are not informed at all. The chance that the respondent who does not take any hormonal contraception is better informed about the negative effects of hormonal contraception on fertilized egg is up to 3.9 times higher than for respondents taking hormonal contraceptives. While identifying dependencies between the known effects of hormonal contraception on an already fertilized egg and its use, Pearson's contingency coefficient confirmed mild dependence $(\mathbf{p}<<\mathbf{0 . 0 0 0 1}, \mathbf{C p}$ $=0.28$ ).

An important variable in relation to the research topic was the belief in God. 31.1\% (118) of 379 respondents marked themselves as those ,who believe in God" and 68.9\% (261) as those „who are faithless.“ Of the respondents who said they did not believe in God, 64\% take hormonal contraceptives. On the other hand, hormonal contraceptives are used by $55.1 \%$ (65) of the respondents believing in God. The chance that respondents who believe in God have taken or are taking hormonal contraceptives is $\mathbf{0 . 6 8}$ times lower than in the case of respondents who said they did not believe in God. In the selection group of respondents, we were unable to demonstrate a relationship between faith in God and use, respectively not taking hormonal contraception $(p=0.09>0.05)$. We believe that although the respondents claim to faith in God, for them, hormonal contraceptive use it may be a private matter that may not be linked with generally accepted religious values. The analysis shows that $51.7 \%$ of respondents believing in God think that the beginning of human life begins at conception. The same view is held only by $28.7 \%$ of respondents who said they did not believe in God. In examining the dependence we have concluded that there is a correlation between faith in God and the idea that the beginning of human life begins at conception ( $p<<0.0001)$, with respect to mild dependence $(\mathrm{Cp}=\mathbf{0 . 2 2})$. We can assume that believing in God users of hormonal contraceptive considered conception as the beginning of human life. The chance that a believer in God respondent has mastery of view of human life beginning at conception is $\mathbf{2 . 6 5}$ times higher than that of respondents who do not subscribe to the faith. We must admit that there occurs a discrepancy with previous results which showed that faith in God and hormonal contraceptive use are unrelated. Respondents who believe in God on one hand considered conception for the formation of human life and on the other hand, there isn't a significant difference in the use of hormonal contraceptives of the respondents who do not believe in God. We believe that the reason may be lack of awareness of the respondents, inconsistent practice of faith and move away from its values. 


\section{Conclusion}

In connection with the use of hormonal contraceptives, it is necessary to point out at our actions that may have other consequences than we wish, and our behavior is based on the free will to decide, especially in the responsibility paradigm for our actions. It is important to realize the consequences and bear responsibility for the consequences. To accept responsibility means facing a constant and unlimited choice between one decision and another. Woman's self-determination itself, using hormonal contraception, should be based on consistent information that is shaping our decision in the context of the direct consequences.

Modernization of society brought about radical new ways to interfere with the reproductive life of a woman, while a woman has been put into the role of the person who has the responsibility in her hands. How is the issue of reproductive behavior of a woman in the 21 st century, it depends on many factors. Free decision on the use of hormonal contraceptives should be the subject to the widest possible awareness and education of young people who are at the beginning of their reproductive life and are often confronted with the question of the use or non-taking of hormonal contraceptives.

\section{References}

1. ANDIE. (2012) Leiden mutation. [Online] [cit. 12.4.2013] Available at: http:// www.wikiskripta.eu/index.php?title $=$ Leidensk\%C3\%A1_mutace\&ol$\mathrm{did}=205605$.

2. CITTERBART, K. (2001) Gynecology. Prague: Galén. ISBN 80-7262-094-0.

3. ČEPICKÝ, P. (2002) Introduction to contraception for doctors non-gynecologists. Prague: Levret. [Online]. (cit. 2013-02-10). Available at: http://www.levret.cz/publikace/knihy/2002/uvod-do-antikoncepce/
4. BALTHASAR, S. (2007) Frauen haben die Wahl. [Online]. [cit. 2015. 09. 26.] Available at: http://www.pharmazeutische-zeitung.de/index.php?id=4055

5. GRINDLAY a kol. (2013) Pharmacists' Attitudes towards Three Models of Expanded Access

6. HABÁNOVÁ, M. - SLÁVIKOVÁ, E. ŠVIKRUHOVÁ, J. (2010) Hormonal contraception and its relation to breast cancer. In: Klin Onkol, 23, 6, 428 - 432.

7. HARDON, A. (2007) Women's Views and Experiences of Hormonal, Contraceptives: What We Know and What We Need to Find Out . In: ( ed) Cite this article as Rocca CH, Schwarz EB, Stewart FH, et al. Beyond access: Acceptability, use, and nonuse of emergency contraception among young women. Am J Obstet Gynecol, 196: 29. e1 29. e 6, 68 -77.

8. HYÁNEK, J. et al. (2010) Thromboembolic events by girls and young women taking hormonal contraceptives, Czech-slovak Pediat, 65, 6, 369-383.

9. KOLÁŘOVÁ, M. (2003) Painful menstruation I. Prague: Triton. 51.

10. KOŠČ, J. M. (2013) Contraception, Catholic Church teaching and pastoral practice, Ružomberok: Verbum, KU, ISBN 978-80561-0010-3 (broch.)

11. LARIMORE, W. L. (2000) The abortifacient effect of the birth control pill and the principle of double effect: Ethics and Medicine, 16, 1, $23-30$.

12. NetDoktor. (2011) Hormone - Vor- und Nachteile. [Online]. [cit.2011. 08. 29.] Available at: http://www.netdoktor.de/ Gesund-Leben/Verhuetung/Ratgeber/Hormone-Vor-und-Nachteile-3980.html

13. PROCHÁZKA et al. (2007) Cerebral venous thrombosis by hormonal contraceptive users. Czech and Slovak Neurology N 2007; 70/103, 5, $521-527$.

14. ROBINSON, A. S. - DOWELL, M. PEDULLA, D. - CAULEY, L. Mc. (2004) Do the emotional side-effects of hormonal 
contraceptives come from pharmacologic or psychological mechanisms? In: Medical Hypotheses, Volume 63, Issue 2, 268 - 273.

15. SABATINI, R. - CAGIANO, R. 2010. Depression as adverse effect of Hormonal contraception. [Online]. [cit. 2013-08-30]. Avilable at: http://www.health.am/gyneco/more/ depression-as-adverse-effect-of-hormonal contraception/

16. STRUNECKÁ, A. - PATOČKA, J. (2011) Poison age. Prague: Triton, 266.

17. SZAREWSKÁ, A. - GUILLEBAUD, J. (1996) Contraception - a practical guide, Prague: Victoria Publishing, 218.
18. TESAŘOVÁ, P. (2012) Hormonal contraception and cancer. What are the risks? [Online]. [cit. 2013-03-20]. Available at: http:// www.toplekar.cz/ to Hormonal Contraception in Pharmacies

19. WELLING, L. L. (2013) Psychobehavioral effects of hormonal contraceptive use. In Evolutionary Psychol, 11, 3, $718-742$.

20. WINNEROVÁ, F. L. (2007) (The Bare) truth about sex, Bratislava: Porta Libri, ISBN 978-80-89067-48-0. 


\section{Assessment of thromboembolic disease in the context of evidence-based nursing}

\section{L'. Tkáčová1, B. Grešš Halász', M. Murgová2, M. Gliganičová2}

\section{Original Articles}

${ }^{1}$ St. Elizabeth University of Health and Social Work in Bratislava, Slovak Republic

${ }^{2}$ Department of Blessed P. P. Gojdič and Blessed Dominic Trčka Michalovce, Slovak Republic

\section{Correspondence to:}

St. Elizabeth University of Health and Social Work, Department of Blessed P. P. Gojdič and Blessed Dominic Trčka Michalovce, Nám. slobody 3, P. O. Box 104, 810 00, Bratislava, Slovak Republic

Submitted: 23.4.2016

Revised: 1.6.2016

Accepted: 15.8.2016

\section{Reviewers:}

Pawel S. Czarnecki

Rector of the Warsaw Management University, Poland

A. Wolf

Association of palliative and hospice care, Kiev, Ukraine

\section{Key words:}

Deep vein thrombosis, pulmonary embolism, practice based on evidence, thromboembolism

CSWHI 2016; 7(2): 91-96 (c) 2016 Clinical Social Work and Health Intervention

\section{Abstract:}

The aim of the study was to find out how nursing behavior is perceived by nurses and patients with thromboembolic disease. The sample consisted of 264 patients, and a comparative sample consisted of 92 nurses. The standardized measuring tool Caring Behaviors Inventory (CBI-24) was used for the data collection, supplemented by questions of its own design. Exploratory methods and chi-square test of independence were used for the needs of statistical processing. Based on the results it can be concluded that the perception and assessment of the provided nursing care was more positively evaluated by the patients.

\section{Introduction}

We encounter the issue of thromboembolic disease in virtually all fields of medicine. It is a condition characterized by a blood clot - thrombus in a certain place of blood circulation, but especially in the deep veins of the legs and its subsequent pulmonary embolism. It directly threatens the patient's life, reduces its quality, prolongs 
hospitalization, aggravates postoperative course, which of course increases the cost of a medical facility. According to the European Statistical Institute, TED is the second most common medical complication, the second leading cause of prolonged patient hospitalization and the third leading cause of death (Eurostat Statistics Explained, 2015). The most important prevention of TED in nursing care is the early mobilization of the patient, the proper bandaging of legs, patient positioning and adequate hydration. A nurse should seek the care management and coordination of the various procedures, to reduce the risk of dehydration to a minimum (Kabátová, Puteková 2015). A risk factor is not only posed by operating performance, but also older age, obesity, fractures of the lower limbs and malignancy. The problem in the prevention of thromboembolic disease is the lack of information on preventive measures or risk factors (Widimský, Malý et al., 2005). Nursing access to evidence-based practice is different from the standard biomedical model. The nurse provides holistic care, but rather works with the patient than on them. Within decision-making, the nurse must consider not only the effectiveness of treatment, but also the choice of interventions, acceptability by the patient and also cost effectiveness. Therefore, evidence-based nursing practice is a process in which the best practices are associated with nurse expertise and the patient's preferences, ensuring optimal care (Jarošová, Zeleniková, 2014).

\section{Patients and Methods}

The aim of this study was to identify problem areas in meeting the needs of patients with TED, finding out how patients with TED perceive the provided nursing care and how nurses perceive the nursing care of patients with TED. The sample consisted of 264 patients, and a comparative sample consisted of 92 nurses. Respondents were chosen through purposive sampling. The research was conducted from October 2015 to January 2016. The selected research method was quantitative research. The use of tools for data collection was standardized questionnaire, supplemented by questions on its own design. The standardized measuring tool Caring Behaviors Inventory (CBI-24) was used for the data collection. CBI is based on Watson's transpersonal theory of care. CBI-24 items are grouped into four dimensions of nursing care:

1st dimension - security, includes 8 items, security in dealing and patient care; coming into the patient's room of their own will; communicating with patients; prompting the patient to voice their problems; helping with pain management; expressions of interest in the patient; timely implementation of therapeutic procedures and drug administration; the management of symptoms of the disease;

2nd dimension - knowledge and skills, includes 5 items, skill when administering injections; professional knowledge and skills; intelligent use and handling of equipment and devices; confidential treatment of the patient; responding quickly to the patient's call;

3rd dimension - respect, includes 5 items, attentive listening to the patient; individual approach to the patient; encouraging the patient; manifestation of empathy and identification with the patient; enabling patient to express their feelings about the illness and treatment; performance of expressed and unexpressed needs of the patient;

4th dimension - connectedness, includes 6 items, providing information and patient education; spending time with the patient; assisting the patient in their development; manifestation of patience and perseverance in patient care; involving the patient in their care planning (Wu, Larrabee, Putman, 2006). From among the statistical methods, 
the chi-square test was used. $\mathrm{P}<0.05 \%$ is the $\%$ difference of patients versus nurses; it is statistically significant at the $5 \%$ significance level. $\mathrm{P}>=0.05$, the difference is not statistical. The multinomic division homogeneity test was used to test the hypotheses. Classic test of independence or homogeneity is based on the test of good conformity, thus comparing the expected frequencies in each cell in the table (assuming that the observed values of both characters are independent of each other) and actual frequencies. Categorical variables were assessed using the $\chi 2$ test. Statistical tests were evaluated at the statistical significance level $\alpha=$ 0.05 (Pavlíček, Dobríková, 2007).

\section{Results and Discussion}

The assumption that within nursing care, patients with TED better evaluate nursing interventions as meeting their needs was verified by the $\mathrm{t}$ - test statistical method. The result is shown in Table 1. Patients whose evaluation was generally higher included nursing skills regarding the administration of injections, professional knowledge and skills, alleviation of the disease symptoms in a patient, help with pain management in the patient and timely implementation of therapeutic procedures and administration
Table 1 Comparison of nursing interventions and the patient's needs

\begin{tabular}{|l|c|l|}
\hline & $\begin{array}{l}\text { Nursing } \\
\text { interventions }\end{array}$ & $\begin{array}{l}\text { Patient's } \\
\text { needs }\end{array}$ \\
\cline { 1 - 2 } $\begin{array}{l}\text { Average } \\
\text { evaluation }\end{array}$ & 1.25 & 1.36 \\
\cline { 1 - 2 } $\mathrm{T}-$ test & \multicolumn{2}{|c|}{$\mathrm{P}=0.001$} \\
\cline { 1 - 2 } difference & \multicolumn{2}{|c|}{0.11} \\
\hline
\end{tabular}

Source: Our own research

of drugs as the most important items. The listed items are part of the Security dimension and Skills and Experience dimension. We accept the assumption.

Next, we compared the perception of nursing care in relation to the intervention procedures from the perspective of patients and nurses, following the CBI - 24 standardized questionnaire. Based on an overall evaluation of the provided nursing care from the perspective of both studied groups, the $\mathrm{t}$ - test did not discover any statistically significant difference $\mathrm{p}=0.14$ in the perception of the monitored areas. The result is shown in Table 2.

When evaluating the various dimensions of the questionnaire, i.e. respect,

Table 2. Evaluation of nursing care in relation to the intervention procedures by both groups comparison

\begin{tabular}{|l|c|c|c|c|}
\hline \multicolumn{1}{|c|}{$\begin{array}{c}\text { Dimension of CBI } \\
\text { questionnaire }\end{array}$} & patients & nurses & $\mathrm{t}$ - test & $\mathrm{p}$ - value \\
\hline CBI & $4.61(0.75)$ & $5.03(0.44)$ & 6.31 & 0.0000 \\
\hline respect & $4.39(0.88)$ & $4.90(0.56)$ & 6.53 & 0.0000 \\
\hline connectedness & $4.31(0.90)$ & $4.67(0.54)$ & 4.83 & 0.0000 \\
\hline $\begin{array}{l}\text { knowledge and } \\
\text { experience }\end{array}$ & $5.06(0.76)$ & $5.27(0.63)$ & 3.10 & 0.0020 \\
\hline security & $4.69(0.81)$ & $5.21(0.56)$ & 7.07 & 0.0000 \\
\hline
\end{tabular}

Source: Our own research 
connectedness, security, knowledge and experience, we found that the results of the questionnaire are not very different for the patients and nurses, despite the more positive perception of the patients who considered the nursing activities in a more positive manner. Statistical difference between patients and nurses is found in the dimension of knowledge and experience $\mathrm{p}=0.030$ and the dimension of connectedness $p=0.002$; in other areas we did not find a statistical difference. Based on the above, the assumption cannot be accepted.

We also assumed that the nurses attending to patients with TED are more concerned with the pragmatic than the humanistic area. The terms "care" and "nursing care" represent the activities and values of nursing. Nursing is the moral and ethical basis of caregiving and its essence. Although it is difficult to clearly define nursing - care in caregiving, experts agree that it should include two basic components - instrumental and expressive. The instrumental component refers to the physical and technical aspects of care, while the expressive element is associated with the implementation of the psychosocial and emotional needs of the patient. Based on these findings, we focused on comparing the technical focus of nurses and the humanistic approach. When evaluating we used the dimension of knowledge and experience that we assigned to the pragmatic area and the dimension of respect, which is the humanistic area. Based on statistical processing using $\mathrm{t}$ - test $(\mathrm{p}=0.025)$, we found that the pragmatic area, meaning experience and knowledge, is better evaluated by nurses than the area of the humanistic approach to the patient. The result is shown in Table 3. We accept the assumption.

We assumed that nurses are more focused on performance than on establishing a relationship of security and safety for patients. In the evaluation we used the comparison results of the Knowledge and Experience
Table 3. Evaluation of nurses in humanistic and pragmatic field of nursing care

\begin{tabular}{|l|c|c|}
\hline & $\begin{array}{l}\text { pragmatic } \\
\text { focus }\end{array}$ & $\begin{array}{l}\text { humanistic } \\
\text { approach }\end{array}$ \\
\cline { 1 - 2 } $\begin{array}{l}\text { Average } \\
\text { evaluation }\end{array}$ & 5.4 & 4.8 \\
\cline { 1 - 2 } $\mathrm{T}-$ test & \multicolumn{2}{|c|}{$\mathrm{P}=0.024$} \\
\cline { 1 - 2 } difference & \multicolumn{2}{|c|}{0.6} \\
\hline
\end{tabular}

Source: Our own research

dimension and Security dimension. From the perspective of nurses, items focused on performance were more positively rated than items with a focus on security. From the statistical compilation based on the $t$ test $(p=0.036)$ it is possible to accept the assumption.

Table 4. Evaluation of nurses focused on performance and establishing a relationship of security in nursing

\begin{tabular}{|l|c|c|}
\hline & $\begin{array}{l}\text { focus of nurses } \\
\text { on performance }\end{array}$ & $\begin{array}{l}\text { providing } \\
\text { security to } \\
\text { the patient }\end{array}$ \\
\hline $\begin{array}{l}\text { Average } \\
\text { evaluation }\end{array}$ & 5.4 & 5.2 \\
\cline { 1 - 1 } T-test & \multicolumn{2}{|c|}{$\mathrm{p}=0.034$} \\
\cline { 1 - 1 } difference & \multicolumn{2}{|c|}{0.2} \\
\hline
\end{tabular}

Source: Our own research

The first surveyed area in our research was respect, in which the results of the responses of patients and nurses indicate almost identical perceptions of the two compared groups. We agree with Baňovičová and Bubeníková (2011), who state that the ability to empathize with others is an important prerequisite for the job as a nurse and at the same time empathy can be seen as a kind of communication. The second area surveyed in the questionnaire was the 
Connectedness dimension - it means to be available to the patient and help them to actively participate in their care, and has emerged from the expert discussion of nursing professionals and professional English teachers. Berman, Snyder et al. (2012) state, inter alia, that the Connectedness dimension means ensuring a supportive, protective and positive environment for the patient. In this area, we noticed slight differences in perception on the part of patients and nurses. The third surveyed area of our research was the skills and experiences of nurses in nursing care. On closer examination of the results of our research it can be assumed that it is mainly influenced by the length of experience, age and education of individual nurses. However, the issue of motivation and interest come to the fore in connection with the above mentioned facts, in addition to adequate education and skills (Kabat, 2015). The last surveyed questionnaire area was the area of security. Here we recorded similar perception on the part of both patients and nurses based on the results of the questionnaire responses; a statistically significant difference $(p=0.046)$ was also seen in a negative response to the question of communication with the patient. This area was more positively assessed by nurses than patients. Communication is a crucial but often underestimated element in providing quality nursing care for older people. It is the basis of the relationship between nurse and patient. It is particularly important for elderly patients because of their ability to understand and stick to their treatment and their satisfaction with nursing care providers are largely influenced just by communication (Kabátová, 2015). Pokorná (2008) states in her research investigations that nurses rate their overall communication skills better than patients. From this it can be inferred that communication is among the weaker skills of nurses in nursing care.

\section{Conclusion}

The study found that there are differences in the perception of nursing behavior between nurses and patients. Comparison of the views of patients and nurses is important as feedback for caregivers and for the development of nursing care focused on the patient. The patients' perception of care is important information for nursing practice and research, because the main recipient of nursing care is the patient. One of the main assumptions of this model is the patients' perception of quality of care. The results of the research show that technical skill is better evaluated by nurses than humanistic approach to the patient. Conversely, patients evaluated the nursing fields focused on performance better than the creation of a sense of safety and security for the patient. The area of communication appeared problematic. The ability of communication between the patient and the nurse is affected by disease progression. The nurse must always keep in mind that even if the patient is unable to communicate verbally, they still perceive and experience emotions (Martinková, 2016). It should also be noted that patients generally evaluated nursing behavior in caregiving better and more positively than nurses.

\section{References}

1. BÁNOVIČOVÁ, L.- BUBENÍKOVÁ, M. 2011. Empathy in Nursing. In Nursing and Midwifery. [online]. 2011, vol. 2, issue 1, p. 165 -170. [cit. 2016-02-28]. Available on the Internet:http://periodika.osu.cz/osetrovatelstviaporodniasistence/dok/201101/4 banovcicova_bubenikova.pdfn. ISSN 1804-2740.

2. BERMAN, A.- SNYDER, S. et al. 2012. Kozier \& Erb's Fundamentals of Nursing: Concepts, Process, and Practise. 9th ed. New Jersey (USA): Pearson International 
Edition. 2012. 1631 p. ISBN: 978-0-13261137-4.

3. EUROSTAT STATISTICS EXPLAINED. 2015. Statistics of Causes of Death. [online]. 2015 [cit. 2015-09-28]. Available on the Internet: http://ec.europa.eu/eurostat/ statistics-explained/index.php/Causes_of_ death_statistics/sk.

4. JAROŠOVÁ, D.- ZELENÍKOVÁ, R. 2014. Evidence Based Nursing. Grada Publishing, a.p. Prague, 2014. p. 136 ISBN 978-80247-5345-4.

5. KABÁTOVÁ, O. 2015. Expressions of Elderspeak in Nursing Practice. In New Trends in Nursing II. Trnava : Trnava University in Trnava, Faculty of Health and Social Work, 2015. p. 76 - 82. ISBN 978-80-8082-864-6.

6. KABÁTOVÁ, O. 2015. Interest of Nursing Students in Working with Seniors. In Nursing and Midwifery. - ISSN 1336-183X. - issue 6 (2015), p. 53-55.

7. KABÁTOVÁ, O.- PUTEKOVÁ, S. 2015. Nursing Care in Geriatrics II. 1. pub. - Trnava: Typi Universitatis Tyrnaviensis, 2015. - p. 84 ISBN 978-80-8082-918-6.
8. MARTINKOVÁ, J. 2016. Management of Problem Behavior in Patients with Dementia in a Medical Facility. In Deinstitutionalisation of Social Services in the Context of Helping Professions. Bratislava: St. Elizabeth University of Health and Social Work, DP Michalovce, 2016. p. 230 - 237. ISBN $978-80-8132-144-3$.

9. PAVLÍČEK, J.- DOBRÍKOVÁ, P. 2007. Social Research and Statistical Data Processing. Bratislava: St. Elizabeth University of Health and Social Work, 2007. p. 81 ISBN 978-80-89271-16-0.

10. POKORNÁ, A. 2008. Effective Communication Techniques in Nursing. 2. pub. Brno: NCO NZO, 2008. p. 100 ISBN 978-807013-466-5.

11. WIDIMSKÝ, J.- MALÝ, J. et al. 2005. Acute Pulmonary Embolism and Venous Thrombosis. 2. pub. Prague: Triton, 2005. p. 384 ISBN 80-7254-639-2.

12. WU, Y.- LARRABEE, J. H.- PUTMAN, H. P. 2006. Caring Behaviors Inventory. A reducing of the 42-Item Instrument. In Nursing Research, vol. 55, issue 1, p. 13-25. 


\section{Satisfaction level of participants in workers social security agency (BPJS) employment services in health care in Indonesia}

\section{Siagian}

Original Articles

Faculty of Social and Political Sciences, University of Sumatera Utara, Indonesia

\section{Correspondence to:}

Lecturer of Department of Social Welfare, Head of the Laboratory of Social Welfare Faculty,

School of Social and Political Science, Universitas Sumatera Utara,

Jl. Dr. A. Sofian No. 1 Telp/Fax: 061-8221346 - Medan-Indonesia Postal Code 20122;

e-mail: matias.siagian@ymail.com

Submitted: 24.7.2016

Revised: 7.8 .2016

Accepted: 17.8.2016

\section{Reviewers:}

A. Shahum

University of North Carolina at Chapel Hill School of Medicine, USA

P. Kalanin

Pavol Jozef Šafárik University in Košice, Slovak Republic

\section{Keywords:}

Health care, BPJS Employment program, welfare, satisfaction levels.

CSWHI 2016; 7(2): 97-104 @ 2016 Clinical Social Work and Health Intervention

\section{Abstract:}

This study aims to determine the level of satisfaction of health services by participants of BPJS Employment and families living in the village of Tanjung Gusta, to the area of Medan. The study sample consisted of 41 participants working families of BPJS Employment determined using purposive sampling technique, with the use of a minimum of three times the health care facility as a condition. Data were collected using a questionnaire and analyzed using descriptive statistics. To determine the level of employee satisfaction, the measurement of data was using Likert scale.

The study concluded, in general, Social Security service has not been satisfactory. Neither the implementation of stages of socialization and registration, turns out to be not satisfactory, in the sense that it is still in the stage of neutral or unsatisfactory. While special in the implementation of health services it turns out that it is not satisfying workers and families. 


\section{Introduction}

One of the changes in the employment policies in Indonesia is the abolition of Social Security Workers and replaced with a new policy, namely Workers Social Security Agency (BPJS) is a public program that provides protection for workers in order to address specific socio-economic risks and the implementation of its mechanisms of social insurance. In accordance with Law No. 24 of 2011 on BPJS, PT. Jamsostek transformed into Workers Social Security Agency (BPJS) since January 1, 2014. The amendment became effective since July 1 , 2015. Workers have a strategic position, because it is an executor of plans established by managerial. Therefore, it is reasonable to keep an eye on the welfare of employees and their families so that they can optimally contribute their labor in the production process (Simanjuntak, 2005).

Attention to workers are still lacking, whereas their participation in development is strategic . As a result of these conditions, the level of welfare of workers or employees is still relatively low. Including workers' health problems. Health development is an integral part of the development of social welfare (Sinaga, 2005). As the decisive factor in winning the competition, the protection of labor is very important so that the workers can contribute its expertise in the production process through the operationalization of science and technology (Mahyuni, 2006). Labour, as well as other poor people in general do not have access to education and health services through market mechanisms. In these circumstances, the creation of a special mechanism in the form of social security is a creative activity that must be done to meet the needs of the workers (Gofin, Gofin, Neumark 2002).

Zastro (2005) suggests, at least four attempts or services performed in the realization of social welfare, ie: 1)Personal services (such as individual counseling, group counseling, rehabilitation, and social therapy), 2)Protection services (such as consumer protection, legal remedies in order to truly protect the public, housing and health care services), 3)Information services (such as consultancy, information for consumers, education, library services, financial consulting), and 4) Care services (such as child care, care of workers, public welfare programs and social security programs). The state develops a social security system for all citizens and empower the weak and underprivileged in accordance with human dignity (Pakpahan and Sihombing 2012).

If we trace back, then we know that the formation history of BPJS Employment was previously called Jamsostek experienced a long process, starting from Law No.33/1947 jo Law No.2 / 1951 on the work accidents, Ministry of Labour (PMP) 48/1952 jo PMP No.8 / 1956 on setting up of aids for attempts in the implementation of health workers, PMP No.15 / 1957 on the establishment of the Foundation of Social Workers, PMP No.5 / 1964 on the establishment of Social Security of Fund Foundation (YDJS), the enactment of Law No.14 / 1969 on the Principles of Labor. Chronologically the process of the birth of workers' social insurance has become more transparent.

After experiencing progress and development, both related to the legal basis, forms of protection as well as for the organization, in 1977 obtained an important milestone with the issuance of Government Regulation (PP) 331977 on the implementation of workers' social insurance programs (ASTEK), that obliges each employer / private entrepreneurs and state enterprises to follow ASTEK program. It was also published PP No.34 / 1977 on the establishment of the organizer container of ASTEK namely Perum Astek.

Progress of Companies that promote the interests and basic rights of Manpower in 
Indonesia continues. Until now, PT. Jamsostek (Persero) provides protection of 4 (four) programs, that includes Accident Insurance Program (JKK), Death Benefit (JKM), Old Age Security (JHT) and Health Insurance (JPK) for all workers and their families. In 2011, enacted Law No. 24 of 2011 on Social Security Agency. In accordance with the mandate of the law, dated 1 Janury 2014 PT Jamsostek will turn into Public Law Firm. PT Jamsostek still believed to hold workers' social security programs, which include JKK, JKM, JHT with the addition of pensions started July 1, 2015 (Lagunturu, 2014). Companies that are directly concerned with the welfare of workers and their families. Therefore, the company is obliged to make prosper workers and their families. One way to ease the burden on employers in implementing its obligations, among others, to provide accident benefits, health care and guarantees in old age for workers are with the policy of entrepreneurs participate their works in Jamsostek (Lubis, 2007).

A quiet interesting question rose, whether by the enactment of a new regulation in the area of employment the workers would feel the benefits? We try to do a study of the previous policy, where the Workers' Social Security policies still apply. Head of Regional Office I PT. Jamsostek (Persero) H. Mas'ud Muhammad argued that the company's participation in the implementation of the Social Security program for its employees in the Territory of NAD, North Sumatra and West Sumatra, which is the working area is still very alarming. It is evident from the number of workers that reached to 9.3 million, while the number of participants of Health Insurance (JPK) includes single participants of 4,951 people, married 88.725 people, 218.489 families and the insured (the entirely registered in JPK) as many as 356.725 people (Pelita Online Daily, 2009).

A significant difference between the number of companies and workers with participants in Jamsosstek sets up a kind of alternative institutions, organizers of Jamsostek, among others, General Services Agency by the Provincial Government of South Sumatra. This breakthrough is based on the idea of the responsibility of Local Government on community welfare in accordance with the demands of regional autonomy as stipulated in Law No. 32 Year 2004 on Regional Government. However, the welfare of society is a central issue in governance, both by the Central Government and Local Government (Retnaningsih, Misnaniarti, Aini 2012).

The implementation of Jamsostek classified as bad is rooted in monopolistic practices. Jamsostek implemented in accordance with the legislation in force. Currently the rule in question is Act No. 3 of 1992 on Social Security of Labor. Article 4 Paragraph (3) of the Act regulating the requirements and procedures for the implementation of the Social Security program, which is implemented by Government Regulation No. 14 of 1993 and Government Regulation No. 36 of 1995 by establishing PT. Jamsostek (Persero) as a single entity organizer of Social Security. These conditions require legal reforms in the framework of the implementation of Jamsostek (Wijayanti, 2007).

Public services in the form of social security is a form of government protection for workers, whose implementation is motivated by various factors, such as (1) the increasing role of labor both in quantity and quality, (2) the increasing use of technology in various sectors of business activity, and (3) the higher the risk threatens the safety, health and welfare of the workforce (Basjir, 2003). The importance of a good implementation of social security for workers in Indonesia is increasingly urgent considering the majority of workers in Indonesia in the private sector are those with little education (junior and equal $66.75 \%$ ). But until now 
the state has not been able to develop social security programs as appropriate (Suparjan, 2010).

It should be recognized that the implementation of the health insurance program of poor families are still struggling with various problems. Data is inaccurate, socialization is not optimal, full service is not free, extortion, denial, bad service, stand in long lines, cramped space, action is not immediate, late physician and hospital refuse are a basket of issues that deprive the poor (Kodim, 2009). Furthermore it can be argued that the health service satisfaction is the result of the influence of skills, knowledge, attitudes, behavior and the provision of facilities. Patients and families in expressing satisfaction or dissatisfaction with health care depends on the experience before and after receiving medical care in a hospital (Widujani, Mukti, Hendrartini 2004).

Low levels of satisfaction on public services is a common symptom. The results about the comparison of participant satisfaction level of mandatory and voluntary health insurance for the quality of health services in the city of Kendari level I shows: (1) 34.26\% doctor service for users of compulsory health insurance, voluntary health insurance users is $31.00 \%$, (2) Prescribing drug $21.67 \%$ for compulsory health insurance, voluntary health insurance users $18.76 \%$, (3) $7.51 \%$ referral system for compulsory health insurance users, while for the voluntary health insurance $6.46 \%$,
(4) access of services $21,46 \%$ for the compulsory health insurance, voluntary health insurance user $19.40 \%$ (5) $24.18 \%$ of the physical environment facilities for users of compulsory health insurance, voluntary health insurance user 21.81\% (Aga, Hendrartini, Margo 2005).

\section{Research Method}

The research conducted is a descriptive study, using a quantitative approach. The research objective is specifically to obtain a picture of the level of satisfaction of workers and their families in the service of BPJS Employment. The study was conducted in the village of Tanjung Gusta Subdistrict of Sunggal District of Deli Serdang, North Sumatra. Mulyo Rejo village is located on the outskirts of the city of Medan. The study population was family of labor of BPJS Employment participants numbered 196 families. The sampling technique was done by using purposive technique by defining conditions, namely families who have used at least 3 times the facility of BPJS Employment in health care (Siagian, 2012).

\section{Results}

\section{Socialization of BPJS Employment Program}

The level of employee satisfaction with regard to the implementation of this socialization is:

Table 1 The level of employee satisfaction in Socialization of BPJS Employment Program

\begin{tabular}{|c|l|c|c|c|c|}
\hline No. & \multicolumn{1}{|c|}{ Socialization Activity } & Satisfied & Neutral & $\begin{array}{c}\text { Not } \\
\text { Satisfied }\end{array}$ & Total \\
\hline 1 & Timing of information & 12 & 17 & 12 & 41 \\
\hline 2 & How information is provided & 14 & 21 & 6 & 41 \\
\hline 3 & completeness of information & 11 & 18 & 12 & 41 \\
\hline
\end{tabular}




\begin{tabular}{|c|l|c|c|c|c|}
\hline 4 & $\begin{array}{l}\text { Space availability for announcements } \\
\text { and completeness of information }\end{array}$ & 12 & 21 & 8 & 41 \\
\hline 5 & Understanding information & 11 & 16 & 14 & 41 \\
\hline $\begin{array}{c}\text { Amount of } \\
\text { Each Category } \\
\text { of Answers }\end{array}$ & & 60 & 93 & 52 & 205 \\
\hline
\end{tabular}

Source: research results, 2015.

There is a company providing information included as complete, less complete or not complete. This condition gives birth to an impression in a form of working satisfactory level related to the socialization of BPJS Employment. Likert scale calculations produce an average of 0,039 . This suggests that workers in category "neutral", in the sense of excluding "satisfied" and also includes "not satisfied" in the process of socialization of BPJS Employment.

\section{Process of Registration}

The following are the data related to the level of worker satisfaction related to participant registration process.

Becomes participants in BPJS Employment program is workers' rights. In connection to rights the company's involvement in the process of registration of workers as a participant of BPJS Employment is different. This certainly gives a distinct impression in the form of employee satisfaction levels in the process of enrollment into the program participants of BPJS Employment. The results of likert scale calculation produces a mean of 0.284 , which means that employees in the category of "neutral" in the implementation of the registration of a participant of Jamsostek.

\section{Implementation of Health Care}

In Table 3 below are presented overview of the level of satisfaction in health care worker.

This service conditions give effect to the level of satisfaction in health care workers. Another factor is the attitude of officers. These factors are certainly affecting feelings of patients and their families. The attitude is

Table 2 The level of employee satisfaction in the Registration as BPJS Employment Program Participant

\begin{tabular}{|c|l|c|c|c|c|}
\hline No. & \multicolumn{1}{|c|}{ Registration Actvity } & Satisfied & $\begin{array}{c}\text { Less } \\
\text { Satisfied }\end{array}$ & $\begin{array}{c}\text { Not } \\
\text { Satisfied }\end{array}$ & Total \\
\hline 1 & $\begin{array}{l}\text { The involvement of companies in } \\
\text { registration }\end{array}$ & 21 & 12 & 8 & 41 \\
\hline 2 & Registration procedure & 20 & 14 & 7 & 41 \\
\hline 3 & Duration to become participants & 17 & 16 & 8 & 41 \\
\hline \multicolumn{2}{|l|}{ Amount of Each Category of Answers } & 58 & 42 & 23 & 123 \\
\hline
\end{tabular}

Source: research results, 2015. 
Table 3 Levels of Satisfactory in Heath Care

\begin{tabular}{|c|l|c|c|c|c|}
\hline No. & \multicolumn{1}{|c|}{ Service Activity of JPK } & Satisfied & Less Satisfied & Not Satisfied & Total \\
\hline 1 & Engagement / corporate concern & 21 & 14 & 6 & 41 \\
\hline 2 & Administrative procedures & 15 & 15 & 11 & 41 \\
\hline 3 & Administrative services & 11 & 15 & 15 & 41 \\
\hline 4 & Speed of service & 8 & 12 & 21 & 41 \\
\hline 5 & Attitude of officers & 8 & 14 & 19 & 41 \\
\hline 6 & Completeness of drugs & 12 & 16 & 13 & 41 \\
\hline 7 & Quality of drugs & 12 & 15 & 14 & 41 \\
\hline 8 & Quality of medical services & 11 & 17 & 13 & 41 \\
\hline \multicolumn{2}{|l|}{ Amount of Each Category of Answers } & 98 & 118 & 112 & 328 \\
\hline
\end{tabular}

Source: research results, 2015.

a picture of appreciation, hospital officials and business partners of BPJS Employment program to the patient, which in turn affects the level of employee satisfaction in the implementation of health. The result of likert scale calculation generates a mean amounted to -0.004 , which means that employees in the category of "not satisfied" in health care.

\section{Discussion}

The results showed that the implementation of the BPJS Employment program which is a constitutional mandate (Pakpahan, Sihombing, 2012) turns out is still not satisfying workers and families participating in the program. Admittedly, working class communities and other poor communities are often marginalized in various public services. As if the competent authorities forget that workers are the key holder, in the sense of having a great contribution and strategic in the production process ( $\mathrm{Si}$ manjuntak, 2005), thus fulfillment of various types of their needs are necessary, including various service items included in the program of BPJS employment should be taken into great account and need attention sincerely (Sinaga, 2005), which among others realized through the implementation of the quality BPJS Employment and satisfying workers. With the BPJS Employment program, workers will feel comfortable in working, so that it can contribute its expertise to the fullest in the production process through the operationalization of science and technology, (Mahyuni Eka Lestari 2006).

Accordingly, state initiative in establishing Social Security as labor rights is a public policy that benefits companies (Manullang, Sendjun, 2005). Furthermore, the social security system was first put forward Otto von Bismark (Sulastomo, 2008) was a statewide initiative in order to create conducive conditions in the production process by reducing the burden on companies to implement their obligation (Lopez, 2007). However the company's management was less aware of the positive side of such a large program of implementation of BPJS Employment) against the company. It is known by the socialization of Social Security program that is not good, in the sense of not satisfying the employees (according to the size of the 
Likert scale is only in the category of "neutral", with a mean of 0.039). If the company does not have the qualified human resources in the dissemination, management of companies may work together to implement socialization of BPJS Employment program (Wahab, 2002). With this level of education the majority of the workforce in Indonesia is still low (Suparjan 2010) certainly needed a simple bureaucratic procedures making it easier for employees to fill out the form and register at the nearest office of BPJS.

Zastro argued, health care is part of the four attempts or services performed in the realization of social welfare (Zastrow, 2008). Health care is an absolute necessity for workers around the world, because they, like other poor people do not have access if the health service can only be met through market mechanisms. Therefore, the health service through BPJS Employment program is a creative effort in order to meet the needs of labor (Gofin, Neumark, 2002). Unfortunately, the service which is so important is just not going well, which according to the size of the Likert scale results showed that employee is in the category of "not satisfied", with a mean of $-0,004$. The results of this study are identical to the results of research on comparison of the level of participant satisfaction mandatory and voluntary health insurance for the quality of health services in the city of Kendari level I, where the bad condition occurs in all service elements (Aga, Hendrartini, Margo, 2005). This indicates the need for the empowerment of the ranks of health workers, both in terms of skills, knowledge, behaviors and attitudes (Widujani, Mukti, Hendrartini, 2004).

\section{Conclusion}

The results of the analysis of the data on satisfaction levels of workers and their families who participated in BPJS Employment program in Tanjung Gusta concluded, of the three that were studied and analyzed, elements of socialization and registration as the first and second stages in the implementation of BPJS Employment program showed workers and families have not been satisfied, but only in neutral level. If we examine specifically the elements that contribute negatively to the level of satisfaction in the implementation of BPJS Employment BPJS program, it can be seen that the contributors mainly from BPJS partners, such as hospitals and clinics. Weak points are mainly on administrative services, speed of service, the attitude of the officers, the completeness of drugs, drug quality and the quality of medical services. Elements of this activity is substantial.

\section{Suggestion}

Companies should be more proactive in empowering BPJS Employment program implementation, among others, by socializing early on to employees since someone was hired and have started working in the company. The human resources department in any company should be trained specifically in order to truly understand the Social Security program and is able to provide comprehensive information to employees so that they really understand it.

\section{References}

1. AGA, N. A., HENDRARTINI J., MARGO V. 2012. Comparison of Participants Satisfaction Rate Mandatory and Voluntary Health Insurance on Quality of Health Care Level I. Journal of Health Services Management. 8(4), pp. 186-201.

2. BASJIR, W. 2003. Informalization, Social Security and Labor Organizing. Journal of Social Analysis. 8(8). pp. 44-56.

3. GOFIN, J., GOFIN, R., NEUMARK Y. 2002. The Jerusalem Experience: Three 
Decades of Service, Research, and Traning in Community Primary Care. American Journal of Public Health. 92, (11). Pp.89109.

4. Pelita Online Daily, Wednesday, January 27, 2009, accessed from http://www.hupelita. com/baca.php?id= 63654, June 30, 2010, at $14: 38 \mathrm{pm}$.

5. KODIM, N. 2009. Social Security Service Should Honor, Not niceties, Medical Journal of Indonesia. 35(1), pp.23-45,.

6. LAGUNTURU, 2013. History Assessing Health Care in Indonesia, Waspada Publisher.

7. LUBIS, D. 2014. Implementation of Health Insurance by PT. Health Insurance and PT. Social Security. Insight Journal. 13(02). pp. 154-164.

8. MAHYUNI, E. L. 2006. Application Evaluation Work Attitude 5-S in Improving Corporate Productivity in PT. ABC, 2005. Info Public Health, The Journal of Public Health. X(1), pp. 74-75..

9. MANULlANG, S. 2005. Principal Employment Law Indonesia. PT. Rineke Copyright: Jakarta.

10. PAKPAHAN, R., SIHOMBING, E. 2012. Responsibility of States in the Implementation of Social Security. Journals Legislation Indonesia. 9(2). pp. 169-182.

11. RETNANINGSIH E., MISNANIARTI, AINI, A. 2012. Eligibility Assessment Agency Public Service and Social Security Implementation of Alternative Forms of South Sumatra Universe accordance with the Regulation of the National Social Security System. Journal of Health Services Management. 15(01). pp. 20-21.
12. SIAGIAN, M. 2010. Social Research Methods Practical Guidelines Research Division of Social Sciences and Health. Grasindo Monoratama: Medan.

13. SIMANJUNTAK, P. 2005. New Law on Trade Union / Labour Union. International Labour Office: Jakarta.

14. SINAGA, M. 2005. Health On The saleswoman. Info Public Health, The Journal of Public Health. 9(1). pp. 33-54.

15. SULASTOMO 2008. National Social Security System Introductions. Rajawali Press. Jakarta.

16. SUPARJAN 2010. Community-Based Social Security: Response Failure of the State in the Provision of Welfare Assurance. Journal of Social and Political Sciences. 13(3), pp. 2-3.

17. WAHAB, Z. 2002. Pensions and Social Security Workers in Indonesia. PT. Citra Aditya Bakti; Bandung.

18. WIDUJANI I., MUKTI, A., HENDRARTINI 2004. Fees Fee Amount relations with Askes in RSU Participant Satisfaction Wangaya. Journal of Health Services Management. 7(3), p. 142-158.

19. WIJAYANTI, A. 2007. Legal Reform in the Implementation of Social Security For private sector employees. Electronic Journal UM Surabaya. 1(1), pp. 2-12.

20. ZASTROW, C. 2008. Introduction to Social Work and Social Welfare. Thomson Brokks: Belmont, USA. 


\section{Stress factors in the work of nurses}

V. Kozon, E. Zacharova

Original Articles

St. Elizabeth University of Health and Social Work in Bratislava, Slovak Republic

\section{Correspondence to:}

Vienna General Hospital Vienna, Währinger Gürtel 18-20, 1090 Wien, Austria;

eva.zacharova@seznam.cz; vlastimil.kozon@univie.ac.at

Submitted: 2.5 .2016

Revised: 29.7.2016

Accepted: 13.8 .2016

\section{Reviewers:}

V. N. Wanjala

Catholic university of Eastern Africa, Nairobi, Kenya

M. Kopacikova

Faculty of Health, Catholic University in Ruzomberok, Slovakia

\section{Keywords:}

Stress. Strain. Nurse. Burnout syndrome. Stress factors.

CSWHI 2016; 7(2): 105-115 @ 2016 Clinical Social Work and Health Intervention

\section{Abstract:}

Being a nurse is amongst one of the toughest professions. It is a profession in which the nurse will be in contact with different kinds of stress factors. There are often encounters with death, suffering, as well as dying and terminally ill patients. Nurses must be able to communicate with patients who react differently to illness and hospitalization and those patients who can even cause conflicts. In addition to the direct workloads regarding this range of problems there are also bad relationships in the workplace and difficulties in everyday life. There is also the need for continuous training and learning of new skills. The influence of all these factors can lead the nurse into difficult situations in life - such as excessive stress. The aim of this research was to determine stress factors that influence the work of nurses in outpatient and inpatient wards. 


\section{Introduction}

The word stress has been accepted into the Czech language from the English language. In Czech the translation means distress, inconvenience, pressure. In recent years, there has been a growing public interest and professional awareness about stress and its consequences. This is a reaction to the fact that stress has become an integral part of human life in the 21 st century. In recent years the actual understanding of the concept of stress has undergone a significant evolution. It has transferred from the biological level to the psychosocial level. In everyday speech we often refer to everything as stress that somehow pushes us, overloads or strains us, as well as things which are uncomfortable. It accompanies us from birth to old age. It belongs to the natural manifestations of life, if it is reasonable, and does not last a long period. In the modern world a disproportionate amount of stress is a major health risk, as shown by the results of a series of global investigations and contributes to, among other things, the ever-growing intensity of performance, the speed of work and time pressure. People increasingly evaluate their work as mentally demanding and performed at a higher pace of work, rather than as physically strenuous. Nurses working in a health care facility must overcome all the difficulties that occur during their service. In addition to stressful situations there can be poor working conditions, work overload, extraordinary responsibility, daily contact with dying or seriously ill patients, but also the circumstances in relation to interpersonal relationships, financial rewards, etc. $(1,2)$.

\section{Goals}

The goals of the research were to determine stress factors that influence the work of nurses in outpatient and inpatient wards.
Partial goals

1. Determine the workload of nurses in outpatient and inpatient wards.

2. Determine labour relations and mutual cooperation of nurses at work in the outpatient and inpatient wards.

3. Determine the psychological stress of nurses in communications with the patient and their family in outpatient and inpatient wards.

4. Determine whether there are differences in the workload between outpatient and inpatient wards.

\section{Patients and Survey Methods}

The questionnaire survey was conducted in the year 2015 on randomly selected hospitals in the Moravian-Silesian Region. The research involved 135 nurses from outpatient and inpatient wards. The study included various departments - internal, oncological, urological, neurological and gynaecological.

There were 150 questionnaire surveys distributed of which 137 questionnaires surveys were returned. In other words a $91 \%$ success return rate. There were 2 questionnaire surveys excluded from the overall evaluation as they were incompletely filled out. Data collection was preceeded by a pilot study on the basis of which it was verified that the questionnaire survey was comprehensible for the participants and that individual questions were understood correctly. A quantitative method was chosen for information gathering as well as a questionnaire survey. The questionnaire survey was voluntary and anonymous. The questionnaire survey included a total of 30 questions, including 5 demographic, of which 24 were closed and one open. The questions were focused on the area of the workload of nurses, labour relations and collaboration in the workplace, as well as to the psychological stress of nurses taking care of patients. 
It was monitored by subjective evaluation of the intensity of work and the relationship of respondents to the profession. The last question was open, where the respondents expressed their opinion. When processing the results of the research, 135 correctly and completely filled in questionnaire surveys were used, which was taken as a $100 \%$ participation rate. The data obtained was processed using Microsoft Excel.

\section{Results and Discussion}

The aim of the research was to determine, from the questionnaire surveys, what the stress factors that influence the work of nurses in outpatient and inpatient wards were. Based on the survey results the following facts were revealed. The research involved a total of 135 respondents of which 95\% were women and 5\% were men. This means that for the outpatient wards, $44 \%$ were women and 1\% were men. And for the inpatient wards, $51 \%$ were women and $4 \%$ were men. The largest overall group of those nurses questioned, 29\%, were in the age category of 31-40 years. $28 \%$ were in the category of $41-50$ years. $25 \%$ were in the category of 20-30 years. And 18\% were in the category of 51 or more years. For the inpatient wards, the largest representation of nurses were in the age group 2030 years $(43 \%)$, followed by the age group $41-50$ years $(24 \%)$, then the age group 31 40 years $(18 \%)$ and the least representation of nurses were in the age group of over 51 years $(15 \%)$. For the outpatient wards, the largest representation of nurses were in the age group of 31-40 years (43\%), followed by the age group $41-50$ years $(31 \%)$, then the age group of over 51 years $(23 \%)$ and the least representation of nurses were in the age group of $20-30$ years (3\%).

The issue of labour relations is constantly monitored worldwide. The research monitored the atmosphere of the work- place, including relationships between general nurses and doctors, and whether there are general nurses who do specialized tasks that do not fall within their competence. The largest group of nurses working in outpatient wards considered the relationships in the workplace as good (51\%), $20 \%$ of respondents stated very good, $23 \%$ of respondents evaluated interpersonal relations as bad, and $6 \%$ of nurses said relations at their workplace were very bad. For inpatient wards, $40 \%$ of respondents cited it as a good relationship, further $45 \%$ as poor and $8 \%$ very poor. On the contrary, $7 \%$ of nurses felt that working relations were very good (table 1).

Under the relationship with their superior, it was found that $49 \%$ of nurses have a good relationship with their superiors and $18 \%$ of respondents stated it as very good. A group of $21 \%$ of nurses assessed their access to superiors as poor and $12 \%$ of nurses assessed it as very bad. With regards to the attitude of senior nurses to subordinates in inpatient wards, $47 \%$ of respondents said they were bad and $10 \%$ said it was very bad. But $38 \%$ of nurses evaluated the relationship as good and $5 \%$ as very good (table 2).

Research results by Bártlova in 2006, which were carried out on the basis of interviews with 348 nurses across the country, showed similar results. Satisfaction prevails extensively among general nurses in the workplace. Overall, nurses employed in the offices cited a favourable working atmosphere. This is understandable because in these workplaces the nurses operate in close contact with the doctor. Additionally, the number of workers in the workplace is small and labour conflicts are less common than in workplaces with large numbers of employees. Features of the workplace also have a strong influence on the evaluation of the workplace atmosphere (3). Křivohlavý (6) also found in his 
survey that when he asked nurses what the source of their strength and joy in the job was, he frequently received answers such as a good team, good and unbeatable atmosphere in the workplace, cooperation of colleagues in the workplace, and superiors who valued them.

At present, we can say that conditions for new insights into the role of doctors and nurses and other quality of their professional conduct are being created. Cooperation between doctors and nurses should take place at a level of equal relations. In this research, however, $27 \%$ of nurses on inpatient wards evaluate cooperation with a doctor as good, with $11 \%$ as very good. The largest group of $47 \%$ believe that the mutual cooperation is poor and $15 \%$ of respondents consider it as very bad. In the evaluation of cooperation of doctors and nurses in surgeries and outpatient examinations, $45 \%$ of nurses stated it as good, $16 \%$ as very good, $28 \%$ as poor, and $11 \%$ consider it as very poor (table 3 ).

On the question regarding commendations from superiors, $36 \%$ of outpatient nurses said that they sometimes receive support and praise, $23 \%$ stated that they often receive it, $15 \%$ stated very often, and $26 \%$ of respondents stated that they never receive it. For inpatient nurses, 54\% of respondents stated occasional commendations, $11 \%$ stated as receiving it often, 3\% as very often. But a group of $32 \%$ of nurses did not feel like they received any support in their jobs from senior nurses (table 4). This situation is very alarming. According to the survey findings by Vévoda (9), he stated that this factor is significantly important for employees, as the source may not only be a superior but also a professional colleague, client - patient. Vévoda feels that nurses who do not work in continuous operation are often commended with praise and support. The identical result was also noted by Bártlová who found that the happiest nurses are employed in outpatient facilities. Their work with their superiors is the most valued. General nurses often lack a sense of security, motivation and the appropriate valuation of work in relation to the senior nurses.

An area that largely affects the status of nurses in multidisciplinary teams and which also has a significant influence on the relationship of doctors and nurses is the issue of competence. The competence of nurses in the Czech Republic is legally regulated by Act no. 96/2004 Coll. which deals with the conditions for acquisition and recognition of qualifications for exercising paramedical professions and for carrying out the activity of providing health care. Regarding tasks that do not fall within the competence of nurses, the results were $46 \%$ for inpatient nurses and 51\% for outpatient nurses. The second largest group stated that it is very often delegating responsibilities from others. This was 35\% for outpatient nurses and $47 \%$ for inpatient nurses (table 5).

In a 2010 survey entitled "Transfer of competencies between the doctor and nurse" by the authors Bártlová and Hajduchová, they state that nurses are quite often entrusted with the tasks falling within the competence of someone else and that do not match their qualifications (4). This is a delegation of special tasks from doctors or by the senior sister in the execution of work by paramedical personnel. From the analysis the authors revealed that most nurses are entrusted with tasks outside of their competence in administrative natures, i.e. acts related with the management of documents, creating requisitions, compiling reports on health insurance, processing statistical questionnaires, creating prescriptions, providing information, securing informed consent, etc. Inpatient nurses may frequently reject to perform these tasks however nurses working in 
clinics may reject these tasks significantly less frequently. There is a greater tendency to reject tasks outside the competence by nurses working in surgical specialties, by nurses with a higher education (master's degree), and by nurses with long work experience and stationed in an office.

Surprising was the question of education of nurses. Obtaining vocational education forms the foundation which influences the further position of nurses in a multidisciplinary team and in the company (8). The possibility of receiving further vocational training was available to $21 \%$ of respondents in outpatient wards, with inpatient wards showing $25 \%$. Nurses who frequently chose the answer "yes, but I'm not interested" amounted to $65 \%$ for inpatient wards and $54 \%$ for outpatient wards. $23 \%$ of nurses from outpatient wards and $5 \%$ of nurses from inpatient wards stated that they do not have the possibility to take part in further training nor are they interested in it.

The majority of the respondents from this research believe that nurses do not have sufficient social prestige. Only a tiny percentage of respondents evaluated the situation positively (table 7). According to the authors Škrla, Škrlová (8), a permanent change in the image of nursing must start with the education in medical schools, where students are guided with a professional image and provided with the understanding that the nursing profession has a character, and as such it is not just a job but a good career.

The amount of administrative work often burdened on the nurses in the outpatient wards is $38 \%$ and for the inpatient wards is $24 \%$. Nurses who stated being burdened as "very often" accounted for $31 \%$ for outpatient wards, and $60 \%$ for the inpatient wards. The word "sometimes" occurred for $28 \%$ of outpatient nurses and for $12 \%$ for inpatient nurses (table 8 ). The identical findings were by Bártlová who revealed that more than half of the surveyed nurses $(55.7 \%)$ were dissatisfied with the high proportion of administrative work. A greater administrative burden was on inpatient nurses regarding nursing documentation.

Another serious problem that is worth mentioning is the amount of work and the resulting time constraints. $30 \%$ of nurses in the outpatient wards often felt time pressures during the course of their work time and $52 \%$ of respondents stated very often. $38 \%$ of inpatient nurses perceived time constraints as often, with $30 \%$ as very often, and third place was occupied by $24 \%$ with the phrase "sometimes" (table 9). Based on this research, it was found that nurses working in inpatient wards feel greater levels of stress in terms of time constraints exerted on them, especially on the part of the waiting patients and because of the necessity to finish all the work in time. There is the possibility of unfinished work before the next shift for inpatient nurses.

The concept of the term "responsibility" has two meanings for which the nurse is responsible for and also according to her obligations. The legal responsibility for practicing nurses is specified by legislation - laws and moral responsibility have a specified code of ethics. The answers from the nurses in both wards were almost identically matched when asked about work-related stress due to a workload with greater work responsibilities. $47 \%$ of respondents in the inpatient wards felt a high degree of responsibility during their work and 30\% felt it as being often. For the outpatient wards, $43 \%$ of nurses see their profession as having a high burden of responsibility with $30 \%$ seeing it as being often high (table 10). In the research by Buriánek and Malina (5), they reported that the cause of the shortage of nurses in hospitals was due to workplace stress, precisely because of 
the workload with greater responsibilities.

Communication is a very important part of nursing care. For outpatient wards, communication with the patient and their family occasionally bothers $16 \%$ of nurses, $34 \%$ stated frequently and $43 \%$ of respondents admit that it is very often the conversations with patients burden their work. For inpatient wards, communications with respondents were expressed in this way: $32 \%$ of nurses are sometimes worried about communication with the patient and their family, $26 \%$ of nurses stated to having to formulate answers frequently and often (table 11). Communication skills by nurses fundamentally affect the relationship between the nurse, patient and their family.

Nurses who are communicative, helpful, kind and interested in the patient have a positive effect not only on the patient but also on their family. Cooperation with the family of the patient is very important because they are a source of important information about the patient. Conversely, the nurses provide information to the family regarding their necessary care towards the patient. Synergies between the nurse and the family significantly influence the nature and progress of the patient. In her research Bártlová focused on the most common causes of disputes between nurses and patients. Nurses working in outpatient wards often see the cause of conflicts is due to organizational difficulties stemming from the excessive number of patients and also the unjustified request for preferential examination. Inpatient nurses frequently reported health violations of their patients.

Treatment of the seriously ill and dying patients also causes distress for nurses. The largest group of respondents were from the inpatient wards where $57 \%$ feel distress very often when taking care of severely ill patients. $20 \%$ stated frequent and $14 \%$ stated occasional distress. For out- patient wards, $52 \%$ of nurses experience distress in the treatment of severely ill patients. 23\% stated frequent and $17 \%$ stated occasional distress. Only a small percentage from both wards will never feel the burden of care for the seriously ill and dying patients (table 12). It is widely known and confirmed by professional literature that the feelings of the individual in the course of their life is constantly changing and evolving. One of the most important characteristics of nurses in the care of the dying is equanimity including her coming to terms with their own mortality (7).

Both wards studied, almost unanimously agreed on the question as to what their opinion about their profession is. The largest group of nurses from the outpatient wards, $43 \%$, reported that they very often consider their work as challenging, $36 \%$ stated frequently challenging and 19\% stated occasionally challenging. $63 \%$ of inpatient ward respondents chose the answer most often challenging, $26 \%$ stated often challenging whilst $8 \%$ stated they occasionally see their profession as challenging, with possibly only $3 \%$ of respondents stating never challenging (table 13).

More than half of the respondents, $65 \%$ from outpatient wards and $85 \%$ from inpatient wards, feel a heavy burden in their jobs. A moderate load was stated by $30 \%$ of nurses from inpatient wards and $12 \%$ from outpatient ward. Only 5\% of respondents from inpatient wards and 3\% from outpatient wards stated that they do not perceive any burden (table 14).

One of the questions that was given to respondents was conceived as an open question. What time during the day did the nurses consider as the most stressful. Possible answers provided only benefited $2 / 3$ of respondents. Most inpatient ward nurses stated the morning part of their service and their morning rounds. The outpatient nurses perceived stress factors as having 
a waiting room full of impatient patients, improper requests for priority examination and frequently ringing phones.

\section{Improvement Recommendations}

1. Build an effective system of communication, not only between members of the multidisciplinary team, but also between nurse and patient.

2. Improve and continuously investigate working conditions.

3. Appeal to ensure an adequate number of staff at each site.

4. Support and extend supervision in health care.

5. Engage nurses in lifelong learning.

6. Clarify the competence of staff.

7. Improve communication skills.

8. Develop good interpersonal relationships.

9. Remember that people have personal lives, friends and hobbies.

10. Maintain good physical condition.

\section{Conclusion}

The main objective of the research was to describe the stress factors in the work of general nurses. Many factors contribute to inducing stress in the nursing profession. These factors may affect their physiological, emotional and behavioural levels. The results of the survey confirmed that the work of nurses is a very demanding profession in terms of the occurrence of a number of stress factors. The management of stress is a very topical issue for each of them. An important role is played by two motivations: the improvement in the combat of stress and helping others in their struggle with stress. General nurses carry out their work in a stressful environment and they also deal with patients who are also stressed. In their approach to stress, a nurse should keep in mind the above findings and relationships and use them purposefully to the benefit of both parties.

\section{Tables}

Table 1 What are the working relationships at your workplace?

\begin{tabular}{|c|c|c|c|c|}
\hline $\begin{array}{c}\text { Working } \\
\text { relations }\end{array}$ & inpatient & inpatient $\%$ & outpatient & outpatient $\%$ \\
\hline very bad & 4 & $6 \%$ & 6 & $8 \%$ \\
\hline bad & 14 & $23 \%$ & 33 & $45 \%$ \\
\hline good & 31 & $51 \%$ & 30 & $40 \%$ \\
\hline very good & 12 & $20 \%$ & 5 & $7 \%$ \\
\hline total & 61 & $100 \%$ & 74 & $100 \%$ \\
\hline
\end{tabular}

Table $\mathbf{2}$ What is your relationship with your superior?

\begin{tabular}{|c|c|c|c|c|}
\hline $\begin{array}{c}\text { Relationship } \\
\text { with your supe- } \\
\text { rior }\end{array}$ & inpatient & inpatient \% & outpatient & outpatient \% \\
\hline very bad & 7 & $12 \%$ & 7 & $10 \%$ \\
\hline bad & 13 & $21 \%$ & 35 & $47 \%$ \\
\hline
\end{tabular}




\begin{tabular}{|c|c|c|c|c|}
\hline good & 30 & $49 \%$ & 28 & $38 \%$ \\
\hline very good & 11 & $18 \%$ & 4 & $5 \%$ \\
\hline total & 61 & $100 \%$ & 74 & $100 \%$ \\
\hline
\end{tabular}

Table 3 Evaluate the cooperation with doctors during procedures and examinations.

\begin{tabular}{|c|c|c|c|c|}
\hline Cooperation & inpatient & inpatient $\%$ & outpatient & outpatient $\%$ \\
\hline very bad & 7 & $11 \%$ & 11 & $15 \%$ \\
\hline bad & 17 & $28 \%$ & 35 & $47 \%$ \\
\hline good & 27 & $45 \%$ & 20 & $27 \%$ \\
\hline very good & 10 & $16 \%$ & 8 & $11 \%$ \\
\hline total & 61 & $100 \%$ & 74 & $100 \%$ \\
\hline
\end{tabular}

Table 4 Do you receive praise and support from superiors?

\begin{tabular}{|c|c|c|c|c|}
\hline Praise & inpatient & inpatient $\%$ & outpatient & outpatient $\%$ \\
\hline never & 16 & $26 \%$ & 24 & $32 \%$ \\
\hline occasionally & 22 & $36 \%$ & 40 & $54 \%$ \\
\hline often & 14 & $23 \%$ & 8 & $11 \%$ \\
\hline very often & 9 & $15 \%$ & 2 & $3 \%$ \\
\hline total & 61 & $100 \%$ & 74 & $100 \%$ \\
\hline
\end{tabular}

Table 5 Do you have delegated tasks that do not fall within your competencies?

\begin{tabular}{|c|c|c|c|c|}
\hline Competence & inpatient & inpatient $\%$ & outpatient & outpatient $\%$ \\
\hline never & 2 & $3 \%$ & 1 & $2 \%$ \\
\hline occasionally & 7 & $11 \%$ & 4 & $5 \%$ \\
\hline often & 31 & $51 \%$ & 34 & $46 \%$ \\
\hline very often & 21 & $35 \%$ & 35 & $47 \%$ \\
\hline total & 61 & $100 \%$ & 74 & $100 \%$ \\
\hline
\end{tabular}


Table 6 Do you have the possibility of further vocational training?

\begin{tabular}{|c|c|c|c|c|}
\hline Training & inpatient & inpatient $\%$ & outpatient & outpatient $\%$ \\
\hline yes & 13 & $21 \%$ & 18 & $25 \%$ \\
\hline yes, but not offered & 33 & $54 \%$ & 48 & $65 \%$ \\
\hline no, but not offered & 14 & $23 \%$ & 4 & $5 \%$ \\
\hline no & 1 & $2 \%$ & 4 & $5 \%$ \\
\hline total & 61 & $100 \%$ & 74 & $100 \%$ \\
\hline
\end{tabular}

Table 7 Do you think that nurses have sufficient social prestige?

\begin{tabular}{|c|c|c|c|c|}
\hline Prestige & inpatient & inpatient $\%$ & outpatient & outpatient $\%$ \\
\hline yes & 2 & $4 \%$ & 4 & $5 \%$ \\
\hline no & 56 & $91 \%$ & 61 & $83 \%$ \\
\hline cannot judge & 3 & $5 \%$ & 9 & $12 \%$ \\
\hline total & 61 & $100 \%$ & 74 & $100 \%$ \\
\hline
\end{tabular}

Table 8 Are you burdened with the amount of administration?

\begin{tabular}{|c|c|c|c|c|}
\hline Administration & inpatient & inpatient $\%$ & outpatient & outpatient $\%$ \\
\hline never & 2 & $3 \%$ & 3 & $4 \%$ \\
\hline occasionally & 17 & $28 \%$ & 9 & $12 \%$ \\
\hline often & 23 & $38 \%$ & 18 & $24 \%$ \\
\hline very often & 19 & $31 \%$ & 44 & $60 \%$ \\
\hline total & 61 & $100 \%$ & 74 & $100 \%$ \\
\hline
\end{tabular}

Table 9 Do you feel time pressures while performing work tasks?

\begin{tabular}{|c|c|c|c|c|}
\hline Work tasks & inpatient & inpatient $\%$ & outpatient & outpatient $\%$ \\
\hline never & 3 & $5 \%$ & 6 & $8 \%$ \\
\hline occasionally & 8 & $13 \%$ & 18 & $24 \%$ \\
\hline often & 18 & $30 \%$ & 28 & $38 \%$ \\
\hline very often & 32 & $52 \%$ & 22 & $30 \%$ \\
\hline total & 61 & $100 \%$ & 74 & $100 \%$ \\
\hline
\end{tabular}


Table 10 Are you burdened with high responsibility in your work?

\begin{tabular}{|c|c|c|c|c|}
\hline Responsibility & inpatient & inpatient \% & outpatient & outpatient $\%$ \\
\hline never & 7 & $11 \%$ & 10 & $14 \%$ \\
\hline occasionally & 10 & $16 \%$ & 7 & $9 \%$ \\
\hline often & 18 & $30 \%$ & 22 & $30 \%$ \\
\hline very often & 26 & $43 \%$ & 35 & $47 \%$ \\
\hline total & 61 & $100 \%$ & 74 & $100 \%$ \\
\hline
\end{tabular}

Table 11 Are you burdened with communication with the patient and their family?

\begin{tabular}{|c|c|c|c|c|}
\hline Communication & inpatient & inpatient $\%$ & outpatient & outpatient $\%$ \\
\hline never & 4 & $7 \%$ & 12 & $16 \%$ \\
\hline occasionally & 10 & $16 \%$ & 24 & $32 \%$ \\
\hline often & 21 & $34 \%$ & 19 & $26 \%$ \\
\hline very often & 26 & $43 \%$ & 19 & $26 \%$ \\
\hline total & 61 & $100 \%$ & 74 & $100 \%$ \\
\hline
\end{tabular}

Table 12 Do you feel stress with the treatment of seriously ill and dying patients?

\begin{tabular}{|c|c|c|c|c|}
\hline Treatment & inpatient & inpatient $\%$ & outpatient & outpatient $\%$ \\
\hline never & 5 & $8 \%$ & 7 & $9 \%$ \\
\hline occasionally & 10 & $17 \%$ & 10 & $14 \%$ \\
\hline often & 32 & $52 \%$ & 15 & $20 \%$ \\
\hline very often & 14 & $23 \%$ & 42 & $57 \%$ \\
\hline total & 61 & $100 \%$ & 74 & $100 \%$ \\
\hline
\end{tabular}

Table 13 Do you consider your work as demanding?

\begin{tabular}{|c|c|c|c|c|}
\hline Work & inpatient & inpatient $\%$ & outpatient & outpatient $\%$ \\
\hline never & 1 & $2 \%$ & 2 & $3 \%$ \\
\hline occasionally & 12 & $19 \%$ & 6 & $8 \%$ \\
\hline often & 22 & $36 \%$ & 19 & $26 \%$ \\
\hline very often & 26 & $43 \%$ & 47 & $63 \%$ \\
\hline total & 61 & $100 \%$ & 74 & $100 \%$ \\
\hline
\end{tabular}


Table 14 What level of stress do you feel when performing your job?

\begin{tabular}{|c|c|c|c|c|}
\hline Level & inpatient & inpatient $\%$ & outpatient & outpatient $\%$ \\
\hline none & 3 & $5 \%$ & 2 & $3 \%$ \\
\hline mild & 18 & $30 \%$ & 9 & $12 \%$ \\
\hline high & 40 & $65 \%$ & 63 & $85 \%$ \\
\hline total & 61 & $100 \%$ & 74 & $100 \%$ \\
\hline
\end{tabular}

\section{References}

1. Jankechová M., Kunayová A. (2011): The working conditions of nurses in nursing clinical praxis. In Proceedings of the international conference Jihlava's medical days 2011. First year. Jihlava: College of Polytechnics, pp. 281-291. ISBN 978-80-8703537-5.

2. Jankechová M., Gajdošíková E. (2013): Investigation of the risk factors affecting the health of nurses. In Proceedings of the international conference Jihlava's medical days 2013. III. year. New trends in nursing and midwifery. Jihlava: College of Polytechnics, pp. 291-299. ISBN 978-80-87035-726.

3. Bártlová S. (2007): Industrial relations and competencies of nurses in Czech Republic. Nurse, vol. 17, no. 3, pp. 14-17. ISSN 12100404.
4. Bártlová S., Hajduchová H. (2010): Transfer of competencies between the doctor and nurse. Contact, vol. 12, no. 1, pp. 20-33. ISSN 1212 to 4117.

5. Buriánek J., Malina A. (2009): Job satisfaction of nurses. Healthcare in Czech Republic, vol. XII, no. 3, pp. 82-89. ISSN 12136050.

6. Křivohlavý J., Pečenková J. (2004): Mental hygiene of nurses. Praha: Grada, 2004. 80 pp. ISBN 80-247-0784-5.

7. Svatošová M. (2003): Hospice and art accompany. 5th edition. Praha: Ecco homo, 150 pp. ISBN 80-902049-4-5.

8. Škrla P., Škrlová M. (2003): Creative nursing management. Prague: Advent - Orion, 477 pp. ISBN 80-7172-841-1.

9. Vévoda J. et al. (2013): The motivation and job satisfaction of nurses in health care. Prague: Grada, 160 pp. ISBN 978-80-2474732-3. 



\section{Contributor's guidelines}

Allow me to introduce a new expert journal - Clinical Social Work and Health Care. We would like to offer you an opportunity to contribute to its content as we would like to aspire to create a collection of real experiences of social workers, doctors, missionaries, teachers, etc. CWS Journal is published by the International Scientific Group of Applied Preventive Medicine I-GAP in Vienna, Austria.

The journal is to be published semi-annually and only in English language as it will be distributed in various foreign countries.

We prefer to use the term 'clinical social work' rather than social work even though it is less common. In the profession of clinical social work, there clearly is some tension coming from unclear definitions of competence of social workers and their role in the lives of the clients; the position of social work in the structures of scientific disciplines especially in cases where people declare themselves to be professionals even though they have no professional educational background. These are only few of the topics we would like to discuss in the CWS Journal.

\section{Your contribution should fit into the following structure:}

1. Editorial

2. Interview, Case Reports

3. Review

4. Original article

5. Letters

\section{Instructions for contributors:}

All articles must be in accordance with the current language standards in English, current ISO and the law on copyrights and rights related to copyrights.

Your contributions are to be sent via e-mail (addressed to: michalolah (agmail.com) as an attachment or on a CD via regular postal service. In both cases written and saved in MS Word (no older version than year 2000).

Style Sheet Requirements:

Maximum length: 3500 words

Letter type: Times New Roman

Letter size: 12

Lining: 1

\section{All articles must include:}

Name of the article and author's address in English

Article abstract of 150 words in English

Brief professional CV of the author (100 words)

Publishing languages: English

Text of the article consisting of at most 3500 words

Each article must be an original never published before. When using references, parts of other articles or publications it is inevitable to quote them and provide information about the source.

We reserve the right to formally edit and reduce the text if needed. Academic articles undergo an anonymous critique. Each author will receive a prior statement of publishing his/ her article. Reference styles writing: "name and year".

When writing a review it is necessary to attach a copy of the cover of the book.

\section{Published Statement of Human and Animal Rights}

When reporting experiments on human subjects, authors should indicate whether the procedures followed were in accordance with the ethical standards of the responsible committee on human experimentation (institutional and national) and with the Helsinki Declaration of 1975 , as revised in 2000 (5).

\section{Published Statement of Informed Consent}

Patients / klients have a right to privacy that should not be infringed without informed consent. Identifying information, including patients' names, initials, or hospital numbers, should not be published in written descriptions, photographs, and pedigrees unless the information is essential for scientific purposes and the patient (or parent or guardian) gives written informed consent for publication. Informed consent for this purpose requires that a patient who is identifiable be shown the manuscript to be published. Authors should identify Individuals who provide writing assistance and disclose the funding source for this assistance.

Identifying details should be omitted if they are not essential. Complete anonymity is difficult to achieve, however, and informed consent should be obtained if there is any doubt. For example, masking the eye region in photographs of patients is inadequate protection of anonymity. If identifying characteristics are altered to protect anonymity, such as in genetic pedigrees, authors should provide assurance that alterations do not distort scientific meaning and editors should so note.

\section{Published Conflict-of-Interest Statement}

Public trust in the peer review process and the credibility of published articles depend in part on how well conflict of interest is handled during writing, peer review, and editorial decision making. Conflict of interest exists when an author (or the author's institution), reviewer, or editor has financial or personal relationships that inappropriately influence (bias) his or her actions (such relationships are also known as dual commitments, competing interests, or competing loyalties). These relationships vary from those with negligible potential to those with great potential to influence judgment, and not all relationships represent true conflict of interest. The potential for conflict of interest can exist whether or not an individual believes that the relationship affects his or her scientific judgment. Financial relationships (such as employment, consultancies, stock ownership, honoraria, paid expert testimony) are the most easily identifiable conflicts of interest and the most likely to undermine the credibility of the journal, the authors, and of science itself. However, conflicts can occur for other reasons, such as personal relationships, academic competition, and intellectual passion.

The journal works on the non-profit basis. The Original Articles are published free of charge / the scope up up to 3,500 words, over the scope should be paid 50 EUR / USD for every 500 words/. All the published Articles are charged 100 EUR / USD with standard range which cannot be exceed. 


\title{
No. 2, Vol. 7, 2016
}

Editor-in-chief: Peter G. Fedor-Freybergh, Michael Olah

\section{CLINICAL SOCIAL WORK AND HEALTH INTERVENTION}

\author{
Indexed by: \\ ERIH \\ Ulrich's \\ CrossRef \\ Universitat de Barcelona - MIAR \\ International Committee of Medical Journal Editors (ICMJE) \\ JournalGuide \\ Cabell's
}

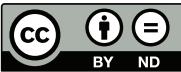

